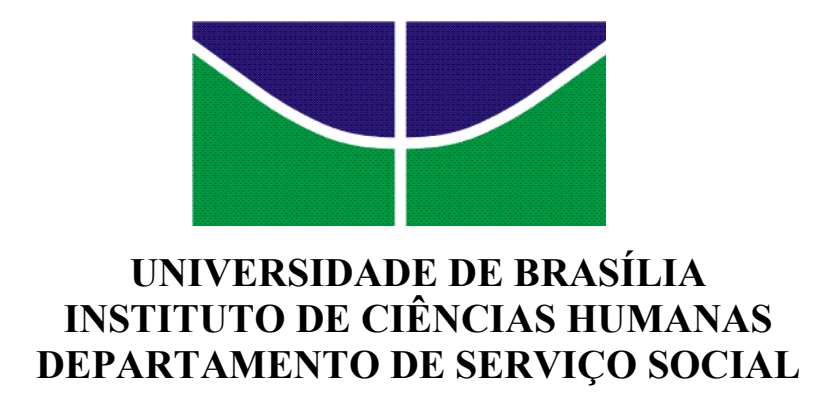

Rozania Piris Morais

REDE SOCIOASSISTENCIAL DE TRATAMENTO AOS USUÁRIOS/DEPENDENTES DE ÁLCOOL E OUTRAS DROGAS NA REGIÃO CENTRO-OESTE (BRASIL 2006/2007)

Brasília (DF), dezembro de 2008. 
Rozania Piris Morais

\title{
REDES SOCIOASSISTENCIAIS DE TRATAMENTO AOS USUÁRIOS/DEPENDENTES DE ÁLCOOL E OUTRAS DROGAS NA REGIÃO CENTRO-OESTE (BRASIL 2006/2007)
}

\author{
Monografia apresentada ao Departamento de \\ Serviço Social para obtenção do diploma de \\ graduação em Serviço Social, sob orientação

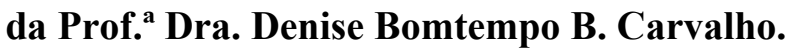

Brasília (DF), dezembro de 2008 
Dedico este trabalho, primeiramente a Deus, por ser essencial em minha vida, à minha família, em especial à minha mãe, que sempre esteve presente e apoiando na minha trajetória acadêmica. 


\section{Agradecimentos}

Agradeço a todos que estiveram presentes na minha trajetória acadêmica.

Aos meus pais, principalmente à minha mãe, que sempre me apoiou nos estudos e nas minhas decisões. Sem ela eu não teria chegado à Universidade.

Às minhas amigas, Marcela Lustosa, Tatiana Travassos, Denise Silva e Wenia de Oliveira. Essas amizades influenciaram de maneira considerável em meu aprendizado e foram de grande importância nessa caminhada.

Às minhas irmãs Diana, Teresinha, Rosalina, por terem me apoiado e acreditado na minha capacidade de realizar o sonho de ter o ensino superior. Sem mais palavras para descrever a gratidão.

Aos meus irmãos José Adão, Valdivino, Valdeci, Luzimar e João Batista, que acreditaram e apoiaram nesta conquista.

Ao Moaci, que sempre esteve presente me incentivando e acreditando na concretização desse sonho.

Ao Wandersom, pelo companheirismo, paciência, fundamentais em minha vida.

À Valnice e Dayanne, que sempre me incentivaram e acreditaram no meu potencial.

Aos Professores que estiveram presentes em minha vida acadêmica e tiveram participação fundamental no meu rendimento. Obrigada por ampliar os meus conhecimentos.

Em especial, à Denise Bomtempo B. Carvalho, ótima orientadora, sempre presente e disposta a ajudar durante o desenvolvimento deste trabalho.

Às professoras Izabel Zaneti e Teresa Cristina, Verônica exemplos de perseverança e sabedoria. Obrigada pelo apoio, pelo carinho e todas as oportunidades durante minha graduação.

Ao professor Dr. Mário Ângelo e a Assistente Social Thaís Imperatori por aceitarem o desafio de participar desta banca de defesa. 
"O senhor é bom, uma fortaleza no dia de angústia, e conhece os que confiam nele".

(Naum 01: 07). 


\section{RESUMO}

O trabalho faz uma breve contextualização do debate que permeou a construção das políticas sobre álcool e outras drogas. Ressalta a dificuldade do Estado brasileiro, ao longo da história, em adotar uma política pública menos conservadora e desvinculada dos interesses internacionais. Visando retratar a realidade das instituições existentes na Região CentroOeste, esse trabalho descreve as redes socioassistenciais de tratamento ao usuários/dependentes de álcool e outras drogas dessa região, utilizando os dados coletados do projeto "Mapeamento das Instituições Governamentais e Não-Governamentais de Atenção às Questões Relacionadas ao Consumo de Álcool e Outras Drogas no Brasil-2006/2007”, coordenado pela professora Dra. Denise Bomtempo B. Carvalho, do Departamento de Serviço Social da Universidade de Brasília, financiada pela Senad. Trata-se de uma pesquisa exploratória, descritiva com análises quantitativa e qualitativa dos dados. Foram pesquisadas 129 instituições de tratamento, recuperação e reinserção social na Região Centro-Oeste, sendo uma sem resposta, 43 instituições governamentais e 85 não-governamentais e analisadas oito entrevistas das 32 instituições entrevistadas. Para análise dos dados, foi empregada a mesma abordagem metodológica utilizada pelo projeto Mapeamento. Os resultados mostraram a falta de recursos humanos, financeiro, materiais, capacitação, desarticulação das redes, entre outros. Relata a realidade das instituições existentes na Região Centro-Oeste, por meio de informações sobre os tratamentos oferecidos, recursos, características dos dirigentes e da equipe profissional. Revela ainda os avanços e as dificuldades que as instituições enfrentam para recuperar e reinserir os dependentes químicos na sociedade. 


\section{LISTA DE SIGLAS}

CAPS

CAPSad

CEBRID

CICAD

COMENS

CONAD

CONENS

CONFEN

Cosam

DPF

OBID

OMS

PAIUAD

PNAD

Senad

Sisnad

SUS

UNODC
Centros de Atenção Psicossocial

Centros de Atenção Psicossocial álcool/drogas

Centro Brasileiro de Informação sobre Drogas

Comissão Interamericana para o Controle de Abuso de Drogas

Conselhos Municipais de Entorpecentes

Conselho Nacional de Políticas sobre Drogas

Conselhos Estaduais de Entorpecentes

Conselho Federal de Entorpecentes

Coordenadoria de Saúde Mental

Departamento de Polícia Federal

Observatório Brasileiro de Informação sobre Drogas

Organização Mundial de Saúde

Política de Atenção Integral aos Usuários de Álcool e outras Drogas

Política Nacional sobre Drogas

Secretaria Nacional de Políticas Públicas sobre Drogas

Sistema Nacional de Políticas sobre Drogas

Sistema Único de Saúde

Escritório das Nações Unidas sobre Drogas e Crime 


\section{LISTAS DE TABELAS}

Tabela 1: Classificação das instituições que realizam tratamento quanto à natureza da instituição.

Tabela 2: Tipos de tratamentos oferecidos de acordo com a natureza da instituição. 41

Tabela 3: Participação da família no tratamento de acordo com a natureza da instituição.......................................43

Tabela 4: Freqüência de visitas da família de acordo com a natureza da instituição.................................................43

Tabela 5: Permissão para início das visitas nas instituições de tratamento de acordo com a natureza da instituição

Tabela 6: Decorrência do atendimento de acordo com a natureza da instituição . .45

Tabela 7: Requisitos para atendimento nas instituições de tratamento de acordo com a natureza da instituição...46 Tabela 8: Abordagem terapêutica utilizada pelas instituições governamentais de tratamento quanto à natureza..47

Tabela 9: Período do tratamento em (meses) utilizado pelas instituições de acordo com a natureza da

instituição .48

Tabela 10: Tratamento complementar realizado de acordo com a natureza da instituição 49

Tabela 11: Encaminhamentos para reinserção social de acordo com a natureza das instituições .50

Tabela 12: Atendimento de situações específicas de acordo com a natureza das instituições. .50

Tabela 13: Ano de criação de acordo com a natureza das instituições de tratamento. .51

Tabela 14: Abrangência das atividades da instituição de tratamento de acordo com a natureza..............................52

Tabela 15: Localização da instituição de tratamento quanto à natureza...............................................................52

Tabela 16: Atendido pela instituição de tratamento de acordo com a natureza.......................................................53

Tabela 17: Faixa etária da população atendida de acordo com a natureza da instituição.........................................53

Tabela 18: Média mensal de atendimentos de acordo com a natureza da instituição.................................................54

Tabela 19: Acesso à população atendida de acordo com a natureza das instituições.............................................55

Tabela 20: Procedência dos encaminhamentos de acordo com a natureza da instituição.....................................55

Tabela 21: Articulação das instituições de acordo com a natureza.......................................................................57

Tabela 22: Existência do conselho antidrogas/entorpecentes no município na percepção do dirigente de acordo com a natureza da instituição.

Tabela 23: Registro das instituições junto ao Conselho Municipal Antidrogas/Entorpecentes de acordo com a natureza. 
Tabela 24: Registro da instituição junto ao Conselho Estadual Antidrogas/Entorpecentes de acordo com a

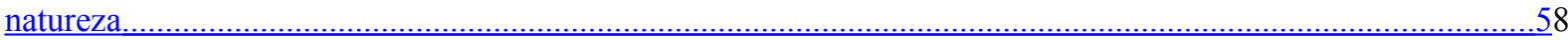

Tabela 25: Recursos materiais de acordo com a natureza da instituição.................................................................60

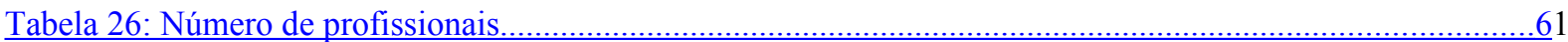

Tabela 27: Recursos financeiros de acordo com a natureza da instituição.............................................................62

Tabela 28: Tipo de recurso governamental de acordo com a natureza da instituição...............................................63

Tabela 29: Idade do dirigente de acordo com a natureza da instituição ...........................................................64

Tabela 30: Sexo do dirigente de acordo com a natureza da instituição.....................................................................65

Tabela 31: Escolaridade do dirigente de acordo com a natureza das instituições de tratamento.............................65

Tabela 32Remuneração do dirigente de acordo com a natureza da instituição........................................................66

Tabela 33: Exercício de atividade remunerada fora da instituição de acordo com a natureza................................66

Tabela 34: Horas semanais dedicadas pelo dirigente de acordo com a natureza da instituição..............................67

Tabela 35: Motivação do dirigente de acordo com a natureza da instituição de tratamento..................................67

Tabela 36: Participação dos dirigentes em conselhos de acordo com a natureza da instituição..............................69

Tabela 37: Previsão de capacitação de acordo com a natureza das instituiç̣ões.....................................................69

Tabela 38: Atividades de capacitação desenvolvidas de acordo com a natureza da instituição...............................70

Tabela 39: Freqüência de capacitação de acordo com a natureza das instituições..................................................70

Tabela 40: Previsão de capacitação externa de acordo com a natureza da instituição............................................71

Tabela 41: Tipo de capacitação externa prevista de acordo com a natureza das instituições..................................71

Tabela 42: Participação em eventos científicos e de mobilização social de acordo com a natureza da instituição72 


\section{SUMÁRIO}

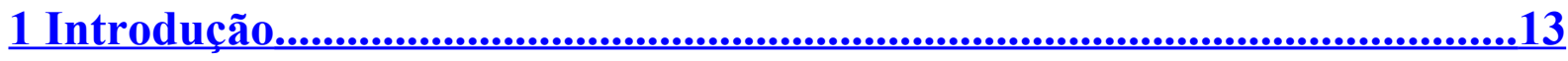

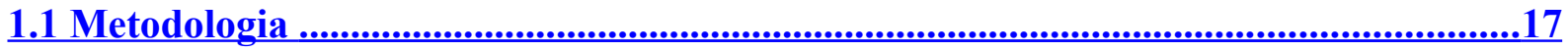

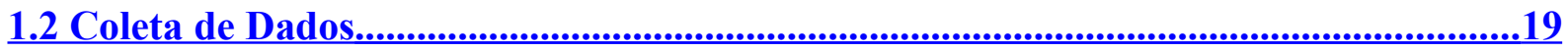

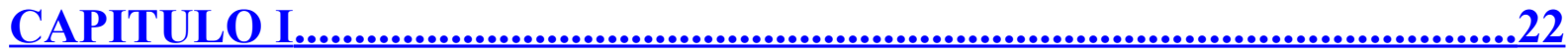

2 Marco Legal da Atenção à Saúde para Usuários de Álcool e Outras

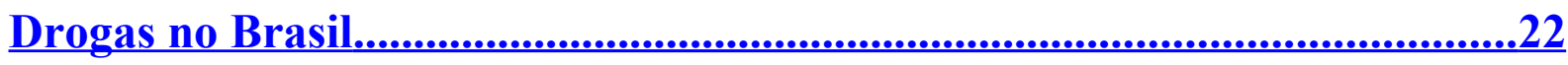

$\underline{3 \text { A construção das Políticas de Atenção ao consumo de álcool e outras }}$

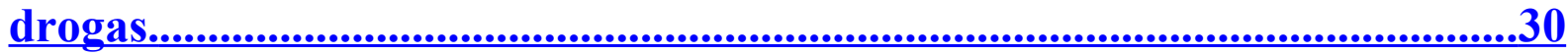

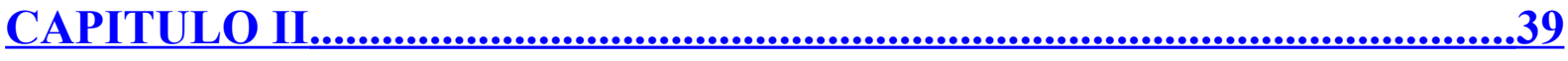

4 Tratamento, Recuperação e Reinserção social de usuários/Dependentes de Álcool e outras Drogas na Região Centro-Oeste do Brasil.............................39

4.1 Instituições que Realizam Tratamento de Acordo com a Natureza da Instituição....41

4.2 Tipos de Tratamentos de Acordo com a Natureza da Instituição.....................................41

4.6 Abordagem Terapêutica de Acordo com a Natureza da Instituição..............................49

4.7 Duração do Tratamento de Acordo com a Natureza da Instituição.................................50

4.8 Tratamento Complementar Realizado de Acordo com a Natureza da Instituição......50

4.9 Reinserção Social...............................................................................................................51

4.10 Atendimento a Situacões Específicas de Acordo com a Natureza das Instituicões...52

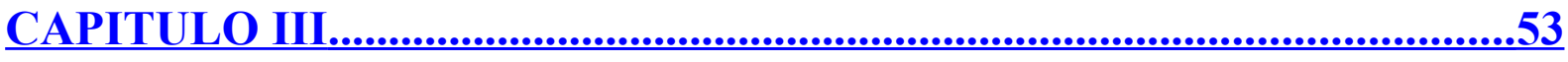

5 Informações Sobre as instituições de Tratamento de usuários/

Dependentes de Álcool e outras Drogas na Região Centro-Oeste no Brasil

5.1 Ano de criação de acordo com a natureza das instituiç̃es de tratamento ...................53

5.2 Abrangência das atividades da instituição de tratamento de acordo com a natureza

5.3 Localização da instituição de tratamento quanto à natureza..............................................54 
5.4 Sexo da população atendida de acordo com a natureza.............................................54

5.5 Faixa etária da população atendida de acordo com a natureza da instituição...........55

5.6 Média mensal de atendimentos de acordo com a natureza da instituição....................56

5.7 Acesso à população atendida de acordo com a natureza das instituições.....................56

5.8 Procedência dos encaminhamentos de acordo com a natureza da instituição.............57

5.9 Articulação das instituições de acordo com a natureza..................................................58

5.10 Existência do conselho antidrogas/entorpecentes no município na percepção do

dirigente de acordo com a natureza da instituição.....................................................59

5.11 Registro das instituições junto ao Conselho Municipal Antidrogas/Entorpecentes de

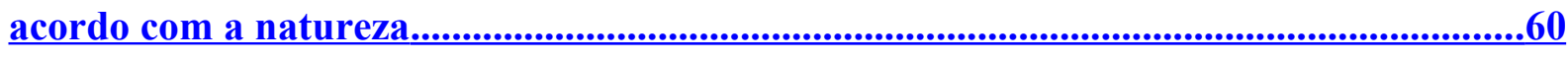

5.12 Registro da instituição junto ao Conselho Estadual Antidrogas/Entorpecentes de

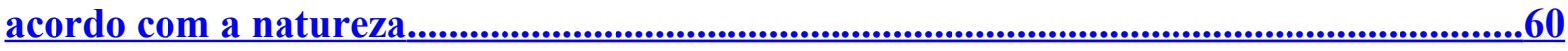

6 Recursos Físicos / Materiais das instituições de Tratamento de usuários/

Dependentes de Álcool e outras Drogas na Região Centro-Oeste do Brasil 61

6.1 Recursos materiais de acordo com a natureza da instituição...................................61

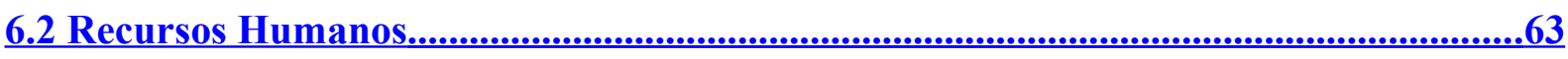

$\underline{6.3}$ Fontes de recursos financeiros das instituições de tratamento......................................63

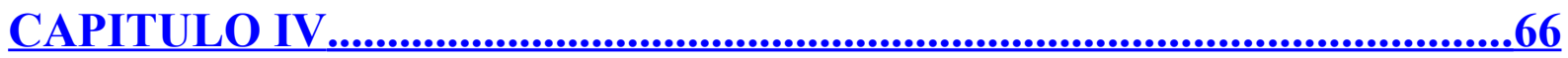

7 Características dos dirigentes das instituições de Tratamento de usuários/

Dependentes de Álcool e outras Drogas na Região Centro-Oeste no Brasil 66

7.1 Idade do dirigente de acordo com a natureza da instituição.........................................66

7.2 Sexo do dirigente de acordo com a natureza da instituição............................................66

7.3 Escolaridade do dirigente de acordo com a natureza das instituições de tratamento 67

7.4 Remuneração do dirigente de acordo com a natureza da instituição...........................67

7.5 Exercício de atividade remunerada fora da instituição de acordo com a natureza....68

7.6 Horas semanais dedicadas pelo dirigente de acordo com a natureza da instituição. 68

7.7 Motivação do dirigente de acordo com a natureza da instituição de tratamento.......69

7.8 Participação dos dirigentes em conselhos de acordo com a natureza da instituição. 70

8 Características da equipe profissional.....................................................................71

8.1 Previsão de capacitação de acordo com a natureza das instituições.............................71

$\underline{\text { 8.2 Atividades de capacitação desenvolvidas de acordo com a natureza da instituição...71 }}$ 
8.3 Freqüência de capacitação de acordo com a natureza das instituiç̧ões........................72

8.4 Previsão de capacitação externa de acordo com a natureza da instituição..................72

8.5 Tipo de capacitação externa prevista de acordo com a natureza das instituições......73

8.6 Participação em eventos científicos e de mobilização social de acordo com a natureza

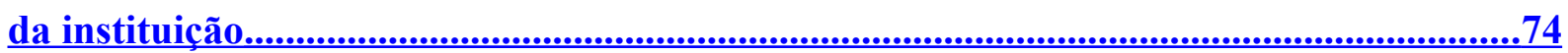

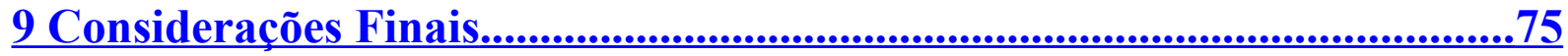

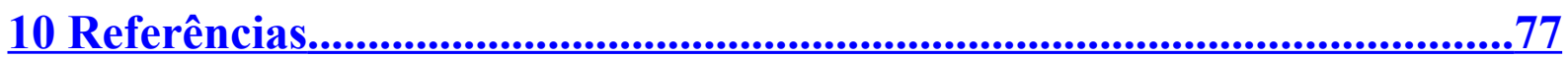




\section{Introdução}

O consumo de drogas psicoativas é considerado um problema de ordem social, não apenas em função de sua presença, mas, sobretudo, devido às conseqüências nocivas para a saúde dos indivíduos e, conseqüentemente, para a sociedade.

A Política do Ministério da Saúde para a Atenção Integral ao Usuário de Álcool e outras Drogas (2005), aponta que a questão do uso abusivo e/ou dependência de álcool e outras drogas tem sido historicamente abordada por uma ótica predominantemente psiquiátrica ou médica, não evidenciando as implicações sociais, psicológicas, econômicas e políticas que devem ser consideradas na apreensão do problema. Além disso, o tema vem sendo associado à criminalidade e a práticas anti-sociais, o que contribui para a promoção de tratamentos inspirados em modelos de exclusão/isolamento dos dependentes químicos do convívio social.

Segundo dados da Organização Mundial de Saúde (OMS, 2004), o álcool é a droga mais consumida no mundo. Aproximadamente dois bilhões de pessoas fazem uso de bebidas alcoólicas, independentemente de idade, sexo, nível de instrução ou poder aquisitivo. O documento também revela que o uso de álcool e outras drogas geralmente causa dependência física e psicológica, além de debilitar gradualmente o organismo de quem as usa. Além disso, entre os prováveis efeitos do consumo de álcool estão: o aumento dos acidentes de trânsito e de trabalho, violência domiciliar e crescimento da criminalidade, também revelados em todos os segmentos sociais.

O Relatório Mundial Sobre Drogas (2008), divulgado pelo Escritório das Nações Unidas contra Drogas e Crime (UNODC), revela que cerca de 208 milhões de pessoas, equivalente a $4,8 \%$ da população adulta do mundo, fizeram uso de drogas ilícitas ao menos uma vez na vida. Os dependentes químicos somam 26 milhões de pessoas, em torno de $0,6 \%$ da população. Sendo que apenas no ano de 2007, cerca de 200 mil usuários morreram em conseqüência do consumo de drogas. Revela, ainda, que o cigarro afeta aproximadamente $25 \%$ da população adulta, ocasionando cerca de 5 milhões de mortes por ano, enquanto no mesmo período o álcool mata aproximadamente 2,5 milhões de pessoas.

A avaliação do UNODC indica que o uso de drogas está diminuindo no mundo, à exceção das Américas, cujo índice cresceu. Dos países americanos, o Brasil foi o país com 
maior crescimento no consumo de maconha, registrando um crescimento de $1,6 \%$ entre os anos de 2001 e 2005. Em 2006, Argentina, Brasil e Estados Unidos ficaram à frente quanto ao consumo de estimulantes, com, respectivamente, 17, 12 e 10 doses diárias para cada mil habitantes. Ressalta-se que, no Brasil, o consumo de anfetaminas equipara-se ao consumo de cocaína.

Os principais estudos sobre o consumo de álcool e outras drogas são realizados, no Brasil, pelo Centro Brasileiro de Informação sobre Drogas Psicoativas (CEBRID). O principal objetivo desses estudos é sensibilizar tanto o Estado quanto à sociedade acerca da carência de políticas públicas de prevenção, controle e tratamento, que levem em consideração as respectivas especificidades dos usuários e dependentes.

Em 1997, foi realizado um estudo pelo CEBRID sobre o uso indevido de drogas no país. Os dados foram coletados de uma amostra com 2.730 estudantes dos antigos $1^{\circ}$ e $2^{\circ}$ graus em 10 capitais. Esse levantamento revelou que 74,1\% dos estudantes já havia feito uso de álcool durante a vida, e 14,7\% deles disseram fazer uso freqüente de álcool. Foi verificado, ainda, que $19,5 \%$ dos estudantes faltaram à escola após beber, e que $11,5 \%$ brigaram sob o efeito do álcool. Isso indica que o uso do álcool está diretamente relacionado com os altos índices de abandono escolar, bem como com a quebra de laços sociais, o que reforçou para a inter-relação entre o consumo de álcool e a criminalidade.

Resultados preliminares da pesquisa encomendada pelo Governo Federal sobre os custos dos acidentes de trânsito no Brasil (IPEA/MS \& COLS, 2003) demonstraram que 53\% do total dos atendimentos, no Ambulatório de Emergência do Hospital das Clínicas/SP, às vitimas de acidentes no trânsito estavam com índices de alcoolemia no sangue superiores aos permitidos pelo Código de Trânsito Brasileiro. Esses pacientes eram, em sua maioria, do sexo masculino, com idades entre 15 e 29 anos.

A Política do Ministério da Saúde para a Atenção Integral a Usuários de Álcool e Outras Drogas (2005) ressalta que os acidentes e a violência ocupam a segunda causa de mortalidade geral. De acordo com o Sistema de Mortalidade do Ministério da Saúde, esse perfil mantém-se nos últimos anos.

O Ministério da Saúde (2007b) indica que foram realizadas 123.061 internações no Sistema Único de Saúde (SUS) no ano de 2006, o que onerou aos cofres públicos 118 milhões de reais. A maioria das internações ocorreu por atropelamento (41.517) e por 
acidentes com motociclistas (34.767). Entre esses acidentes, foi significativo o número de pessoas que havia ingerido algum tipo de bebida alcoólica previamente.

Os dados do DATASUS (2001), retirado da Política do Ministério da Saúde para a Atenção Integral a Usuários de Álcool e outras Drogas, no Brasil, em 2001, mostraram que houve 84.467 internações para o tratamento de problemas relacionado ao uso do álcool. Essas internações tiveram um custo anual para o SUS de mais de 60 milhões de reais.

O II Levantamento Domiciliar Sobre o Uso de Drogas Psicotrópicas no Brasil, realizado pelo CEBRID em parceria com a Secretaria Nacional de Políticas Públicas sobre Drogas (Senad), em 2005, visava, principalmente, avaliar a prevalência do uso de drogas psicotrópicas pela população brasileira. Esse levantamento permitiu avaliar como, em geral, a sociedade brasileira se comporta frente ao uso de drogas lícitas e ilícitas.

$\mathrm{Na}$ pesquisa citada acima, foram entrevistados 7.939 brasileiros, entre 12 e 65 anos, nas cidades com mais de 200 mil habitantes. Verificou-se que 22,8\% da população pesquisada já fizeram uso de drogas. O maior índice de consumo foi encontrado na Região Nordeste, com percentual de 27,6\%; e o menor, na Região Norte, com 14,4\%. O uso de maconha aparece em primeiro lugar entre as drogas ilícitas, com um percentual de consumo de $8,8 \%$ dos entrevistados.

Em relação à porcentagem de dependentes de drogas no Brasil, os resultados da pesquisa apontaram que o consumo abusivo de álcool é um dos maiores problemas de saúde pública nacional, haja vista que cerca de $12 \%$ da população estudada, apresentou-se dependente dessa substância. Os dados também apontaram que o consumo de drogas no Brasil é menos preocupante que nos Estados Unidos e Reino Unido, uma vez que os índices brasileiros são bem menores que os encontrados nesses países. Enquanto no Brasil o uso da maconha foi de 8,8\%, nos EUA esse consumo foi de 40,2 \% e no Reino Unido foi de 30,8\%9 (CEBRID, 2005).

De acordo com o levantamento realizado pelo CEBRID (2005), 12,3\% das pessoas pesquisadas, com idades entre 12 e 65 anos, preenchem o perfil para a dependência de álcool. Cerca de $75 \%$ dos entrevistados já beberam pelo menos uma vez na vida. A pesquisa aponta, também, que o "uso na vida" para qualquer droga (exceto tabaco e álcool) foi de $22,8 \%$, aproximando-se do percentual do "uso na vida" encontrado no Chile, que é de 23,4\%. O "uso na vida" de álcool nas 108 maiores cidades do Brasil foi de 74,6\%, porcentagem inferior a de outros países, tais como a do Chile, com 86,5\% e dos EUA, com 82,4\%. Em 
todas as regiões, pode-se observar que o maior número de dependentes de álcool é do sexo masculino. Os dados também indicam o consumo de álcool em faixas etárias cada vez mais precoces e sugerem a necessidade de revisão das medidas de controle, prevenção e tratamento.

Os transtornos causados pelo uso de substâncias psicoativas exercem importante impacto sobre os indivíduos, suas famílias e a comunidade em geral, ocasionando prejuízo à saúde física e mental dos usuários, interferindo nas relações interpessoais, perdas econômicas e, algumas vezes, chegando a ocasionar problemas de ordem jurídica. Além disso, vários estudos empíricos apontam a consonância entre os transtornos gerados pelo uso de substâncias psicoativas e agravos sociais, tais como a violência doméstica, acidente de trânsito, crime, problemas de saúde, etc. (MINAYO; DESLANDES, 1998).

Segundo Rodrigues (2004), o problema do uso indevido de drogas, verificado nas últimas décadas, é um desafio para a saúde pública do país. O Ministério da Saúde vem definindo estratégias que visam fortalecer a rede de assistência aos usuários de álcool e outras drogas, dando ênfase à sua reabilitação e reinserção social. É necessário compreender esse fenômeno dentro de um contexto multidimensional que envolva aspectos econômicos, sociais, culturais, políticos, entre outros, e que direcione e consubstancie para a formulação de estratégias condizentes com a população brasileira acerca da questão das drogas.

As substâncias psicoativas caracterizam-se como uma questão complexa que envolve, sobretudo, aspectos culturais, simbólicos, econômicos, sociais e também o contexto histórico em que o processo se apresenta, e não só os aspectos subjetivos relacionados ao usuário como era percebida essa problemática até então (BERTOLOTE, 1997). Além disso, a compreensão do fenômeno das drogas por interface entre a justiça e a medicina é insuficiente, pois certos problemas serão rotulados, ora como legais ou ilegais, ora como de demanda da medicina. Esse fato tem conseqüência não apenas na definição das propostas de tratamento, mas principalmente na definição das políticas públicas para a questão das drogas (CRUZ, 2000 apud BASILIO, 2008).

O relacionamento entre os usuários de drogas e a sociedade é problemático devido aos prejuízos que as drogas causam. Os custos para reabilitar um dependente são muito altos. Deve-se, ainda, ressaltar a destruição que a dependência traz para famílias inteiras, os traumas durante o tratamento do indivíduo, isso quando ocorre tratamento, e até fins trágicos como morte por overdose (TAVARES; SBEGUE; UEHARA; OLIVEIRA; OLIVEIRA, 2008). 
O presente estudo, visando conhecer a realidade das instituições de tratamento existentes na Região Centro-Oeste, descreve as redes socioassistenciais de tratamento aos usuários/dependentes de drogas com dados retirado do projeto: "Mapeamento das Instituições Governamentais e Não-Governamentais de Atenção às Questões Relacionadas ao Consumo de Álcool e Outras Drogas no Brasil-2006/2007”.

A monografia está estruturada em quatro capítulos. Inicialmente, serão apresentados a metodologia e os procedimentos realizados na coleta de dados. O primeiro capítulo faz um breve histórico da atenção à saúde para os usuários de álcool e outras drogas buscando contextualizar as discussões que permearam a construção das políticas sobre o problema da dependência química, mostrando como se deram as intervenções na questão do consumo de drogas pelo governo brasileiro. Essa discussão é importante para entender a atual configuração das instituições de tratamento. Para conhecer a atual configuração das redes socioassistenciais de tratamento, recuperação e reinserção social dos dependentes de álcool e outras drogas, localizadas na Região Centro-Oeste, são apresentadas as análises quantitativas e qualitativas dos dados referentes ao tipo de tratamento, no capítulo II; as informações institucionais, no capítulo III; e as características dos dirigentes das instituições, no capítulo IV e as considerações finais.

\subsection{Metodologia}

O interesse em estudar a temática "álcool e outras drogas" surgiu no campo de estágio, no qual trabalhei com adolescentes em cumprimento da medida socioeducativa de semiliberdade localizada no Gama Leste. No estágio observei que entre os adolescentes o uso de drogas era comum. Pude observar também a dificuldade que os educadores apresentavam em relação à situação. Entre as atitudes tomadas por esses profisssionais, diante dessa problemática, havia a proibição e a punição para o adolescente que fosse encontrado fazendo uso de entorpecentes. Apesar de existir dependente de drogas na instituição de semiliberdade, durante todo o período de estagio, não presenciei nenhum encaminhamento para as redes de serviços de dependência química. Isso mostra que ainda há desarticulação entre a instituição de semiliberdade e aquelas que oferecem tratamento para dependência de álcool e outras drogas, em descumprimento à medida do art. 101, VI, do Estatuto da Criança e Adolescente. 
Encontra-se previsto neste artigo a requisição de tratamento médico, psicológico ou psiquiátrico em regime hospitalar ou ambulatorial.

O Programa de Estudos e Atenção às Dependências Químicas (PRODEQUI), em parceria com a equipe da Semiliberdade, realizava reuniões para discutir diversos temas, duas vezes por mês visando suprir o eixo sócio-terapêutico, uma das linhas de trabalho nas medidas socioedeucativas de semiliberdade. Uma das reuniões, destinada ao planejamento das atividades, ocorria sob orientação e supervisão da coordenação do PRODEQUI o qual desenvolve projetos sobre adolescentes, drogadição e delinqüência juvenil. A outra reunião para a execução das atividades com adolescentes e familiares.

Foram nessas reuniões que tive o primeiro contato com trabalhos realizados na área da drogadição, e, posteriormente tive acesso ao trabalho do professor do Departamento de Serviço Social, coordenador do pólo de prevenção a Doenças Sexualmente transmissíveis DST e Aids, vinculado ao Núcleo de Estudos e Ações Multilaterais de Cooperação em Educação e Saúde (Neamces), que abordava a questão das Aids e sua relação com as drogas injetáveis. Tais fatos foram de grande relevância no período de estágio e na minha formação, principalmente com o advento do aumento do consumo de álcool e outras drogas na sociedade. Observei que existe pouca referência bibliográfica que trata do tema álcool e outras drogas na área do Serviço Social.

Por meio de sugestões da minha orientadora, tive a oportunidade de conhecer o trabalho do Projeto "Mapeamento das Instituições Governamentais e Não-Governamentais de Atenção às Questões Relacionadas ao Consumo de Álcool e Outras Drogas no Brasil2006/2007" realizado em todo o Brasil. A partir disso, surgiu a idéia de analisar os dados coletados das redes socioassistenciais de tratamento, recuperação e reinserção social, relativos aos dados da Região Centro-Oeste, buscando dados para fomentar as discussões sobre a temática "álcool e outras drogas" nessa região, levando-se em consideração a especificidade, a realidade e a configuração institucional existente.

\footnotetext{
${ }^{1}$ Relatório "Mapeamento das Instituições Governamentais e Não-Governamentais de Atenção às Questões Relacionadas ao Consumo de Álcool e Outras Drogas no Brasil”. Disponível em:. http://www.obid.senad.gov.br/ portais/OBID/biblioteca/documentos/Dados_Estatisticos/Instituicoes/327691.pdf Acessado em: 10 de outubro de 2008
} 


\subsection{Coleta de Dados}

O levantamento das informações necessárias para a realização da pesquisa ocorreu por meio de coleta de dados secundários, ou seja, os dados analisados foram retirados do projeto "Mapeamento das Instituições Governamentais e Não-Governamentais de Atenção às Questões Relacionadas ao Consumo de Álcool e Outras Drogas no Brasil-2006/2007”. Esse projeto foi coordenado pela professora Dra. Denise Bomtempo B. Carvalho, do Departamento de Serviço Social da Universidade de Brasília, financiada pela Senad.

Trata-se de pesquisa exploratória. Uma investigação descritiva sobre tipos de tratamentos oferecidos pelas instituições, atividades executadas, recursos, características dos dirigentes e da equipe profissional dessas instituições de tratamento. Para Gil (1991), os estudos exploratórios são desenvolvidos quando o tema é pouco explorado, no qual se torna difícil formular proposições precisas e operacionalizáveis sobre o tema pesquisado.

O projeto supracitado foi desenvolvido em três etapas. A primeira etapa constituiu-se no mapeamento e cadastramento de 9.503 instituições governamentais e nãogovernamentais que realizavam atividades nos eixos de Prevenção; Tratamento, Recuperação e Reinserção Social; Redução de Danos; e Ensino e Pesquisa. Os cadastros foram atualizados por meio de busca ativa, via serviço de telemarketing, bem como por meio da aplicação do questionário resumido contendo os seguintes dados: nome, endereço, telefone da instituição, nome do dirigente, e-mail da instituição e do dirigente, página na internet, natureza da instituição (governamental ou não-governamental), tipos de atividades desenvolvidas (prevenção ao uso indevido de álcool e outras drogas; tratamento, recuperação e reinserção social; redução de danos sociais e à saúde, ensino e pesquisa) (CARVALHO; DUARTE, 2007)

A segunda etapa do Projeto Mapeamento consistiu na aplicação do questionário ampliado contendo questões fechadas e abertas, aos dirigentes das instituições mapeadas e cadastradas na Etapa 1localizadas no país, para complementação dos cadastros e coleta de dados quantitativos referentes à atuação das referidas instituições nas áreas de prevenção, tratamento, redução de danos sociais e à saúde e ensino e pesquisa. Foram enviados 2.000 questionários, via postal, às instituições citadas, no intuito de obter informações acerca dos objetivos, atividades, rotinas de acolhimento, composição e qualificação dos recursos humanos, infra-estrutura 
física e financeira dessas instituições. Foram respondidos 1.884 (94\%) questionários e validados 1.642 (82\%)(CARVALHO; DUARTE, 2007).

A terceira etapa do Projeto Mapeamento consistiu de visitas e realização de entrevistas com os dirigentes das instituições, objetivando avaliar qualitativamente as informações prestadas pelos mesmos no questionário ampliado (Etapa 2).Foram selecionados $10 \%$ das instituições cujos questionários foram validados. Nessa etapa, foram avaliadas qualitativamente as informações prestadas pelos dirigentes das instituições. Para a constituição da amostra (10\%) as instituições foram divididas em grupos considerando os seguintes aspectos: a natureza da instituição (governamental e não-governamental), região geográfica, capitais dos estados brasileiros e o tipo de atividade (prevenção, tratamento, redução de danos sociais e à saúde e ensino e pesquisa).

A pesquisa qualitativa foi realizada nas 27 capitais do país, perfazendo um total de 211 instituições A análise qualitativa foi feita por meio das questões abertas do questionário ampliado, das entrevistas e dos relatórios descritivos dos pesquisadores. Nessa etapa, foi utilizada a análise de conteúdo, tendo como critérios: a) a natureza das instituições (governamentais e nãogovernamentais); b) as atividades desenvolvidas em relação aos eixos da pesquisa. (CARVALHO; DUARTE, 2007).

Para fins desse trabalho de conclusão de curso, foram analisadas as redes socioassistenciais do eixo Tratamento, Recuperação e Reinserção social por intermédio de dados qualitativos e quantitativos de acordo com a natureza da instituição na região CentroOeste do Brasil. Ao todo foram analisadas 129 instituições de Tratamento, Recuperação e Reinserção Social, as quais 43 são instituições governamentais, 85 não-governamentais e uma sem resposta. Para a análise dos dados, foi utilizada a mesma abordagem metodológica empregada no projeto "Mapeamento das Instituições Governamentais e Não-Governamentais de Atenção às Questões Relacionadas ao Consumo de Álcool e Outras Drogas no Brasil”.

O questionário utilizado para a coleta dos dados quantitativos foi estruturado em cinco eixos contendo questões objetivas e discursivas (o que admite mais de uma resposta na contabilização das respostas), aplicado aos dirigentes das instituições. Dos eixos, listados abaixo, foram utilizados e analisados apenas os dados dos eixos 1 e 3 por possuir informações pertinentes ao foco do trabalho que é descrever as instituições que realizam atividades de Tratamento, Recuperação e Reinserção Social.

Eixo 1: Instituições

Parte1: Informações institucionais 
Parte2: Perfil dos dirigentes

Parte3: Perfil da instituição

Parte4: Recursos humanos

Parte5: Recursos físicos/materiais

Eixo 2: Prevenção ao uso indevido de álcool e outras drogas

Eixo 3: Tratamento aos usuários de álcool e outras drogas

Eixo 4: Redução de danos sociais e à saúde

Eixo 5 - Ensino e pesquisa sobre a temática álcool e outras drogas (CARVALHO; DUARTE, 2007).

Objetivando complementar e avaliar qualitativamente as informações prestadas pelos dirigentes das instituições no questionário e com o intuito de validar a pesquisa, foram selecionadas oito entrevistas, entre as 32 aplicadas aos dirigentes das instituições da região Centro-Oeste. Essas entrevistas também possuíam questões objetivas e subjetivas, seguindo os mesmos eixos utilizados para os questionários. As entrevistas foram escolhidas de modo a representar as instituições governamentais e não-governamentais das quatro capitais na Região Centro-Oeste. 


\section{CAPITULO I}

\section{Marco Legal da Atenção à Saúde para Usuários de Álcool e Outras Drogas no Brasil}

A relação entre o indivíduo, a sociedade e a questão das drogas tem perpassado toda a existência da humanidade. Historicamente, as drogas foram utilizadas por grupos variados com fins que se estendem desde a diversão, em busca de prazeres, até ritos de exaltação místico-religiosa. É notável o uso de drogas para fins curativos, seja no âmbito das práticas religiosas tradicionais, seja no contexto médico da atualidade. (PRATTA; SANTOS, 2006).

O uso de drogas, até o final do século XIX, era raramente concebido como ameaçador à ordem social brasileira. De modo que o consumo de bebidas alcoólicas não constituía um alvo de preocupação governamental. A não intervenção por parte dos governantes nessa área contribuiu para o surgimento de estabelecimentos de caráter privado, que se encarregaram de dar início a uma educação antialcoólica e de promover as primeiras medidas assistenciais para alcoólatras (MUSUMESCI, 1994 apud MACHADO, 2006). No começo as intervenções foram marcadas por percepções moralistas e higienistas.

Segundo Machado e Miranda (2007), somente no início do século XX é que o governo brasileiro iniciou as primeiras intervenções na questão do consumo de drogas. Tais intervenções ocorreram por meio da criação de um aparato jurídico-institucional destinado a estabelecer o controle do uso e do comércio de drogas, devido à associação destas, à criminalidade e a práticas anti-sociais. $\mathrm{O}$ aparato jurídico-institucional foi constituído por uma série de Leis e Decretos que proibiam e criminalizavam as várias condutas associadas à produção, ao comércio e ao uso de drogas. Previa penas que levavam à exclusão dos usuários do convívio social, determinando sua permanência em prisões, sanatórios e, a partir da década de 1970, em hospitais psiquiátricos. Essas medidas eram recomendadas e influenciadas por convenções internacionais (MACHADO, 2006).

A atenção do Estado Brasileiro com a questão das substâncias psicoativas materializa-se com o Regulamento Imperial de 1851, que instituía a polícia sanitária e disciplinava a venda de remédios, mas não faz referência sobre a proibição da fabricação ou do consumo de drogas. Caindo em uma contradição, na qual a intervenção sanitária legal 
permite à classe médica o monopólio do receituário, mas ao mesmo tempo, confere ao Estado toda a autoridade para fiscalizar a relação médico-paciente (RODRIGUES, 2004).

A partir da promulgação dos códigos sanitários, houve um gradativo processo de institucionalização do saber médico, em que o Estado tornava-se regulador legítimo do saber médico-cientifico e, portanto, único autorizado a regulamentar a venda de drogas e as políticas de saúde pública (KARAM, 2000).

Em 1914, os Estados Unidos adotaram o Harrison Narcotic Act, proibindo o uso da cocaína e heroína fora do controle médico. Severas penas contra o consumo foram adotadas em convenções internacionais das décadas de 1920 e 1930. Portanto, no início do século XX, os norte-americanos começaram a pressionar o Brasil para que efetivasse sua adesão à Convenção do Ópio, o qual visava o controle da produção de drogas narcóticas, assinada em Haia em 1912. Pressionado por tratados internacionais, o Brasil participou da Convenção em Haia, porém só assinou o documento em 1914, internalizando as resoluções, por meio do Decreto Federal n 11.481 de 1915 (RODRIGUES, 2004).

Por meio da Lei Federal no 4.294 de 1921, regulamentada pelo Decreto $n^{\circ} 14.969$ do mesmo ano, o Código Penal Brasileiro propôs pena de prisão para aqueles que comercializassem ópio, e seus derivados e cocaína; fortalecendo a polícia sanitária em suas prerrogativas e reafirmando as restrições do uso legal de substâncias psicoativas para fins terapêuticos. Com relação ao consumo de álcool, os que causassem atos lesivos a si próprios, a outrem ou à ordem pública, receberiam como punição a internação obrigatória em "estabelecimento correcional adequado" (BITTENCOURT, 1986; FIORE, 2005 apud MACHADO; MIRANDA, 2007). O Decreto n ${ }^{\circ} 14.969$ de 1921 cria o "sanatório para toxicômanos", no qual era oferecido o tratamento para pessoas que apresentavam consumo compulsivo de substâncias psicoativas (RODRIGUES, 2004).

Os anos trinta do século XX caracterizam-se pela publicação de leis, regulamentos e decretos para controlar as drogas. Nos Estados Unidos, elaboraram-se o Marihuana Tax Act (ato de imposto sobre maconha) de 1937; na Venezuela a Ley de Estupefactivos de 1934; na Colômbia, a Ley 18 de 1033 e a Ley 95 que modifica o Código Penal; e no Brasil, por exemplo, a lei de entorpecentes de 1930, substituiu uma série de decretos anteriores (OLMO, 1990 apud BASÍLIO, 2008).

No governo de Getúlio Vargas, foram adotadas diversas medidas complementares para o combate ao tráfico. Em 1931, foi editado o Decreto-Lei $\mathrm{n}^{\circ}$ 891, que limitava a 
produção, o uso e a comercialização de substâncias entorpecentes e fornecia a lista das substâncias controladas (ROCCO, 2000 apud BASÍLIO, 2008).

O posterior Decreto-Lei no 790 de 1936 trazia atualização de sanções já previstas e também a determinação de novos parâmetros punitivos que ampliava a capacidade reguladora e repressiva do Estado. Esse decreto criou a Comissão Permanente de Entorpecentes, órgão espelhado na Liga das Nações, encarregada de centralizar as informações sobre produção, circulação e comércio legal de drogas controladas (RODRIGUES, 2004).

O Decreto-Lei n 891 de 1938 sintetizava as principais determinações das legislações anteriores e, ainda, reforçava a estratégia repressiva do Estado em relação à produção, tráfico e consumo de drogas controladas (GRECO FILHO, 2006; RODRIGUES, 2004).

Em 1940 entrou em vigor o novo Código Penal Brasileiro. Entre os artigos que tratam de ações referentes às drogas encontra-se o artigo 281, dos crimes contra a saúde pública, que passou a reger a política das drogas no Brasil (ROCCO, 2000 apud BASÍLIO, 2008).

Em 1941, por meio do Decreto nº 3.114 , ocorreu a concretização da Comissão Nacional de Fiscalização de Entorpecentes no sistema de combate ao tráfico e ao uso ilegal de drogas, o qual deliberava sobre a composição e as funções específicas da comissão. A regulamentação concluíu a construção do importante texto legal sobre o controle de drogas no Brasil (GRECO FILHO, 2006; RODRIGUES, 2004).

Nos anos 50, foram enunciadas pelos especialistas internacionais das Nações Unidas, por meio da OMS as primeiras observações e medidas de controle em termos farmacológicos, médicos e jurídicos. Os anos 60 poderiam ser classificados como o período de propagação do modelo médico-sanitário e de caracterização da droga como sinônimo de dependência (OLMO, 1990 apud BASÍLIO, 2008).

No dia 27 de agosto de 1964 de foi aprovado pelo Congresso Nacional a Convenção Única sobre Entorpecentes no Brasil, por meio do Decreto $\mathrm{n}^{\mathrm{o}}$ 54.216, que incorporava ao seu ordenamento interno, o acordo de abrangência internacional (Convenção Única sobre Entorpecentes) assinado em Nova York em 30 de março de 1961 pelas Nações Unidas (BRASIL, 1964). A aceitação brasileira à Convenção abria espaço dentro do próprio corpo jurídico nacional para o aperfeiçoamento das medidas de repressão e aparelhamento do 
Estado, a fim de concretizar a luta contra as drogas, a qual o país se comprometera (RODRIGUES, 2004).

A partir da década de 1970, a medicina passou a influenciar a legislação brasileira sobre a questão das drogas, contribuindo com subsídios tecnocientíficos para a legitimação do controle do uso de drogas. À concepção moral do fenômeno das drogas, somou-se ao discurso médico, contribuindo para que os aspectos socioeconômicos, étnicos, morais ou políticos presentes nas intervenções se tornassem mais difusos. Esse contexto cultural contribuiu para a consolidação de uma política proibicionista (RODRIGUES, 2004).

A Lei $n^{\circ}$. 5.726 de 1971, sob a influência da ordem médico-psiquiátrica, introduziu mudanças significativas na interpretação do uso de drogas, ainda que no âmbito da justiça penal. A concepção médico-psiquiátrica, no qual o usuário de drogas passou a ser tratado como um doente, tornou-se preponderante. Para tratar dos infratores e viciados, foram propostos diferentes aparelhos assistenciais: a princípio, hospitais psiquiátricos e, posteriormente, centros especializados de tratamento, públicos ou filantrópicos com o objetivo de salvar, recuperar, tratar e não simplesmente punir (FIORE, 2005 apud MACHADO; MIRANDA, 2007). Essa lei pôs fim ao nivelamento penal entre dependente e traficante. Com isso, os dependentes poderiam ser condenados à internação obrigatória, de acordo com o estabelecido pelo juiz responsável pelo caso.

O Decreto $n^{\circ} 69,845$ de 1971, implementou a Lei $\mathrm{n}^{0} 5.726$ de 1971, definindo a competência dos órgãos estatais na abordagem da questão das drogas. Trouxe como inovação a proposição de ações, tais como execução de planos e programas nacionais e regionais de esclarecimento popular sobre os prejuízos gerados pelo uso indevido das substâncias entorpecentes, criação do Conselho de Prevenção Antitóxico que passaria a coordenar os cursos de formação de educadores contra o uso de drogas, entre outros. Essa lei não modificou substancialmente a legislação de 1938, todavia constituiu avanço na preparação geral do Estado para enfrentar os crimes estabelecidos pela norma vigente (RODRIGUES, 2004).

Em 1976, foi aprovada e promulgada a Lei $n^{\circ}$. 6.368, que reafirmou a intenção de abordar o uso e a dependência de drogas no campo médico-psiquiátrico. A Lei dos Tóxicos, como ficou conhecida, reunia num único documento todas as disposições pertinentes à repressão ao tráfico e à prevenção ao uso de drogas, estipulando as sanções penais para os crimes previstos. Conquistou, a princípio, a autonomia em relação ao artigo 281 do Código 
Penal, que, até então, era responsável por determinar as penas para os casos de crime de tráfico e de uso indevido de drogas (GREGO FILHO, 2006; RODRIGUES, 2004). A lei refere-se proibição de vender, expor à venda ou oferecer substâncias entorpecentes e pune a pessoa que as adquire ou traz consigo para uso próprio. (VELOSO; CARVALHO; SANTIAGO, 2004).

A Lei $\mathrm{n}^{\mathrm{o}}$. 6.368 foi sancionada após ter verificado o aumento do consumo de drogas ilícitas no país, a partir da década de 1960. O consumo de maconha, antes limitado a setores situados às margens das grandes cidades, passou a ser consumido também nas classes médias. Essa comprovação provocou um grande alarme social e, na tentativa de estabelecer o controle do consumo de drogas, o governo brasileiro começou a desenvolver ações para a redução da oferta de drogas. (CRUZ; FERREIRA, 2001; MISSE, 2003 apud MACHADO; MIRANDA, 2007).

Entre as mudanças propostas pela Lei de 1976, destaca-se a substituição do termo "viciado" por "dependente de drogas" e a criação de estabelecimentos público especializados no tratamento em regime hospitalar e extra-hospitalar. No artigo $9^{\circ}$, capítulo II dessa Lei foram definidas as atribuições para o Sistema de Saúde e para o Ministério da Previdência e Assistência Social, responsáveis pela rede pública sanitária (MACHADO; MIRANDA, 2007).

Essa lei favoreceu a consolidação e ampliação do aparato jurídico institucional de controle do uso e do tráfico de drogas e estabeleceu as bases legais para a criação do Sistema Nacional de Prevenção, Fiscalização e Repressão de Entorpecentes e do Conselho Federal de Entorpecentes - CONFEN, em 1980, no âmbito do Ministério da Justiça (MACHADO; MIRANDA, 2007). Essa estrutura sinalizava a construção de um mecanismo de controle do Estado, marcada por um trabalho político e policial de sujeição a um ideário de harmonia social, da disciplina das pessoas, a partir da "ameaça" social de comportamentos ditos “desviantes" em um contexto autoritário, discriminatório e repressivo (BUCHER; OLIVEIRA, 1994).

A partir da década de 1980, foram criados os primeiros centros de tratamento no Brasil. Esses centros estavam vinculados direta ou indiretamente ao poder público, favorecendo o surgimento da assistência à saúde para usuários de drogas e colocando em exercício as orientações legislativas previstas na Lei $\mathrm{n}^{\circ}$. 6.368/76 (BITTENCOURT, 1986 apud MACHADO 2006). Segundo Machado (2006), esses centros de tratamento (as chamadas portas assistenciais) foram criados para o atendimento de consumidores de drogas 
ilícitas. Esse fato reafirmava o compromisso do Brasil assumido no plano internacional que era de controlar e reprimir o uso de drogas ilícitas.

Obedecendo à Lei $n^{\circ}$ 6.368, são criados pelo Decreto $n^{\circ} 85.110$ de 1980, o Conselho Federal de Entorpecentes (CONFEN), os Conselhos Estaduais de Entorpecentes (CONENS) e os Conselhos Municipais de Entorpecentes (COMENS). Tais conselhos, todos normativos, vinculavam-se, respectivamente, ao Ministério da Justiça e às Secretarias de Justiças dos Estados e Municípios. (OLIVEIRA, 2004)

O CONFEN foi criado e regulamentado em 1980 durante o período da ditadura militar, destacou-se como órgão normativo dos diversos assuntos e dos programas governamentais relativos ao tema drogas. Sua atuação e suas principais funções foram definidas no Decreto $n^{\circ} .85 .110$ de 1980. A ele cabia:

Art. 4... Propor a política nacional de entorpecentes, elaborar planos, exercer orientação normativa, coordenação geral, supervisão, controle e fiscalização das atividades relacionadas com o tráfico e uso de entorpecentes e substâncias que determinem dependência física ou psíquica (BRASIL, MINISTÉRIO DA JUSTIÇA, 1992 apud MACHADO; MIRANDA, 2007 ).

O CONFEN é composto por representantes dos vários ministérios: um representante do Ministério da Justiça; um representante do Ministério da Saúde; um representante do Ministério da Educação e Cultura; um representante do Ministério da Previdência e Assistência Social; um representante do Ministério da Fazenda; um representante do Ministério das Relações Exteriores; um representante do Estado-Maior das Forças Armadas; um representante do órgão de repressão a entorpecentes do Departamento de Polícia Federal; um representante do órgão de vigilância sanitária do Ministério da Saúde; um jurista de comprovada experiência em assuntos de entorpecentes, indicado e designado pelo Ministro da Justiça e um médico psiquiatra com ampla atuação na área de entorpecentes indicado pela Associação Médica Brasileira e designado pelo Ministro da Justiça (BRASIL, 1980).

Segundo Garcia e Leal (2006 apud BASÍLIO, 2008), o Conselho Nacional de entorpecentes (em 1998 passou a ser chamado Conselho Nacional Antidrogas) vivenciou momentos diferentes e formulou propostas de políticas para a sua área como:

A Política Nacional na Questão das Drogas, de 1988. Responsável pelo reconhecimento e pela consolidação de centros de referência em prevenção e tratamento ao uso abusivo de drogas lícitas e ilícitas. Muitos desses centros de tratamento, pesquisa e 
prevenção na área das drogas foram criados nas universidades públicas. Apenas dois deles foram criados no âmbito do setor público estadual de saúde: o Centro Mineiro de Toxicomania (CMT), em Minas Gerais, e o Centro Eulâmpio Cordeiro de Recuperação Humana (CECRH), em Pernambuco. Muitos atores e práticas de atenção que influenciaram a política de saúde para usuários de álcool e outras drogas tiveram suas origens nesses centros (MACHADO, 2006).

O Programa de Ação Nacional Antidrogas de 1996. Desenvolveu ações de prevenção, repressão e tratamento, abordando a questão do crescimento do consumo de drogas com a disseminação do vírus HIV, no caso dos usuários de drogas injetáveis. Esse documento estabeleceu critérios e normas para o funcionamento de instituições de tratamento. Instituiu a substituição do modelo assistencial de saúde mental por serviços específicos de atenção às dependências químicas e estabeleceu o apoio técnico e financeiro às entidades filantrópicas e a promoção de capacitação de recursos humanos. A coordenação e o acompanhamento dessas ações foram atribuídos ao Ministério da Justiça, à Secretaria de Planejamento das Ações de Segurança Pública e ao Departamento de Entorpecentes (MACHADO, 2006).

Projeto para uma Nova Política de Drogas no País de 1992. Reafirmou a necessidade de modificações da visão jurídico-penal, associada à perspectiva médicopsiquiátrica das políticas de drogas brasileira, já ressaltadas no documento de 1988. (MACHADO, 2006).

Em 1986 foi criada a Lei $\mathrm{n}^{\mathrm{o}}$. 7.468 que dispôs sobre a obrigatoriedade das emissoras de rádio e televisão de promoverem campanhas educativas sobre as conseqüências prejudiciais do uso de drogas entorpecentes. Após oito anos, foi aprovada a Lei $\mathrm{n}^{\circ}$. 9.294, regulamentada pelo Decreto $\mathrm{n}^{\mathrm{o}} 2.018$ de 1996, que dispôs sobre as restrições ao uso e à propaganda de produtos, entre eles bebidas alcoólicas (BRASIL, 1986, apud BASÍLIO, 2008).

Em 1990 foi editada a Lei n'. 8.080 “dispõe sobre as condições para a promoção, proteção e recuperação da saúde, a organização e o funcionamento dos serviços correspondentes", incluiu em seu Artigo 6 ${ }^{\circ}$, Inciso IX a participação do Ministério da Saúde no controle e na fiscalização da produção, transporte, guarda e utilização de substâncias e produtos psicoativos, tóxicos e radioativos como competência de atuação do SUS (BRASIL, 1990). 
O Decreto $\mathrm{n}^{\mathrm{o}}$. 85.110 de 1980 instituiu o Sistema Nacional de Prevenção, Fiscalização e Repressão de Entorpecentes, que integra as atividades de prevenção, fiscalização e repressão ao tráfico e uso de substâncias entorpecentes ou que determinem dependência física ou psíquica, bem como as atividades de recuperação de dependentes (BRASIL, 1980). No entanto, treze anos após a sua criação, foi estruturado por meio da Lei $n^{\circ}$. 8.764 de 1993, incumbido de exercer atividades concernentes à prevenção, fiscalização e repressão do uso e tráfico ilícito de entorpecentes e substâncias que determinem dependência física ou psíquica, normatizadas pelo Conselho Federal de Entorpecentes (BRASIL, 1993).

Seguindo a recomendação formulada pela Comissão Interamericana para o Controle de Abuso de Drogas, no ano de 1999, o Brasil implantou o Observatório Brasileiro de Informação sobre Drogas (OBID), que somente iniciou suas atividades em 2002. O objetivo da criação dessa instituição consistia em dispor de um sistema integrado que reunisse as informações relacionadas aos resultados de pesquisas e estudos sobre o uso indevido de drogas (GARCIA; LEAL, 2006 apud BASÍLIO, 2008).

Em 1998, o Conselho Federal de Entorpecentes e a Secretaria Nacional de Entorpecentes foram extintos. Em seu lugar, foi instituído o Sistema Nacional de Políticas sobre Drogas (Sisnad), por meio do Decreto nº 2.362 de 1998, posteriormente, substituído pelo Decreto $\mathrm{n}^{\mathrm{o}}$. 3.696, de 21 de 2000. Entre seus objetivos estão: formular a Política Nacional Antidrogas e compatibilizar planos nacionais com planos regionais, estaduais e municipais, bem como fiscalizar suas respectivas execuções. O Sisnad conta com dois órgãos executivos: a Secretária Nacional Antidrogas (Senad) e o Departamento de Polícia Federal (BRASIL, 2000a).

Inicialmente, a Senad propunha-se a coordenar as ações de combate ao tráfico e de prevenção ao consumo de entorpecentes no Brasil. Todavia, constitucionalmente, o papel de repressão cabe à Polícia Federal, o que ocasionou um choque de competências, obrigando à Presidência a redefinir o papel da Senad. Visando adequá-la às necessidades burocráticas, sua estrutura foi modificada e aprovada pelo Decreto $n^{\circ} .3 .845$ de 2001. Após as devidas estruturações, a Senad consolidou-se como órgão executivo do grupo de atividades de prevenção, ou seja, responsável pela coordenação das atividades de redução de demanda. Em contrapartida, o Ministério da Justiça, por intermédio do Departamento de Polícia Federal, permaneceu como órgão executivo do grupo de repressão, responsável pelas atividades de redução de oferta. (MACHADO; MIRANDA 2007). 
Apesar da SENAD e o SUS terem responsabilidades e atribuições semelhantes, aquela tem a função executiva das ações preventivas destinadas aos dependentes de drogas e esta, da prestação de assistência integral à saúde de todos os cidadãos brasileiros. Destarte, apesar do SUS ser responsável pela assistência integral, nenhuma das atividades do grupo de prevenção, tratamento, recuperação e reinserção social foram atribuídas a esse órgão. Observa-se que esses espaços institucionais permaneceram desarticulados até o início do governo Lula, em 2003, quando se fez um esforço de integração das diversas áreas ligadas ao tema (MACHADO; MIRANDA 2007).

A complexidade e a gravidade dos problemas envolvendo o uso e o abuso do álcool e outras drogas exigem a ação de atores sociais de formação diversificada, tais como, profissionais responsáveis pelo cumprimento das leis (juízes, promotores, policias etc.), profissionais de saúde, educadores, religiosos, familiares de usuários de drogas, ex-usuários, usuários atuais de drogas, entre outros (CRUZ, 2006).

\section{A construção das Políticas de Atenção ao consumo de álcool e outras drogas.}

Em relação à política de drogas, observa-se que o Brasil (e outros países) privilegiou a repressão às substâncias ilícitas pressionado por tratados internacionais, entretanto pouco se fez no campo da prevenção, por meio da educação para a saúde. Ao longo da história, a saúde pública brasileira não se preocupou devidamente com o problema da prevenção e tratamento de transtornos associados ao consumo de álcool e outras drogas. Conseqüentemente, essa falta de atenção produziu uma lacuna na política pública de saúde. (SICA, 2005,)

Até os anos 90, não existia uma política específica para tratar a questão das drogas, apenas ações voltadas para repressão, feitas de forma pouco coordenada ou planejada. Não havia programas consolidados, somente ações difusas e descontínuas de prevenção e tímidas iniciativas na área do uso indevido de drogas pelo Ministério da Saúde, o que refletia o descaso do Estado e o desinteresse das instituições públicas para tratar do tema (OLINGERS s/d). De acordo com Rodrigues (2004), no Brasil o processo de proibição do comércio de drogas teve como base o modelo internacional proibicionista, vinculado a interesses econômicos e comerciais. 
O processo de formulação da Política Nacional Antidrogas teve início a partir de 1998 com a realização do I Fórum Nacional Antidroga. Esse fórum contou com a presença de agentes que atuavam na questão de drogas: policiais, pessoas vinculadas às comunidades terapêuticas, profissionais ligados à área científica e pessoas ligadas aos projetos de redução de danos. As federações de comunidades terapêuticas, que estavam presentes em maior número, reivindicaram e fizeram constar ao documento (Política Nacional Antidrogas), da necessidade de iniciar o processo de definição das normas mínimas de regulamentação das instituições de tratamento. Ressalte-se que o documento não fez nenhuma menção de articulação entre a área ligada ao problema das drogas e o setor público de saúde.

O processo de normatização das comunidades terapêuticas, necessário para o estabelecimento de condições mais dignas aos usuários, contribuiu para o financiamento público a essas instituições. Revelando a tendência histórica de manutenção da atenção aos problemas relacionados ao álcool e outras drogas fora do âmbito do setor público de saúde. (MACHADO; MIRANDA 2007).

Após a formatação do Sisnad e da consolidação do Senad, essas Secretarias juntamente com o Departamento de Policia Federal (DPF) e outros agentes do Sistema lançaram em 2001 a Política Nacional Antidrogas, decretada pelo então presidente Fernando Henrique Cardoso e apresentado à sociedade brasileira por meio do $2^{\circ}$ Fórum Nacional Antidrogas (MACHADO; MIRANDA 2007). Essa política estabeleceu os objetivos, as diretrizes e as estratégias para a ação antidrogas, o que representou um importante marco no combate às drogas.

Para conseguir lidar com a demanda de pacientes que necessitam de tratamento, a Agência Nacional de Vigilância Sanitária (ANVISA) e a Secretaria Nacional Antidrogas (Senad) editaram uma Resolução no 101/2001 que instituiu o Regulamento Técnico (seguindo os parâmetros já definidos pelo modelo psicossocial, também conhecido como comunidades terapêuticas) que disciplina as exigências mínimas para o funcionamento de serviços de atenção à pessoa com transtornos decorrentes do uso e abuso de álcool e outras drogas. Essa resolução define comunidades terapêuticas como: "serviços de atenção a pessoas com transtornos decorrentes do uso ou abuso de substâncias psicoativas (SPA), em regime de residência ou outros vínculos de um ou dois turnos". (SABINO; CAZENAVE, 2005).

Em 2001, a Lei $n^{\circ}$. 10.216, considerada um marco legal da Reforma Psiquiátrica, aprovou as diretrizes básicas que formam o SUS, garantindo aos usuários de serviços de 
saúde mental e, conseqüentemente, aos que sofrem por transtornos decorrentes do consumo de álcool e outras drogas a universalidade de acesso e direito à assistência, bem como a sua integralidade. Com esse ordenamento houve a valorização da descentralização do modelo de atendimento ao determinar a configuração de redes assistenciais mais próximos do convívio social de seus usuários, contribuindo para o desempenho de serviços e ações de acordo com as necessidades da população (BRASIL, 2003).

Essa norma propiciou um novo sentido ao modelo assistencial em saúde mental. Estabelecendo:

\footnotetext{
Art. $6^{\circ}$ A internação psiquiátrica somente será realizada mediante laudo médico circunstanciado que caracterize os seus motivos.

Parágrafo único. São considerados os seguintes tipos de internação psiquiátrica:

I - internação voluntária: aquela que se dá com o consentimento do usuário;

II - internação involuntária: aquela que se dá sem o consentimento do usuário e a pedido de terceiro; e

III - internação compulsória: aquela determinada pela Justiça. (BRASIL, 2001).
}

Nessa lei as situações de emergências foram mantidas, uma vez que as internações psiquiátricas somente serão realizadas, por meio de laudo médico especificados os motivos. Segundo Lange (2002), na internação voluntária, a pessoa assina uma declaração consentindoa. Na internação involuntária, o Ministério Público é comunicado tanto da internação quanto da alta da pessoa assistida. Já a internação compulsória é determinada pelo juiz competente

A necessidade de definição de estratégias específicas para a construção de uma rede pública de tratamento aos usuários de álcool e outras drogas, com ênfase também na reinserção social, levou o Ministério da Saúde a instituir, no âmbito do SUS, o Programa Nacional de Atenção Comunitária Integrada aos Usuários de Álcool e outras Drogas (PAIUAD), já no ano de 2002. (BRASIL, 2003).

A partir de 2003, reconhecido o elevado custo social que representa o uso abusivo de substâncias psicoativas pela Organização Mundial da Saúde, foi iniciada uma discussão mais sistemática sobre as questões relacionadas ao álcool e outras drogas no campo da saúde pública. Desse modo, o SUS, com a intenção de delimitar espaço nesse território, assumiu, definitivamente em 2003, a responsabilidade pela atenção e prevenção de danos associados ao consumo prejudicial de álcool e outras drogas com a efetivação da Política de Atenção Integral aos Usuários de Álcool e outras Drogas (PAIUAD) elaborada pela Área Técnica de Saúde Mental/Álcool e Drogas (BRASIL, 2003). 
Essa política destaca a importância dos serviços de saúde voltados à população usuária de drogas e propõe diretrizes de prevenção, tratamento e educação. As propostas adotam uma perspectiva intersetorial, com articulações envolvendo programas do Ministério da Saúde, de outros setores do governo, de organizações não governamentais e representantes da sociedade civil organizada.

Ainda em 2003, o Ministério da Saúde apresentou proposta inédita de política pública voltada para usuário de álcool e outras drogas: A Política do Ministério da Saúde para a Atenção Integral a Usuários de Álcool e outras Drogas. A intersetorialidade e a atenção integral são as duas de suas mais importantes diretrizes e estão em consonância com o princípio da política mental (MACHADO, 2006).

A intersetorialidade advém do reconhecimento de que o abuso do álcool e outras drogas é um problema transversal a outras áreas além da saúde, como a justiça, a educação e o desenvolvimento social; conseqüentemente, exige intensa articulação entre esses grupos. Já a atenção integral requer diferentes iniciativas que incluem propostas de prevenção, capacitação de profissionais e diversos modelos de atenção. (CIRINO, 2006)

Por meio da articulação de diferentes órgãos do Governo Federal, foi instituído o Grupo de Trabalho Interministerial (GTI) pelo Presidente Lula, para elaborar propostas para ações relacionadas às bebidas alcoólicas. Dessa interlocução interministerial, foi criado o Grupo de Trabalho em Álcool e Outras Drogas (GAOD) no sentido de discutir a Política de Álcool e Outras Drogas do Ministério da Saúde. Esse grupo foi responsável pela elaboração da Política do Ministério da Saúde para a Atenção Integral a Usuários de Álcool e outras Drogas (BRASIL, 2007).

Na reformulação, ocorrida em 2004, da Política do Ministério da Saúde para a Atenção Integral a Usuários de Álcool e outras Drogas, houve um debate sobre modelos e dispositivos assistenciais a serem adotados no país. De um lado, havia pressão das comunidades terapêuticas para obter financiamento do SUS, posição que contava com apoio de alguns setores do Ministério da Saúde e da Senad; do outro, havia pressão de outros setores do ministério, como a Coordenação de Saúde Mental, para que a questão do álcool e outras drogas fossem abordadas no âmbito do SUS. Tratava-se de adotar uma política coerente com o discurso antidrogas ou de inaugurar outra proposta política focada na redução dos problemas associados ao consumo de álcool e outras drogas (MACHADO; MIRANDA 2007). 
Prevaleceu, no Ministério da Saúde, a posição daqueles que defendiam a inclusão da atenção aos usuários de álcool e outras drogas no SUS. As comunidades terapêuticas receberam o Estatuto de Rede de Suporte Social, sem receber financiamento do SUS. (BRASIL, Ministério da Saúde, 2004 apud MACHADO; MIRANDA 2007).

Foi apenas em 2003, após quinze anos da criação do SUS, que o Ministério da Saúde assumiu o compromisso de enfrentar os problemas associados ao consumo de álcool e outras drogas no Brasil. Isso se deu com a publicação do documento: "A Política do Ministério da Saúde para a Atenção Integral a Usuários de Álcool e outras Drogas"; no qual "assume de modo integral e articulado o desafio de prevenir, tratar e reabilitar os usuários de álcool e outras drogas como um problema de saúde pública" (BRASIL, Ministério da Saúde, 2004a, p.9 apud MACHADO; MIRANDA 2007). Assim sendo, foram definidos o marco teórico-político e as diretrizes para a PAIUAD, aderindo aos princípios e orientações do SUS, da reforma psiquiátrica e da lógica ampliada de redução de danos.

\footnotetext{
A Política Nacional sobre Drogas (PNAD) reconhece a estratégia de Redução de Danos, amparada pelo artigo 196 da Constituição Federal, como medida de intervenção preventiva, assistencial, de promoção da saúde e dos direitos humanos que visa diminuir o impacto dos problemas socioeconômicos, culturais e dos agravos à saúde associados ao uso de álcool e outras drogas (CARVALHO; DUARTE, 2007, p.153).
}

Os Centros de Atenção Psicossocial em Álcool e Drogas (CAPSad), passaram a ser considerados a principal estratégia de tratamento, assim como a estratégia de redução de danos; ambos tidos como ferramentas também nas ações de prevenção e promoção da saúde (BRASIL, 2004).

São diretrizes dessa política: a alocação do uso de álcool e outras drogas entre os problemas de saúde pública; a indicação do paradigma da redução de danos nas ações de prevenção e de tratamento; a desconstrução da concepção do senso comum de que todo usuário de drogas é doente e requer internação ou prisão; e a mobilização da sociedade civil para práticas preventivas, terapêuticas e reabilitadoras. É importante ressaltar que as políticas e as práticas direcionadas para pessoas que apresentam problemas decorrentes do uso de álcool e outras drogas, na esfera de atuação do Ministério da Saúde, necessariamente, precisam estar associadas às propostas elaboradas pela Área Técnica de Saúde Mental/Álcool e Droga do Ministério da Saúde. 
São implantadas, assim, várias experiências no trato dos problemas de álcool e outras drogas na atenção básica. Sendo instigada também a articulação com as redes de suporte social (tais como grupos de ajuda mútua e entidades filantrópicas); do mesmo modo, que é fomentada a implementação nos Hospitais Gerais de uma estrutura de atendimento aos usuários de álcool e outras drogas, privilegiando os cuidados em dispositivos extrahospitalares e a organização de ações menos centradas no controle e na repressão, buscando promover melhores condições sanitárias aos usuários, aos dependentes e à população em geral (BRASIL, 2007).

A Política Nacional sobre Drogas, atualizada e aprovada por resolução em 27 de outubro de 2005 pelo Conselho Nacional Antidrogas, está fundamentada no princípio da participação dos mais diversos segmentos sociais e governamentais na efetivação das ações que possa reduzir a oferta e o consumo de drogas (BRASIL, 2005).

Recentemente entrou em vigor a nova Lei de drogas nº 11.343 de 2006, sancionada pelo Presidente Luiz Inácio Lula da Silva, que instituiu o Sisnad para coordenar as atividades de prevenção, tratamento e reinserção social de usuários e dependentes de drogas e criou as condições institucionais para uma atuação mais articulada do Poder Executivo com o Ministério Público e o Judiciário, em matéria de combate ao narcotráfico. (BRASIL 2006)

Essa lei, por um lado, acenou com a prevenção do uso de drogas e reinserção social de usuários e dependentes; por outro lado, exigiu a repressão à produção e ao tráfico de drogas. Estabeleceu um tratamento de reinserção social, associado à família, enquadrado em um planejamento terapêutico individualizado, multidisciplinar, para interagir com os serviços de saúde e pôs fim ao tratamento obrigatório para dependentes de drogas. (OLINGER, s/d).

Apesar de não abranger toda a complexidade do tema, essa lei significou um progresso na legislação brasileira. Entre os avanços, está a eliminação da pena de prisão para os usuários de drogas, garantindo os direitos dessas pessoas, dando condição para o desenvolvimento de ações de prevenção e tratamento na saúde pública. Ou seja, o usuário de drogas ilícitas não mais é preso, e sim, submetido a ações preventivas de caráter sócioeducativo. O porte de droga para consumo pessoal continua configurando como delito. No entanto, os consumidores não ficam mais sujeitos a penas restritivas de liberdade, serão, agora, submetidos a prestarem serviços comunitários e medidas socioeducativas, aplicadas pelos juizados especiais criminais (OLINGER, s/d). 
Essa legislação revogou a Lei $\mathrm{n}^{0} .6 .368$ de 76, que dispunha sobre medidas de prevenção e repressão ao tráfico ilícito e uso indevido de substâncias entorpecentes, e a Lei $\mathrm{n}^{\mathrm{o}} .10 .409$ de 02 , que dispunha sobre a prevenção, o tratamento, o controle e a repressão à produção, uso e ao tráfico ilícito de produtos, substâncias ou drogas ilícitas que causem dependência física ou psíquica, elencados pelo Ministério da Saúde (BRASIL, 2007).

Alguns avanços na política de drogas podem ser observados em 2007. Nesse ano foi instituído o Decreto $\mathrm{n}^{\mathrm{o}}$. 6.117, que aprova a Política Nacional Sobre o Álcool, dispõe sobre as medidas para redução do uso indevido de álcool e sua associação com a violência e criminalidade e dá outras providências. Entre as diretrizes estabelecidas por essa política, encontra-se o estímulo a medidas que restrinjam, espacial e temporariamente, os pontos de venda e consumo de bebidas alcoólicas, observando os contextos de maior vulnerabilidade às situações de violência e danos sociais (BRASIL, 2007a).

A aprovação do projeto de Lei $n^{0} .2 .733$ adequaria à legislação em vigor ao item III, do Anexo I, do já referido Decreto nº 6.117 de 2007. A nova disposição considera bebida alcoólica toda a que tiver em sua composição meio $(0,5)$ grau Gay-Lussac de álcool, restando, assim, incluídas no conceito as cervejas, vinhos, coolers e outras bebidas do gênero como as “ice”, que contêm em média teor alcoólico de 4 graus. Na prática, a ampliação do conceito terá como efeito imediato a restrição de eventos publicitários desses produtos no período das 6 horas às 21 horas, nos meios de comunicação, como rádio e televisão, conforme já previsto no Artigo $4^{\circ}$, da mesma lei (BRASIL, 2007a).

Outra ação formulada, a partir das diretrizes da Política Nacional sobre Álcool, foi a Medida Provisória ${ }^{\circ} .415$ de 2008 que proíbe a venda de bebidas alcoólicas nas rodovias federais. Desde que entrou em vigor, a medida provisória já foi contestada pela Procuradoria Geral da União. O Supremo Tribunal Federal recebeu no dia 8 de fevereiro de 2008 a Ação Direta de Inconstitucionalidade (ADIN) que questiona a constitucionalidade da medida provisória. Nessa ADIN a Confederação Nacional do Comércio (CNC) alega que a venda de bebida alcoólica é uma atividade lícita, que a medida provisória viola o princípio da livre iniciativa e da livre concorrência e que os direitos individuais estariam sendo desrespeitados (BRASIL, 2008b).Essa medida provisória foi convertida na Lei $\mathrm{n}^{\circ} .11 .705$ de 2008, alterando a Lei $n^{\circ} .9 .503$, de 1997 e a Lei $n^{\circ}$. 9.294, de 1996, para inibir o consumo de bebida alcoólica por condutor de veículo automotor e dá outras providências (BRASIL 2008c). 
Com a publicação da Lei $n^{\circ}$. 11.754, que "acresce, altera e revoga dispositivos da Lei $n^{\circ} .10 .683$ de 2003 cria a Secretaria de Assuntos Estratégicos da Presidência da República, cria cargos em comissão; revoga dispositivos das Leis $\mathrm{n}^{\text {os }} 10.869$ de 2004, e 11.204, de 2005; e dá outras providências", a Secretaria Nacional Antidrogas, que é vinculada ao Gabinete de Segurança Institucional (GSI) da Presidência da República, responsável por coordenar a PNAD, por meio da articulação e integração entre Governo e sociedade, passou a se chamar Secretaria Nacional de Políticas sobre Drogas (Senad). A Lei também alterou o nome do Conselho Nacional Antidrogas para Conselho Nacional de Políticas sobre Drogas (CONAD) e o nome do UNODC no Brasil para Escritório das Nações Unidas sobre Drogas e Crime. Salientando que as siglas das instituições permanecem as mesmas (BRASIL, 2008).

\begin{abstract}
A idéia para essa mudança surgiu após o processo de realinhamento da Política Nacional sobre Drogas, em 2004. Na ocasião, entendeu-se que o termo 'Antidrogas' não era adequado para abranger as drogas lícitas como tabaco, álcool e medicamentos, as quais estão incluídas no universo de competência da Senad. (Senad, 2008)
\end{abstract}

Ao longo da história, destaca-se que os sucessivos governos brasileiros têm cedido ao $l o b b y^{2}$ dos produtores. Percebe-se que existem vários jogos de interesses na arena política em torno da discussão das drogas, influenciando diretamente nas políticas públicas que reproduzem interesses competitivos, valores e ideologias. Por outro lado, o aumento crescente do uso de sustâncias psicoativas e os elevados custos sociais provocado pelo consumo vêm exigindo políticas públicas, tanto direcionadas à redução da demanda, quanto na adoção de medidas mais eficazes sob o ponto de vista da saúde pública (LARANJEIRA; ROMANO, 2003). Esse cenário tem contribuído para o surgimento de alguns movimentos da sociedade que vêm pressionando a Câmara Federal, por intermédio de abaixo-assinados e protestos para aprovação de medidas relacionadas às drogas, qual ocorre para a aprovação, em regime de urgência, do Plano de Lei $\mathrm{n}^{\circ} .2 .733$ de 2008, com limitações a propagandas de bebidas com teor alcoólico superior a meio grau Gay-Lussac de 21 horas às 6 horas da manhã (BRASIL, 2007a).

Analisando o processo histórico de criação das políticas sobre o álcool e outras drogas e a discussão recente sobre a regulamentação das propagandas de bebidas alcoólicas

\footnotetext{
${ }^{2}$ De acordo com o dicionário Houaiss, lobby pressupõe atividade de pressão de um grupo organizado sobre políticos e poderes públicos, que visa exercer sobre estes qualquer influência ao seu alcance, mas sem buscar o controle formal do governo.
} 
entre outras, como afirma Oliveira (2004), o Brasil vem avançando na discussão sobre a temática droga, embora não o suficiente, dado que as bases teóricas da PNAD chocavam-se com as bases conceituais da PAIUAD, demonstrando a dificuldade do Estado brasileiro em adotar uma proposta de política pública menos conservadora e desvinculada dos interesses internacionais.

Face ao exposto, com o intuito de retratar a realidade das instituições de tratamento existentes na Região Centro-Oeste no Brasil, serão apresentadas, no próximo capítulo, as informações referentes ao tratamento, recuperação e reinserção social de usuários/ dependentes de álcool e outras drogas. 


\section{CAPITULO II}

\section{Tratamento, Recuperação e Reinserção social de usuários/Dependentes de Álcool e outras Drogas na Região Centro-Oeste do Brasil.}

De acordo com Ribeiro (2004), a discussão sobre tratamento da dependência química é recente. Antigamente, o termo dependência apenas enfatizava as complicações clínicas do consumo, ou seja, não levava em consideração o comportamento em si. A dependência, também chamada de toxicomania ou de drogadição, era considerada um desvio de caráter ou um conjunto de sinais e sintomas físicos. Somente a partir da segunda metade do século XX é que a dependência começa a ganhar características de transtorno mental. Atualmente, dependência química é conceituada como uma doença que possui uma causa ligada a alterações do funcionamento cerebral, manifestadas por meio de sinais e sintomas específicos, (SILVA; LARANJEIRA, 2004), tais como, consumo freqüente, compulsivo e descontrolado, com intuito de aliviar sintomas de mal estar, desconforto físico e mental, reconhecidamente acompanhados por síndrome de abstinência, problemas psicológicos e sociais.

Por muito tempo o tratamento para dependentes de álcool e outras drogas era, predominantemente, em regime hospitalar. Recentemente, segundo a Secretaria Nacional Antidrogas (Senad, 2002), há uma tendência de "desospitalização" dos tratamentos de dependentes de álcool e outras drogas, voltando-se para um regime ambulatorial e de abordagens comunitárias (SUDBRACK, 2002).

Existem situações em que o tratamento em regime de internação é obrigatório, porém ela será indicada somente em casos graves, em que os pacientes não se sentem capazes de resistir por conta própria às brechas para o consumo de drogas. Logo, a internação deve estar, necessariamente, vinculada a seguimento ambulatorial e aos grupos de auto-ajuda, em um processo de atuação em rede de forma integrada para a obtenção de bons resultados (Brasil, 2000; SUDBRACK, 2002).

Independentemente das estratégias de enfrentamento disponíveis e da abordagem teórica utilizada é preciso considerar que cada usuário de droga é singular, necessitando de intervenção específica em acordo com suas necessidades e motivações. A indicação mais 
adequada a cada paciente dependerá do grau de dependência desenvolvido e da especificidade dos danos relacionados à utilização da substância. Assim sendo, surgiu a necessidade de organizar serviços que acolhessem aos usuários em seus diferentes estágios, considerando também sua reabilitação psicossocial e qualidade de vida. Desse modo, foram sendo criados ou adaptados serviços de atendimento para o tratamento dos diversos estágios da dependência químicas tais como: ambulatórios, centros de convivência, internações breves e longas, hospitais-dia, moradias assistidas, acompanhamento terapêutico, agentes multiplicadores, entre outros. Para ampliar o atendimento a esses usuários/dependentes, houve a necessidade de sensibilizar a rede primária de atendimento para o diagnóstico precoce e à motivação dos usuários/dependentes para o tratamento (RIBEIRO, 2004).

\footnotetext{
O regime de tratamento varia em função da disponibilidade de modalidades específicas de tratamento, do grau de restrição ao acesso às substancias que são provavelmente abusadas, da disponibilidade de cuidados médicos gerais e psiquiátricos e do meio geral e filosófico de tratamento indicado (ANDRADE; DUARTE; CUNHA, 2000, p.177).
}

Ribeiro (2004) afirma que no Brasil, apesar de existir serviços de atendimento para o tratamento dos diversos estágios da dependência química, ainda não há uma legislação normatizadora dos níveis de atendimento, muito menos do papel de cada profissional da saúde no tratamento das dependências químicas, apesar de problemas acerca do tema já terem sido identificados por diversos estudos nacionais. Para nortear a assistência àqueles que sofrem com o problema de dependência de álcool e outras drogas, tem-se como referencia os princípios gerais de tratamento baseados em evidencias científicas, desenvolvidas pelas duas importantes e conhecidas instituições normatizadora do assunto: o Instituto Nacional de Abuso de Droga (NIDA) e Associação Psiquiátrica Americana (APA). Essas normas se encontram estabelecida na área da dependência química com o objetivo de proporcionar eficácia e avanço no tratamento da dependência de álcool e outras drogas. (ANDRADE; DUARTE; CUNHA, 2002).

Para a análise dos dados, ao todo foram mapeadas e cadastradas na região CentroOeste, 129 instituições de Tratamento, Recuperação e Reinserção Social, destas, 43 instituições são governamentais, 85 não-governamentais, e uma sem resposta. Os questionários possuem questões abertas e fechadas que admite mais de uma resposta na computação dos dados nas tabelas. Com relação às entrevistas, foram analisadas oito no total de 32 aplicadas aos dirigentes das instituições. 


\subsection{Instituições que Realizam Tratamento de Acordo com a Natureza da Instituição.}

Analisando os tipos de instituições de tratamento presentes na Região CentroOeste, fazendo o cruzamento da classificação da instituição com a sua natureza governamental e não-governamental, conforme apresentado na Tabela 1, pode-se inferir que: das 39 instituições de tratamento que se classificam como comunidade terapêutica, $2(5,1 \%)$ são governamentais e 37 (94,9\%) não-governamentais. Cabe ainda ressaltar que 90,9\% dos CAPSad, são governamentais, já entre as instituições que se denominam hospitais psiquiátricos, 100\% são não-governamentais.

Com relação os dados analisados, entre as instituições governamentais, há uma maior proporção de CAPSad. Esses dados estão em conformidade com a Política do Ministério da Saúde que definiu por meio da Portaria/GM n. o 336, de 19 de fevereiro de 2002, as normas e diretrizes para a organização de serviços que prestam assistência em saúde mental, os CAPS, incluindo aqui os CAPS voltados para o atendimento aos usuários/dependentes de álcool e outras drogas, os CAPSad. Nas instituições nãogovernamentais prevalecem as comunidades terapêuticas.

Tabela 1: Classificação das instituições que realizam tratamento quanto à natureza da instituição.

\begin{tabular}{|c|c|c|c|c|c|c|c|c|}
\hline \multicolumn{9}{|c|}{ Natureza da organização X Classificação da instituição } \\
\hline & \multicolumn{2}{|c|}{ Não resposta } & \multicolumn{2}{|c|}{ Governamental } & \multicolumn{2}{|c|}{ Não-governamental } & \multicolumn{2}{|c|}{ Total } \\
\hline & $\mathbf{N}$ & $\%$ cit. & $\mathbf{N}$ & $\%$ cit. & $\mathbf{N}$ & $\%$ cit. & $\mathbf{N}$ & $\%$ cit. \\
\hline Não resposta & 1 & \begin{tabular}{|l|l}
4,8 \\
\end{tabular} & 13 & 61,9 & 7 & $\mathbf{3 3 , 3}$ & 21 & 100,0 \\
\hline Clínica particular & $\mathbf{0}$ & $\mathbf{0 , 0}$ & $\mathbf{0}$ & $\mathbf{0 , 0}$ & 5 & $\mathbf{1 0 0 , 0}$ & 5 & $\mathbf{1 0 0 , 0}$ \\
\hline Hospital psiquiátrico & $\mathbf{0}$ & $\mathbf{0 , 0}$ & $\mathbf{0}$ & $\mathbf{0 , 0}$ & 8 & 100,0 & 8 & $\mathbf{1 0 0 , 0}$ \\
\hline Hospital geral & $\mathbf{0}$ & $\mathbf{0 , 0}$ & 1 & 100,0 & $\mathbf{0}$ & $\mathbf{0 , 0}$ & 1 & 100,0 \\
\hline Hospital-dia & $\mathbf{0}$ & $\mathbf{0 , 0}$ & 1 & $\mathbf{1 0 0 , 0}$ & $\mathbf{0}$ & $\mathbf{0 , 0}$ & 1 & $\mathbf{1 0 0 , 0}$ \\
\hline Comunidade terapêutica & $\mathbf{0}$ & $\mathbf{0 , 0}$ & 2 & 5,1 & 37 & 94,9 & 39 & $\mathbf{1 0 0 , 0}$ \\
\hline Centro de Atenção Psicossocial Álcool e Drogas-CAPSad & $\mathbf{0}$ & $\mathbf{0 , 0}$ & 10 & 90,9 & 1 & 9,1 & 11 & $\mathbf{1 0 0 , 0}$ \\
\hline $\begin{array}{l}\text { Centro de Atenção Psicossocial-CAPS / Núcleo de Atenção } \\
\text { Psicossocial-NAPS }\end{array}$ & $\mathbf{0}$ & $\mathbf{0 , 0}$ & 8 & 100,0 & $\mathbf{0}$ & $\mathbf{0 , 0}$ & 8 & 100,0 \\
\hline Residência terapêutica & $\mathbf{0}$ & $\mathbf{0 , 0}$ & $\mathbf{0}$ & $\mathbf{0 , 0}$ & 4 & 100,0 & 4 & $\mathbf{1 0 0 , 0}$ \\
\hline Grupo de auto-ajuda & $\mathbf{0}$ & $\mathbf{0 , 0}$ & 2 & 14,3 & 12 & $\mathbf{8 5 , 7}$ & 14 & 100,0 \\
\hline Instituição de redução de danos & $\mathbf{0}$ & $\mathbf{0 , 0}$ & 3 & $\mathbf{5 0 , 0}$ & 3 & $\mathbf{5 0 , 0}$ & 6 & 100,0 \\
\hline Outra & $\mathbf{0}$ & $\mathbf{0 , 0}$ & 8 & 33,3 & 16 & 66,7 & 24 & 100,0 \\
\hline
\end{tabular}

\subsection{Tipos de Tratamentos de Acordo com a Natureza da Instituição}

O desenvolvimento de sistemas adequados de prevenção e tratamento ainda tem se mostrado muito aquém do crescimento da referida problemática. Pode-se observar que existem incontáveis tipos de ambientes de tratamento, cada um possui vantagens e desvantagens na prestação de auxílio ao dependente químico. Cada qual com diferentes 
abordagens de tratamento, fazendo com que se busquem pacientes mais indicados para cada serviço. A compreensão e o entendimento das possibilidades e limitações de cada ambiente de tratamento auxiliam o processo de adequação de um serviço às necessidades da comunidade a qual presta assistência. "Não há serviço melhor que o outro, mas sim pacientes mais indicados para cada serviço" (RIBEIRO, 2007, p.7)

O momento do tratamento influência a escolha do serviço, como bem exemplifica Ribeiro (2007, p.7).

\begin{abstract}
Usuários de álcool com sintomas agudos de abstinência podem requerer um ambiente ambulatorial não-intensivo, intensivo, hospital-dia ou até uma internação para desintoxicação. Três semanas depois, porém, os sintomas de abstinência já não são mais o problema preponderante e abordagens menos intensivas e comunitárias poderão ser instituídas. Dessa maneira, é preciso reconhecer o serviço mais indicado para aquele momento e saber combiná-lo a outros ambientes onde a seqüência do tratamento se dará.
\end{abstract}

A carência de uma legislação normatizadora dos níveis de atendimento, e também do papel de cada profissional da saúde no tratamento das dependências químicas, dificulta o encaminhamento racional daqueles que procuram auxílio especializado, sobrecarregando setores que deveriam se responsabilizar por apenas uma parte do tratamento (RIBEIRO, 2004).

Cabe então a instituição de atendimento da dependência química determinar, mesmo que superficialmente, qual o seu ponto de inserção dentro da rede de tratamento disponível em uma determinada região. Com isso, as instituições, utilizam-se da estratégia de serviços de apoio com os demais serviços de tratamento disponíveis, numa espécie de formação de redes de apoio mútuo. Isso reforça e amplia a eficácia do tratamento e dos serviços, possibilitando o encaminhamento daqueles que já concluíram o tratamento proposto, mas ainda necessitam de outras abordagens oferecidas por outras instituições (Ribeiro, 2004).

Estão listados na Tabela 2 alguns dos tipos de tratamentos oferecidos nas instituições de tratamento, recuperação e reinserção social de atenção aos usuários/dependentes de álcool e outras drogas. Os dados revelam o ponto de inserção de cada instituição dentro da rede de serviços mostrando a necessidade de articulação com as demais instituições para complementar o tratamento, reforçando a afirmação do autor Ribeiro (2004).

Ao analisar o cruzamento do tipo de tratamento oferecido com a natureza da instituição de tratamento, destaca-se entre as instituições governamentais a internação em 
Hospital Geral, pois das quatro instituições que realizam esse tipo de tratamento, três $(75 \%)$ são governamentais e apenas uma (25\%) não-governamentais. Entre as alternativas de tratamento a Psicoterapia de grupo é a mais utilizada. Das 61 instituições, 24 (39,3\%) são instituições governamentais e 37 (60,7\%) instituições não-governamentais. Em segundo lugar está a modalidade, Psicoterapia individual. Das 59 instituições que oferecem essa modalidade de tratamento, 24 (40,7\%) são instituições governamentais e 35 (59,3 \%) não-governamentais. Entre as instituições que oferecem tratamentos de internação em comunidade terapêutica, 38 $(92,7)$ são instituições não governamentais, ficando as instituições governamentais responsáveis por apenas três $(7,3 \%)$ dos tratamentos.

Os tipos de tratamento citados pelas instituições governamentais seguem a lógica do tratamento oferecido pelos CAPSad, que é oferecer atendimento diário à população que apresenta graves transtornos decorrentes do uso e dependência de substâncias psicoativas, evitando internações. Nas instituições não-governamentais, o foco é a internação em comunidades terapêuticas, seguida da psicoterapia de grupo.

Tabela 2: Tipos de tratamentos oferecidos de acordo com a natureza da instituição

\begin{tabular}{l|c|c|c|c|c|c|c|c}
\hline \multicolumn{7}{c}{ Natureza da organização X Tipo de tratamento } \\
\hline & Não resposta & Governamental & \multicolumn{2}{c|}{$\begin{array}{c}\text { Não- } \\
\text { governamental }\end{array}$} & \multicolumn{2}{c}{ Total } \\
\hline & $\mathbf{N}$ & $\mathbf{\%}$ cit. & $\mathbf{N}$ & $\mathbf{\%}$ cit. & $\mathbf{N}$ & $\mathbf{\%}$ cit. & N & \% cit. \\
\hline Não resposta & $\mathbf{1}$ & $\mathbf{5 , 0}$ & $\mathbf{1 2}$ & $\mathbf{6 0 , 0}$ & $\mathbf{7}$ & $\mathbf{3 5 , 0}$ & $\mathbf{2 0}$ & $\mathbf{1 0 0 , 0}$ \\
\hline Tratamento ambulatorial & $\mathbf{0}$ & $\mathbf{0 , 0}$ & $\mathbf{2 0}$ & $\mathbf{5 1 , 3}$ & $\mathbf{1 9}$ & $\mathbf{4 8 , 7}$ & $\mathbf{3 9}$ & $\mathbf{1 0 0 , 0}$ \\
\hline Internação em pronto-socorro & $\mathbf{0}$ & $\mathbf{0 , 0}$ & $\mathbf{2}$ & $\mathbf{3 3 , 3}$ & $\mathbf{4}$ & $\mathbf{6 6 , 7}$ & $\mathbf{6}$ & $\mathbf{1 0 0 , 0}$ \\
\hline Internação em hospital geral & $\mathbf{0}$ & $\mathbf{0 , 0}$ & $\mathbf{3}$ & $\mathbf{7 5 , 0}$ & $\mathbf{1}$ & $\mathbf{2 5 , 0}$ & $\mathbf{4}$ & $\mathbf{1 0 0 , 0}$ \\
\hline Internação em hospital psiquiátrico & $\mathbf{0}$ & $\mathbf{0 , 0}$ & $\mathbf{9}$ & $\mathbf{4 5 , 0}$ & $\mathbf{1 1}$ & $\mathbf{5 5 , 0}$ & $\mathbf{2 0}$ & $\mathbf{1 0 0 , 0}$ \\
\hline Internação em hospital-dia & $\mathbf{0}$ & $\mathbf{0 , 0}$ & $\mathbf{3}$ & $\mathbf{5 0 , 0}$ & $\mathbf{3}$ & $\mathbf{5 0 , 0}$ & $\mathbf{6}$ & $\mathbf{1 0 0 , 0}$ \\
\hline Internação em comunidade terapêutica & $\mathbf{0}$ & $\mathbf{0 , 0}$ & $\mathbf{3}$ & $\mathbf{7 , 3}$ & $\mathbf{3 8}$ & $\mathbf{9 2 , 7}$ & $\mathbf{4 1}$ & $\mathbf{1 0 0 , 0}$ \\
\hline Internação domiciliar & $\mathbf{0}$ & $\mathbf{0 , 0}$ & $\mathbf{1}$ & $\mathbf{1 4 , 3}$ & $\mathbf{6}$ & $\mathbf{8 5 , 7}$ & $\mathbf{7}$ & $\mathbf{1 0 0 , 0}$ \\
\hline Grupos de auto-ajuda & $\mathbf{0}$ & $\mathbf{0 , 0}$ & $\mathbf{1 1}$ & $\mathbf{2 5 , 6}$ & $\mathbf{3 2}$ & $\mathbf{7 4 , 4}$ & $\mathbf{4 3}$ & $\mathbf{1 0 0 , 0}$ \\
\hline Psicoterapia individual & $\mathbf{0}$ & $\mathbf{0 , 0}$ & $\mathbf{2 4}$ & $\mathbf{4 0 , 7}$ & $\mathbf{3 5}$ & $\mathbf{5 9 , 3}$ & $\mathbf{5 9}$ & $\mathbf{1 0 0 , 0}$ \\
\hline Psicoterapia familiar & $\mathbf{0}$ & $\mathbf{0 , 0}$ & $\mathbf{1 7}$ & $\mathbf{3 7 , 8}$ & $\mathbf{2 8}$ & $\mathbf{6 2 , 2}$ & $\mathbf{4 5}$ & $\mathbf{1 0 0 , 0}$ \\
\hline Psicoterapia de grupo & $\mathbf{0}$ & $\mathbf{0 , 0}$ & $\mathbf{2 4}$ & $\mathbf{3 9 , 3}$ & $\mathbf{3 7}$ & $\mathbf{6 0 , 7}$ & $\mathbf{6 1}$ & $\mathbf{1 0 0 , 0}$ \\
\hline Terapia comunitária & $\mathbf{0}$ & $\mathbf{0 , 0}$ & $\mathbf{5}$ & $\mathbf{2 1 , 7}$ & $\mathbf{1 8}$ & $\mathbf{7 8 , 3}$ & $\mathbf{2 3}$ & $\mathbf{1 0 0 , 0}$ \\
\hline Outro & $\mathbf{0}$ & $\mathbf{0 , 0}$ & $\mathbf{1 4}$ & $\mathbf{4 8 , 3}$ & $\mathbf{1 5}$ & $\mathbf{5 1 , 7}$ & $\mathbf{2 9}$ & $\mathbf{1 0 0 , 0}$ \\
\hline Total & $\mathbf{1}$ & $\mathbf{0 , 2}$ & $\mathbf{1 4 8}$ & $\mathbf{3 6 , 7}$ & $\mathbf{2 5 4}$ & $\mathbf{6 3 , 0}$ & $\mathbf{4 0 3}$ & $\mathbf{1 0 0 , 0}$ \\
\hline
\end{tabular}

\subsection{Participação da Família no Tratamento de Acordo com a Natureza da Instituição.}

O documento do Ministério da Saúde (2003) sugere que o envolvimento da família, da comunidade e dos usuários/dependentes de drogas deve ser incluído entre as ações básicas na área da saúde mental, especificamente no campo do uso de álcool e outras drogas. A abordagem da família é importante, pois, seja ela qual for, nas suas mais distintas 
configurações, ainda é o meio relacional básico para as interações com o mundo, da norma à transgressão, da saúde à patologia.

Segundo MINAYO e SCHENKER (2004), entre tantos fatores que podem influenciar de maneira positiva na reabilitação e ressocialização do usuário de drogas, a família é um dos mais importantes. A família é um fator fundamental tanto na dependência como em seu tratamento. A participação desta na reabilitação e ressocialização, aumenta a chance de o dependente obter o sucesso esperado. Ressaltando que só o apoio da família não garante ao indivíduo a recuperação, a vontade de fazer o tratamento tem que partir dele.

Como afirma Groisman; Lobo e Cavour, (1996) apud Seadi (2007, p. 22), "na terapia familiar, o foco da atenção terapêutica deixa de incidir unicamente no indivíduo e passa a iluminar o interior de um sistema de forças, a família (...)”. O processo terapêutico deve envolver a conscientização da participação familiar no processo de reabilitação do dependente no qual beneficia o membro problemático, assim como toda a família.

Nas entrevistas feitas aos dirigentes da instituição, foram ressaltadas que "a família é a chave principal para o tratamento de alcoolismo e outras drogas". Em uma instituição que trata o alcoolismo, o dirigente salienta que "o prontuário do paciente é feito com as narrativas da família, e não do paciente, porque se você for ouvir o paciente ele minimiza, você nunca vai classificar o alcoolismo dele com a narrativa real". Diz ainda que a orientação à família sobre a dependência é importante, pois, "a família tem muita expectativa. Quando eles procuram ajuda, eles acham que uma vez o paciente está desintoxicado, resolveu o problema do alcoolismo. Eles não sabem o que é a doença, quais as conseqüências que o alcoolismo" (entrevista no. 08. Inst. Não-Governamental). Com isso "a família precisa de um trabalho bem maior do que muitas vezes é oferecido, porque gera uma expectativa muito grande no dependente". Esse trabalho, além de oferecer conhecimento às famílias é importante no sentido de oferecer suporte de apoio ao dependente evitando as recaídas (entrevistado $\mathrm{n}^{\mathrm{o}} .06$ Inst. Governamental).

Analisando a Participação da família no tratamento de acordo com a natureza da instituição na região Centro-Oeste apresentada na Tabela 3, pode se observar que das 98 instituições que prevêem a participação da família no tratamento, $27(27,6 \%)$ são governamentais, e 71(72,4\%) não-governamentais. Percebe-se que apesar da importância dada à participação da família no tratamento, ainda existem instituições, tanto governamentais quanto não-governamentais que não prevêem essa participação. 
Tabela 3: Participação da família no tratamento de acordo com a natureza da instituição

\begin{tabular}{|c|c|c|c|c|c|c|c|c|}
\hline \multicolumn{9}{|c|}{ Família participa do tratamento $X$ Natureza da organização } \\
\hline & \multicolumn{2}{|c|}{ Não resposta } & \multicolumn{2}{|c|}{ Governamental } & \multicolumn{2}{|c|}{$\begin{array}{c}\text { Não- } \\
\text { governamental }\end{array}$} & \multicolumn{2}{|c|}{ Total } \\
\hline & $\mathbf{N}$ & $\%$ cit. & $\mathbf{N}$ & $\%$ cit. & $\mathbf{N}$ & $\%$ cit. & $\mathbf{N}$ & $\%$ cit. \\
\hline Não resposta & 1 & 4,5 & 14 & 63,6 & 7 & 31,8 & 22 & 100,0 \\
\hline Sim & $\mathbf{0}$ & 0,0 & 27 & 27,6 & 71 & 72,4 & 98 & 100,0 \\
\hline $\begin{array}{l}\text { Não } \\
\end{array}$ & $\mathbf{0}$ & 0,0 & 2 & 22,2 & 7 & 77,8 & 9 & 100,0 \\
\hline Total & 1 & 0,8 & 43 & 33,3 & 85 & 65,9 & 129 & 100,0 \\
\hline
\end{tabular}

A Tabela 4 refere-se à distribuição da freqüência permitida de visitas de familiares de acordo com a natureza da instituição. Percebe-se a maiorias das visitas ocorrem mensalmente, 27, sendo que, desse total, 25 (92,6\%) são em instituições não-governamentais e dois $(7,4 \%)$ em instituições governamentais. Em segundo lugar, destaca-se a permissão de visitas semanal, em que, das 23 respostas obtidas, seis $(26,1 \%)$ referem-se a instituições governamentais e $17(73,9 \%)$ a não-governamentais.

Tabela 4: Freqüência de visitas da família de acordo com a natureza da instituição

\begin{tabular}{|c|c|c|c|c|c|c|c|c|}
\hline \multicolumn{9}{|c|}{ Natureza da organização X Permissão de visita da família } \\
\hline & \multicolumn{2}{|c|}{ Não resposta } & \multicolumn{2}{|c|}{ Governamental } & \multicolumn{2}{|c|}{$\begin{array}{c}\text { Não- } \\
\text { governamental }\end{array}$} & \multicolumn{2}{|c|}{ Total } \\
\hline & $\mathbf{N}$ & $\%$ cit. & $\mathbf{N}$ & $\%$ cit. & $\mathbf{N}$ & $\%$ cit. & $\mathbf{N}$ & $\%$ cit. \\
\hline Não resposta & 1 & 2,3 & 22 & 51,2 & 20 & 46,5 & 43 & 100,0 \\
\hline Diariamente & $\mathbf{0}$ & $\mathbf{0 , 0}$ & 9 & 42,9 & 12 & 57,1 & 21 & 100,0 \\
\hline Semanalmente & $\mathbf{0}$ & $\mathbf{0 , 0}$ & 6 & 26,1 & 17 & 73,9 & 23 & 100,0 \\
\hline Quinzenalmente & $\mathbf{0}$ & $\mathbf{0 , 0}$ & 1 & 11,1 & 8 & 88,9 & 9 & 100,0 \\
\hline Mensalmente & $\mathbf{0}$ & $\mathbf{0 , 0}$ & 2 & 7,4 & 25 & 92,6 & 27 & 100,0 \\
\hline Eventualmente & $\mathbf{0}$ & $\mathbf{0 , 0}$ & 2 & 28,6 & 5 & 71,4 & 7 & 100,0 \\
\hline Outros & $\mathbf{0}$ & $\mathbf{0 , 0}$ & 1 & 50,0 & 1 & $\mathbf{5 0 , 0}$ & 2 & 100,0 \\
\hline Não são permitidas visitas & $\mathbf{0}$ & & $\mathbf{0}$ & & $\mathbf{0}$ & & $\mathbf{0}$ & 100,0 \\
\hline Total & 1 & $\mathbf{0 , 8}$ & 43 & 32,6 & 88 & 66,7 & 132 & 100,0 \\
\hline
\end{tabular}

Fazendo o cruzamento das respostas referentes à etapa do tratamento a partir da qual é permitida a visita aos pacientes de acordo com a natureza da instituição apresentada na Tabela 5, pode se observar que das 129 instituições pesquisada, em 31, a permissão de visitas acontece a partir do $30^{\circ}$ dia de internação sendo que $30(96,8 \%)$, são instituições nãogovernamentais. 
Tabela 5: Permissão para início das visitas nas instituições de tratamento de acordo com a natureza da instituição

\begin{tabular}{|c|c|c|c|c|c|c|c|c|}
\hline \multicolumn{9}{|c|}{ Natureza da organização X Etapa do tratamento permitida visita da família } \\
\hline & \multicolumn{2}{|c|}{ Não resposta } & \multicolumn{2}{|c|}{ Governamental } & \multicolumn{2}{|c|}{$\begin{array}{c}\text { Não- } \\
\text { governamental }\end{array}$} & \multicolumn{2}{|c|}{ Total } \\
\hline & $\mathbf{N}$ & $\%$ cit. & $\mathbf{N}$ & $\%$ cit. & $\mathbf{N}$ & $\%$ cit. & $\mathbf{N}$ & $\%$ cit. \\
\hline Não resposta & 1 & 2,2 & 23 & 51,1 & 21 & 46,7 & 45 & 100,0 \\
\hline Desde o início da internação & $\mathbf{0}$ & $\mathbf{0 , 0}$ & 4 & 28,6 & 10 & 71,4 & 14 & 100,0 \\
\hline A partir do $7^{\circ}$ dia da internação & $\mathbf{0}$ & $\mathbf{0 , 0}$ & 1 & 25,0 & 3 & 75,0 & 4 & 100,0 \\
\hline A partir do $15^{\circ}$ dia da internação & $\mathbf{0}$ & $\mathbf{0 , 0}$ & $\mathbf{0}$ & $\mathbf{0 , 0}$ & 9 & 100,0 & 9 & 100,0 \\
\hline A partir do $30^{\circ}$ dia da internação & $\mathbf{0}$ & $\mathbf{0 , 0}$ & 1 & 3,2 & 30 & 96,8 & 31 & 100,0 \\
\hline A partir do $60^{\circ}$ dia da internação & $\mathbf{0}$ & $\mathbf{0 , 0}$ & $\mathbf{0}$ & $\mathbf{0 , 0}$ & 2 & $\mathbf{1 0 0 , 0}$ & 2 & $\mathbf{1 0 0 , 0}$ \\
\hline A partir do $90^{\circ}$ dia da internação em diante & $\mathbf{0}$ & $\mathbf{0 , 0}$ & $\mathbf{0}$ & $\mathbf{0 , 0}$ & 1 & $\mathbf{1 0 0 , 0}$ & 1 & 100,0 \\
\hline Outro & $\mathbf{0}$ & $\mathbf{0 , 0}$ & 14 & 60,9 & 9 & 39,1 & 23 & 100,0 \\
\hline Total & 1 & $\mathbf{0 , 8}$ & 43 & 33,3 & 85 & 65,9 & 129 & 100,0 \\
\hline
\end{tabular}

\subsection{Decorrência do atendimento de Acordo com a Natureza da Instituição.}

$\mathrm{Na}$ distribuição dos problemas do consumo de drogas pelo qual se busca tratamento de acordo com a natureza da organização, Tabela 6, percebe-se que, das 49 instituições que realizam atendimento dos transtornos causados pelo uso/abuso/dependência de tabaco, nove $(18,4 \%)$ são governamentais e $40(81,6,0 \%)$ não-governamentais.

Apesar de o atendimento a pacientes com problemas psiquiátricos associados ao consumo de álcool e outras drogas prevalecer nas instituições governamentais (Tabela 6) e aparecer em penúltimo lugar nas instituições não-governamentais, estas últimas representam um maior número de instituições. Das 47 instituições que realizam atendimento a esse tipo de problema, 20 (42,6 \%) são governamentais e 27 (57,4\%) são não-governamentais.

Percebe-se que os atendimentos mais prestados pelas instituições de tratamento decorrem de transtornos causados pelo uso/abuso/dependência de álcool, pois, dos 376 atendimentos, 90 foram notificados nessa área. Após esses atendimentos, prevalecem nas instituições governamentais, os atendimentos a pacientes com transtornos causados pelo uso/abuso/dependência de outras drogas, e nas instituições não-governamentais, os atendimentos decorrentes de transtornos causados pelo uso/abuso/dependência de álcool. 
Tabela 6: Decorrência do atendimento de acordo com a natureza da instituição

\begin{tabular}{|c|c|c|c|c|c|c|c|c|}
\hline \multicolumn{9}{|c|}{ Natureza da organização X Decorrência do atendimento } \\
\hline & \multicolumn{2}{|c|}{ Não resposta } & \multicolumn{2}{|c|}{ Não resposta } & \multicolumn{2}{|c|}{$\begin{array}{c}\text { Não- } \\
\text { governamental }\end{array}$} & \multicolumn{2}{|c|}{ Total } \\
\hline & $\mathbf{N}$ & \% cit. & $\mathbf{N}$ & \% cit. & $\mathbf{N}$ & $\%$ cit. & $\mathbf{N}$ & $\%$ cit. \\
\hline Não resposta & 1 & 4,3 & 14 & 60,9 & 8 & 34,8 & 23 & 100,0 \\
\hline Transtornos causados pelo uso/abuso/dependência de álcool & $\mathbf{0}$ & $\mathbf{0 , 0}$ & 21 & 23,3 & 69 & 76,7 & 90 & 100,0 \\
\hline Transtornos causados pelo uso/abuso/dependência de tabaco & $\mathbf{0}$ & 0,0 & 9 & 18,4 & 40 & 81,6 & 49 & 100,0 \\
\hline $\begin{array}{l}\text { Transtornos causados pelo uso/abuso/dependência de outras } \\
\text { drogas }\end{array}$ & $\mathbf{0}$ & 0,0 & 22 & 24,7 & 67 & 75,3 & 89 & 100,0 \\
\hline $\begin{array}{l}\text { Intoxicação aguda causada por qualquer substância } \\
\text { psicoativa }\end{array}$ & 0 & $\mathbf{0 , 0}$ & 13 & 39,4 & 20 & 60,6 & 33 & 100,0 \\
\hline $\begin{array}{l}\text { Problemas psiquiátricos associados ao consumo de álcool } \\
\text { e/ou outras drogas }\end{array}$ & 0 & 0,0 & 20 & 42,6 & 27 & 57,4 & 47 & 100,0 \\
\hline $\begin{array}{l}\text { Problemas clínicos associados ao consumo de álcool e/ou } \\
\text { outras drogas }\end{array}$ & 0 & 0,0 & 11 & 34,4 & 21 & 65,6 & 32 & 100,0 \\
\hline Outros & 0 & 0,0 & 4 & 30,8 & 9 & 69,2 & 13 & 100,0 \\
\hline Total & 1 & 0,3 & 114 & $\mathbf{3 0 , 3}$ & 261 & 69,4 & 376 & 100,0 \\
\hline
\end{tabular}

\subsection{Requisitos para admissão do paciente de Acordo com a Natureza da Instituição.}

Dificilmente um indivíduo assume que está usando droga ou álcool excessivamente e procura tratamento. Geralmente essa procura acontece na medida em que aumenta os prejuízos causados pelo consumo. Entre os problemas que contribuem para a busca dos serviços de assistência estão as complicações médicas, a perda de emprego, problemas interpessoais, tais como, separação conjugal, imposição familiar, por sentença judicial, por problemas financeiros ou psiquiátrica decorrentes do consumo entre ouros. (BRASIL, 2000).

Segundo Sudbrack (2002), para atender essa complexidade, o tratamento da dependência de substâncias psicoativas, deve ter uma abordagem multidisciplinar, ou seja, participação de profissionais de diversas áreas do conhecimento ou especialidades (psiquiatra, médico clínico, enfermeiro, psicólogo, assistente social, etc.). Onde o trabalho individual do profissional é ao mesmo tempo autônomo e integrado na estratégia de acolhimento e recuperação do indivíduo.

Com relação aos requisitos para atendimento de acordo com a natureza da instituição apresentada na Tabela 7, observa-se que em relação às 56 instituições que citaram como requisito o encaminhamento formal de profissionais de outras instituições (psicólogos, assistentes sociais, enfermeiros, entre outros), apenas $12(21,4 \%)$ são governamentais e 44 (78,6\%) não-governamentais. É importante ressaltar que o requisito para admissão de paciente mais freqüente é a concordância do paciente em se submeter ao tratamento com 83 admissões 
dos quais $20(2,1 \%)$ são governamentais e 63 (75,9\%) não-governamentais. Em $2^{\circ}$ lugar em requisito para admissão está o Compromisso da família no acompanhamento do tratamento com 67 admissões dos quais $14(20,9 \%)$ são governamentais e 53 (79, 1\%) nãogovernamentais.

Tabela 7: Requisitos para atendimento nas instituições de tratamento de acordo com a natureza da instituição.

\begin{tabular}{|c|c|c|c|c|c|c|c|c|}
\hline \multicolumn{9}{|c|}{ Natureza da organização X Requisitos para admissão do paciente } \\
\hline & \multicolumn{2}{|c|}{ Não resposta } & \multicolumn{2}{|c|}{ Governamental } & \multicolumn{2}{|c|}{$\begin{array}{c}\text { Não- } \\
\text { governamental }\end{array}$} & \multicolumn{2}{|c|}{ Total } \\
\hline & $\mathbf{N}$ & $\%$ cit. & $\mathbf{N}$ & $\%$ cit. & $\mathbf{N}$ & \% cit. & $\mathbf{N}$ & $\%$ cit. \\
\hline Indicação médica formal & $\mathbf{0}$ & $\mathbf{0 , 0}$ & 11 & 25,0 & 33 & 75,0 & 44 & 100,0 \\
\hline Autorização judicial & $\mathbf{0}$ & $\mathbf{0 , 0}$ & 12 & 23,1 & 40 & 76,9 & 52 & 100,0 \\
\hline Concordância do paciente & 0 & $\mathbf{0 , 0}$ & 20 & 24,1 & 63 & 75,9 & 83 & 100,0 \\
\hline Compromisso da família no acompanhamento do tratamento & $\mathbf{0}$ & $\mathbf{0 , 0}$ & 14 & 20,9 & 53 & 79,1 & 67 & 100,0 \\
\hline Total & 1 & 0,3 & 97 & 26,9 & 262 & 72,8 & 360 & 100,0 \\
\hline
\end{tabular}

Com relação aos requisitos para atendimento nas instituições foi ressaltada nas entrevistas pela maioria dos dirigentes que o ideal seria o quesito aceitação da condição de dependência do paciente. Pois, alegam que quando há o reconhecimento do próprio usuário, a adaptação ao tratamento e a aceitação das normas estabelecidas pela instituição de tratamento é facilitado. Como afirma um dos dirigentes:

(...) "o procedimento para entrar no tratamento primeiramente, que a pessoa reconheça que é dependente. Segundo, que ela esteja em busca de ajuda, se ela não tiver esses dois requisitos é muito difícil, ela permanecer aqui na Instituição, porque existe um grupo de pessoas que nós precisamos estabelecer normas de convivência, e quem reconhece que precisa mudar porque já sofreram bastante então eles se adaptam melhor e então o que procuramos ver na entrevista é justamente esta área" (entrevista 01. Inst. Não-Governamental).

Porém, como afirma a dirigente de outra instituição:

"Toda minha linha é o desejo, vontade de fazer o tratamento, só que nem sempre dá (...), pois, a maioria dos pacientes vem encaminhada pela justiça. Então eles geralmente não têm vontade nenhuma (...) muitos vão embora e só voltam com outra intimação" (entrevista 05 Inst. Não-Governamental). 


\subsection{Abordagem Terapêutica de Acordo com a Natureza da Instituição.}

Devido à complexidade da dependência química, não se pode padronizar os tratamentos para determinadas tipologias de dependência, dificultando, assim respostas mais assertivas. Deste modo, vários esforços vêm sendo empregados a título de alternativas de tratamento, tanto no campo medicamentoso como na esfera psicossocial (RIBEIRO, 2004). Lembrando que a escolha da abordagem terapêutica está intrinsecamente ligada ao tipo de paciente e à fase ou estágio de mudança do tratamento em que o paciente se encontra.

Assim sendo, os dados da Tabela 8 mostram a distribuição das abordagens utilizadas pelas instituições de tratamento de acordo com a natureza da instituição. Apesar da redução de danos ser a abordagem menos utilizada pelas instituições não-governamentais, entre as instituições que adotam este tipo de abordagem, 27, 12 (44,4\%) são governamentais e $15(55,6 \%)$ não-governamentais.

Outros dados relevantes mostram que a Psicoterapia em grupo é oferecida por 78 instituições, 25 (32,1\%) governamentais e 53 (67,9\%) não-governamentais, essa alternativa de tratamento vem se destacando e se consolidando ao longo do tempo; A Psicoterapia individual, com 71 instituições, 24 (33,8\%) governamentais e 47 (66,2\%) nãogovernamentais; e Terapia ocupacional/oficinas terapêuticas que obteve 70 respostas, sendo $20(28,6 \%)$ realizadas por instituições governamentais e $50(71,4 \%)$ realizadas por instituições não-governamentais.

Tabela 8: Abordagem terapêutica utilizada pelas instituições governamentais de tratamento quanto à natureza

\begin{tabular}{|c|c|c|c|c|c|c|c|c|}
\hline \multicolumn{9}{|c|}{ Natureza da organização X Abordagem utilizada no tratamento } \\
\hline & \multicolumn{2}{|c|}{ Não resposta } & \multicolumn{2}{|c|}{ Governamental } & \multicolumn{2}{|c|}{$\begin{array}{c}\text { Não- } \\
\text { governamental }\end{array}$} & \multicolumn{2}{|c|}{ Total } \\
\hline & $\mathbf{N}$ & $\%$ cit. & $\mathbf{N}$ & $\%$ cit. & $\mathbf{N}$ & \% cit. & $\mathbf{N}$ & $\%$ cit. \\
\hline Não resposta & 1 & 4,2 & 15 & 62,5 & 8 & 33,3 & 24 & 100,0 \\
\hline Psicoterapia individual & $\mathbf{0}$ & $\mathbf{0 , 0}$ & 24 & 33,8 & 47 & 66,2 & 71 & 100,0 \\
\hline Psicoterapia em grupo & $\mathbf{0}$ & $\mathbf{0 , 0}$ & 25 & 32,1 & 53 & 67,9 & 78 & 100,0 \\
\hline Psicoterapia familiar & $\mathbf{0}$ & $\mathbf{0 , 0}$ & 17 & $\mathbf{3 1 , 5}$ & 37 & 68,5 & 54 & 100,0 \\
\hline Assistência médica clínica & $\mathbf{0}$ & $\mathbf{0 , 0}$ & 17 & 34,7 & 32 & 65,3 & 49 & 100,0 \\
\hline Assistência médica farmacológica & $\mathbf{0}$ & $\mathbf{0 , 0}$ & 17 & 48,6 & 18 & 51,4 & 35 & 100,0 \\
\hline Assistência médica psiquiátrica & $\mathbf{0}$ & $\mathbf{0 , 0}$ & 21 & 43,8 & 27 & 56,3 & 48 & 100,0 \\
\hline Método Minessota - 12 passos & $\mathbf{0}$ & $\mathbf{0 , 0}$ & 5 & 20,0 & 20 & $\mathbf{8 0 , 0}$ & 25 & 100,0 \\
\hline Grupo de prevenção da recaída & $\mathbf{0}$ & $\mathbf{0 , 0}$ & 10 & 27,8 & 26 & 72,2 & 36 & 100,0 \\
\hline Aconselhamento motivacional & $\mathbf{0}$ & $\mathbf{0 , 0}$ & 13 & 22,4 & 45 & 77,6 & 58 & 100,0 \\
\hline Terapia ocupacional / oficinas terapêuticas & $\mathbf{0}$ & $\mathbf{0 , 0}$ & 20 & 28,6 & 50 & 71,4 & 70 & 100,0 \\
\hline Terapia comunitária & $\mathbf{0}$ & $\mathbf{0 , 0}$ & 2 & 8,3 & 22 & 91,7 & 24 & 100,0 \\
\hline Redução de danos & $\mathbf{0}$ & $\mathbf{0 , 0}$ & 12 & 44,4 & 15 & 55,6 & 27 & 100,0 \\
\hline Outras & $\mathbf{0}$ & $\mathbf{0 , 0}$ & 4 & 20,0 & 16 & 80,0 & 20 & 100,0 \\
\hline Total & 1 & 0,2 & 202 & 32,6 & 416 & 67,2 & 619 & 100,0 \\
\hline
\end{tabular}




\subsection{Duração do Tratamento de Acordo com a Natureza da Instituição.}

A duração do tratamento deve ser determinada de acordo com as necessidades de cada indivíduo e pode variar de poucos meses a vários anos. A monitoração para o uso de substância deve ser intensificada nos períodos de alto risco para recaída, que são geralmente os estágios iniciais de tratamento, período de transição para níveis menos intensivos de cuidados e no primeiro ano seguinte ao término do tratamento (ANDRADE; DUARTE; CUNHA, 2002). Nota-se que o tratamento mais prolongado é nas instituições governamentais.

Tabela 9: Período do tratamento em (meses) utilizado pelas instituições de acordo com a natureza da instituição.

\begin{tabular}{l|c|c|c|c|c|c|c|c}
\hline \multicolumn{7}{c}{ Natureza da organização X Período do tratamento (meses) } \\
\hline & \multicolumn{2}{|c|}{ Não resposta } & \multicolumn{2}{c}{ Governamental } & \multicolumn{2}{c}{$\begin{array}{c}\text { Não } \\
\text { governamental }\end{array}$} & \multicolumn{3}{c}{ Total } \\
\hline & N & \% cit. & N & \% cit. & N & \% cit. & N & \% cit. \\
\hline Não resposta & $\mathbf{1}$ & $\mathbf{1 , 4}$ & $\mathbf{3 4}$ & $\mathbf{4 8 , 6}$ & $\mathbf{3 5}$ & $\mathbf{5 0 , 0}$ & $\mathbf{7 0}$ & $\mathbf{1 0 0 , 0}$ \\
\hline Menos de 3 & $\mathbf{0}$ & $\mathbf{0 , 0}$ & $\mathbf{1}$ & $\mathbf{2 0 , 0}$ & $\mathbf{4}$ & $\mathbf{8 0 , 0}$ & $\mathbf{5}$ & $\mathbf{1 0 0 , 0}$ \\
\hline De 3 a 5 & $\mathbf{0}$ & $\mathbf{0 , 0}$ & $\mathbf{5}$ & $\mathbf{4 5 , 5}$ & $\mathbf{6}$ & $\mathbf{5 4 , 5}$ & $\mathbf{1 1}$ & $\mathbf{1 0 0 , 0}$ \\
\hline De 6 a 8 & $\mathbf{0}$ & $\mathbf{0 , 0}$ & $\mathbf{0}$ & $\mathbf{0 , 0}$ & $\mathbf{1 5}$ & $\mathbf{1 0 0 , 0}$ & $\mathbf{1 5}$ & $\mathbf{1 0 0 , 0}$ \\
\hline De 9 a 11 & $\mathbf{0}$ & $\mathbf{0 , 0}$ & $\mathbf{3}$ & $\mathbf{1 0 , 7}$ & $\mathbf{2 5}$ & $\mathbf{8 9 , 3}$ & $\mathbf{2 8}$ & $\mathbf{1 0 0 , 0}$ \\
\hline 12 e mais & $\mathbf{0}$ & & $\mathbf{0}$ & & $\mathbf{0}$ & & $\mathbf{0}$ & $\mathbf{1 0 0 , 0}$ \\
\hline Total & $\mathbf{1}$ & $\mathbf{0 , 8}$ & $\mathbf{4 3}$ & $\mathbf{3 3 , 3}$ & $\mathbf{8 5}$ & $\mathbf{6 5 , 9}$ & $\mathbf{1 2 9}$ & $\mathbf{1 0 0 , 0}$ \\
\hline
\end{tabular}

\subsection{Tratamento Complementar Realizado de Acordo com a Natureza da Instituição}

Segundo Payá e Figlie (2004, p.339/340):

No que se refere a dependência química o pressuposto básico preconiza que $\mathrm{s}$ pessoas que usam drogas estão dentro de um contexto no qual seus valores, crenças, emoções e comportamentos influenciam os comportamentos dos membros da família e são por eles influenciados. Por isso, o meio familiar pode ser compreendido como cenário direto do enfoque terapêutico.

O apoio familiar é vital para reestruturação do dependente químico, uma vez que, a dependência interfere diretamente na dinâmica familiar, por isso, se faz necessário algum tipo de orientação de apoio. Essa preocupação está presente nas instituições pesquisadas. Pois, o tratamento complementar mais freqüente é o acompanhamento familiar, sendo que 23 $(28,8 \%)$ desses tratamentos acontecem nas instituições governamentais e $57(71,3 \%)$ em instituições não-governamentais. Esses dados estão representados na Tabela 10, que traz a distribuição do tratamento complementar oferecido de acordo com a natureza das instituições. 
O $2^{\circ}$ tratamento alternativo mais utilizado pelas instituições pesquisadas é a realização de atividades físicas, esportivas, lazer e culturais. Das 61 instituições que utilizam esse tratamento, $16(26,2 \%)$ são governamentais e $45(73,8 \%)$ somos não-governamentais.

Tabela 10: Tratamento complementar realizado de acordo com a natureza da instituição

\begin{tabular}{|c|c|c|c|c|c|c|c|c|}
\hline \multicolumn{9}{|c|}{ Natureza da organização X Tratamento complementar } \\
\hline & \multicolumn{2}{|c|}{ Não resposta } & \multicolumn{2}{|c|}{ Governament } & \multicolumn{2}{|c|}{$\begin{array}{c}\text { Não- } \\
\text { governamental }\end{array}$} & \multicolumn{2}{|c|}{ Total } \\
\hline & $\mathbf{N}$ & $\%$ cit. & $\mathbf{N}$ & $\%$ cit. & $\mathbf{N}$ & $\%$ cit. & $\mathbf{N}$ & $\%$ cit. \\
\hline Não resposta & 1 & 4,2 & 15 & $62,5 \%$ & 8 & $\mathbf{3 3 , 3}$ & 24 & 100,0 \\
\hline Acompanhamento social & $\mathbf{0}$ & $\mathbf{0 , 0}$ & 21 & 35,6 & 38 & 64,4 & 59 & 100,0 \\
\hline Acompanhamento familiar & $\mathbf{0}$ & $\mathbf{0 , 0}$ & 23 & 28,8 & 57 & 71,3 & 80 & 100,0 \\
\hline Grupo de auto-ajuda & $\mathbf{0}$ & $\mathbf{0 , 0}$ & 10 & 19,2 & 42 & 80,8 & 52 & 100,0 \\
\hline Grupo de apoio em geral & $\mathbf{0}$ & 0,0 & 9 & 22,5 & 31 & 77,5 & 40 & 100,0 \\
\hline Assistência religiosa & $\mathbf{0}$ & $\mathbf{0 , 0}$ & 5 & 8,3 & 55 & 91,7 & 60 & 100,0 \\
\hline Assistência jurídica & $\mathbf{0}$ & $\mathbf{0 , 0}$ & 3 & 21,4 & 11 & 78,6 & 14 & 100,0 \\
\hline Assistência previdenciária & $\mathbf{0}$ & $\mathbf{0 , 0}$ & 6 & $\mathbf{4 0 , 0}$ & 9 & 60,0 & 15 & 100,0 \\
\hline Realização de atividades físicas, esportivas, lazer e culturais & $\mathbf{0}$ & $\mathbf{0 , 0}$ & 16 & 26,2 & 45 & $\mathbf{7 3 , 8}$ & 61 & 100,0 \\
\hline \begin{tabular}{l|l} 
Atividades agrícolas/jardinagem \\
\end{tabular} & $\mathbf{0}$ & $\mathbf{0 , 0}$ & 10 & 22,7 & 34 & 77,3 & 44 & $\mathbf{1 0 0 , 0}$ \\
\hline Atividades de artesanato & $\mathbf{0}$ & $\mathbf{0 , 0}$ & 16 & 32,0 & 34 & 68,0 & $\mathbf{5 0}$ & 100,0 \\
\hline Visita domiciliar & $\mathbf{0}$ & $\mathbf{0 , 0}$ & 23 & 38,3 & 37 & 61,7 & $\mathbf{6 0}$ & 100,0 \\
\hline Outras & $\mathbf{0}$ & $\mathbf{0 , 0}$ & $\mathbf{5}$ & $\mathbf{3 8 , 5}$ & $\mathbf{8}$ & 61,5 & 13 & 100,0 \\
\hline Total & 1 & $\mathbf{0 , 2}$ & 162 & 28,3 & 409 & 71,5 & 572 & 100,0 \\
\hline
\end{tabular}

\subsection{Reinserção Social}

A reinserção social é um processo longo, gradativo e dinâmico que deve ocorrer simultaneamente ao tratamento visando capacitar o indivíduo para exercer com plenitude o seu direito à cidadania. Ela é determinante na recuperação das perdas e a criação ou fortalecimento da rede social comprometida pelo período de ingestão (DUARTE, 2002).

Nas entrevistas o dirigente (entrevista 01. Inst. Não-Governamental) ressaltou que a reinserção é um processo pelo qual o paciente é liberado ao convívio social para ver como reage aos fatores de risco. Essa liberação pode ser para visitas à família, participação de cursos profissionalizantes fora da instituição, reabilitação ao trabalho, entre outros. Em algumas instituições a reinserção se dá por meio de encaminhamento para instituições que oferece continuação ao tratamento. Isso importa oferecer atendimento/cuidados intermediários (entre o regime ambulatorial e a internação hospitalar) com ênfase numa abordagem compreensiva e com suporte educacional, social, recreacional, reabilitação psicossocial e reinserção profissional. Dessa forma todo o processo de "cura" é acompanhado com um tipo de tratamento adequado para cada estágio, visando à reabilitação do usuário de álcool e outras drogas. 
Das 52 instituições, Tabela 11, que realizam encaminhamento para reinserção social do usuário/dependente, $16(30,8 \%)$ são governamentais e 36 (69,2\%) nãogovernamentais. Já em relação ao total de instituições que não realizam reinserção social, 11 $(25,6 \%)$ são governamentais e $32(74,4 \%)$ são não-governamentais.

Tabela 11: Encaminhamentos para reinserção social de acordo com a natureza das instituições

\begin{tabular}{|c|c|c|c|c|c|c|c|c|}
\hline \multicolumn{9}{|c|}{ Natureza da organização X Reinserção social } \\
\hline & \multicolumn{2}{|c|}{ Não resposta } & \multicolumn{2}{|c|}{ Governamental } & \multicolumn{2}{|c|}{$\begin{array}{c}\text { Não } \\
\text { governamental }\end{array}$} & \multicolumn{2}{|c|}{ Total } \\
\hline & $\mathbf{N}$ & $\%$ cit. & $\mathbf{N}$ & \% cit. & $\mathbf{N}$ & $\%$ cit. & $\mathbf{N}$ & $\%$ cit. \\
\hline Não resposta & 1 & 2,9 & 16 & 47,1 & 17 & $\mathbf{5 0 , 0}$ & 34 & 100,0 \\
\hline Sim & $\mathbf{0}$ & $\mathbf{0 , 0}$ & 16 & 30,8 & 36 & 69,2 & 52 & 100,0 \\
\hline Não & $\mathbf{0}$ & $\mathbf{0 , 0}$ & 11 & 25,6 & 32 & $\mathbf{7 4 , 4}$ & 43 & 100,0 \\
\hline Total & 1 & 0,8 & 43 & 33,3 & 85 & 65,9 & 129 & 100,0 \\
\hline
\end{tabular}

\subsection{Atendimento a Situações Específicas de Acordo com a Natureza das Instituições}

Observa-se, na Tabela 12, que das 59 instituições que realizam atendimentos a pacientes portadores de HIV/Aids, 18 (30,5\%) são governamentais e 41 (69,5\%) nãogovernamentais. As instituições que atendem pacientes portadores de doenças sexualmente transmissíveis e/ou hepatite somam 48, sendo 17 (35,4\%) governamentais e 31 (64,6\%) nãogovernamentais.

Nas instituições governamentais, observa-se uma proporção maior de instituições que atendem pacientes que, além do problema com o uso de substâncias psicoativas, apresentam algum outro transtorno psiquiátrico. Já nas instituições não-governamentais, a maior proporção de instituições concentra-se no atendimento de portadores de HIV/Aids e Pacientes com deficiência física, auditiva, visual e/ou múltiplas.

Tabela 12: Atendimento de situações específicas de acordo com a natureza das instituições.

\begin{tabular}{|c|c|c|c|c|c|c|c|c|}
\hline \multicolumn{9}{|c|}{ Natureza da organização X Reinserção social } \\
\hline & \multicolumn{2}{|c|}{ Não resposta } & \multicolumn{2}{|c|}{ Governamental } & \multicolumn{2}{|c|}{$\begin{array}{c}\text { Não- } \\
\text { governamental }\end{array}$} & \multicolumn{2}{|c|}{ Total } \\
\hline & $\mathbf{N}$ & $\%$ cit. & $\mathbf{N}$ & $\%$ cit. & $\mathbf{N}$ & \% cit. & $\mathbf{N}$ & $\%$ cit. \\
\hline Não resposta & 1 & 3,4 & 14 & 48,3 & 14 & 48,3 & 29 & 100,0 \\
\hline Pacientes com comprometimento clínico & $\mathbf{0}$ & $\mathbf{0 , 0}$ & 19 & 40,4 & 28 & 59,6 & 47 & 100,0 \\
\hline $\begin{array}{l}\text { Pacientes portadores de doenças sexualmente transmissíveis e/ } \\
\text { ou hepatite }\end{array}$ & $\mathbf{0}$ & $\mathbf{0 , 0}$ & 17 & 35,4 & 31 & 64,6 & 48 & 100,0 \\
\hline $\begin{array}{l}\text { Pacientes com deficiência física, auditiva, visual e/ou } \\
\text { múltiplas }\end{array}$ & $\mathbf{0}$ & $\mathbf{0 , 0}$ & 15 & 31,9 & 32 & 68,1 & 47 & 100,0 \\
\hline Outras & $\mathbf{0}$ & $\mathbf{0 , 0}$ & 3 & 18,8 & 13 & 81,3 & 16 & 100,0 \\
\hline
\end{tabular}




\section{CAPITULO III}

\section{Informações Sobre as instituições de Tratamento de usuários/ Dependentes de Álcool e outras Drogas na Região Centro-Oeste no Brasil}

\subsection{Ano de criação de acordo com a natureza das instituições de tratamento}

A Tabela 13 mostra a distribuição do ano de criação de acordo com a natureza das instituições de tratamento. Das 42 instituições que estão em funcionamento há oito anos, ou seja, que passaram a funcionar a partir de 2000, 25 (59,5\%) são governamentais e 16 $(38,1 \%)$ são não-governamentais. Já das 42 instituições que foram criadas entre 1990 e 1999 , seis (14,3\%) são governamentais e $36(85,7 \%)$ não-governamentais.

Pode inferir que a partir do ano de 1990 o número de instituição governamental aumentou com a criação dos CAPS instituídos juntamente com os Núcleos de Assistência Psicossocial (NAPS), através da Portaria/SNAS No 224 de 29 de janeiro de 1992, que são unidades de saúde locais/regionalizadas que contam com uma população crescente definida pelo nível local e que oferecem atendimento de cuidados intermediários entre o regime ambulatorial e a internação hospitalar, em um ou dois turnos de 4 horas, por equipe multiprofissional, constituindo-se também em porta de entrada da rede de serviços para as ações relativas à saúde mental (BRASIL, 1992a).

Tabela 13: Ano de criação de acordo com a natureza das instituições de tratamento

\begin{tabular}{l|c|c|c|c|c|c|c|c}
\hline \multicolumn{7}{c}{ Natureza da organização X Localização } \\
\hline & \multicolumn{2}{|c|}{ Não resposta } & \multicolumn{2}{c|}{$\begin{array}{c}\text { Não } \\
\text { Governamental }\end{array}$} & \multicolumn{3}{c}{ Total } \\
\hline & $\mathbf{N}$ & $\mathbf{\%}$ cit. & $\mathbf{N}$ & $\mathbf{\%}$ cit. & $\mathbf{N}$ & $\mathbf{\%}$ cit. & N & \% cit. \\
\hline Não resposta & $\mathbf{0}$ & $\mathbf{0 , 0}$ & $\mathbf{6}$ & $\mathbf{3 1 , 6}$ & $\mathbf{1 3}$ & $\mathbf{6 8 , 4}$ & $\mathbf{1 9}$ & $\mathbf{1 0 0 , 0}$ \\
\hline Menos de 1 980 & $\mathbf{0}$ & $\mathbf{0 , 0}$ & $\mathbf{2}$ & $\mathbf{1 5 , 4}$ & $\mathbf{1 1}$ & $\mathbf{8 4 , 6}$ & $\mathbf{1 3}$ & $\mathbf{1 0 0 , 0}$ \\
\hline De 1 980 a 1 989 & $\mathbf{0}$ & $\mathbf{0 , 0}$ & $\mathbf{4}$ & $\mathbf{3 0 , 8}$ & $\mathbf{9}$ & $\mathbf{6 9 , 2}$ & $\mathbf{1 3}$ & $\mathbf{1 0 0 , 0}$ \\
\hline De 1 990 a 1 999 & $\mathbf{0}$ & $\mathbf{0 , 0}$ & $\mathbf{6}$ & $\mathbf{1 4 , 3}$ & $\mathbf{3 6}$ & $\mathbf{8 5 , 7}$ & $\mathbf{4 2}$ & $\mathbf{1 0 0 , 0}$ \\
\hline 2 000 e mais & $\mathbf{1}$ & $\mathbf{2 , 4}$ & $\mathbf{2 5}$ & $\mathbf{5 9 , 5}$ & $\mathbf{1 6}$ & $\mathbf{3 8 , 1}$ & $\mathbf{4 2}$ & $\mathbf{1 0 0 , 0}$ \\
\hline Total & $\mathbf{1}$ & $\mathbf{0 , 8}$ & $\mathbf{4 3}$ & $\mathbf{3 3 , 3}$ & $\mathbf{8 5}$ & $\mathbf{6 5 , 9}$ & $\mathbf{1 2 9}$ & $\mathbf{1 0 0 , 0}$ \\
\hline
\end{tabular}

\subsection{Abrangência das atividades da instituição de tratamento de acordo com a natureza}

$\mathrm{Na}$ Tabela 14, observa-se que do total de 40 instituições cujas atividades abrangem todo o município ou cidade, 23 (57, 5\%) são governamentais e 17 (42,5\%) não- 
governamentais. Em relação às instituições cujas atividades abrangem todo o país, das 37 respostas, quatro $(10,8 \%)$ se referem às instituições governamentais e $33(89,2 \%)$, se referem às não-governamentais.

Tabela 14: Abrangência das atividades da instituição de tratamento de acordo com a natureza

\begin{tabular}{l|c|c|c|c|c|c|c|c}
\hline \multicolumn{7}{c}{ Natureza da organização X Abrangência das atividades } \\
\hline & Não resposta & \multicolumn{2}{c|}{$\begin{array}{c}\text { Nover } \\
\text { governamental }\end{array}$} & \multicolumn{2}{c}{ Total } \\
\hline & $\mathbf{N}$ & $\mathbf{\%}$ cit. & $\mathbf{N}$ & $\mathbf{\%}$ cit. & N & $\mathbf{\%}$ cit. & N & \% cit. \\
\hline Não resposta & $\mathbf{1}$ & $\mathbf{3 3 , 3}$ & $\mathbf{1}$ & $\mathbf{3 3 , 3}$ & $\mathbf{1}$ & $\mathbf{3 3 , 3}$ & $\mathbf{3}$ & $\mathbf{1 0 0 , 0}$ \\
\hline Abrange somente o bairro & $\mathbf{0}$ & $\mathbf{0 , 0}$ & $\mathbf{0}$ & $\mathbf{0 , 0}$ & $\mathbf{2}$ & $\mathbf{1 0 0 , 0}$ & $\mathbf{2}$ & $\mathbf{1 0 0 , 0}$ \\
\hline Abrange todo o município ou cidade & $\mathbf{0}$ & $\mathbf{0 , 0}$ & $\mathbf{2 3}$ & $\mathbf{5 7 , 5}$ & $\mathbf{1 7}$ & $\mathbf{4 2 , 5}$ & $\mathbf{4 0}$ & $\mathbf{1 0 0 , 0}$ \\
\hline Abrange todo o Estado & $\mathbf{0}$ & $\mathbf{0 , 0}$ & $\mathbf{1 0}$ & $\mathbf{2 8 , 6}$ & $\mathbf{2 5}$ & $\mathbf{7 1 , 4}$ & $\mathbf{3 5}$ & $\mathbf{1 0 0 , 0}$ \\
\hline Abrange todo o país & $\mathbf{0}$ & $\mathbf{0 , 0}$ & $\mathbf{4}$ & $\mathbf{1 0 , 8}$ & $\mathbf{3 3}$ & $\mathbf{8 9 , 2}$ & $\mathbf{3 7}$ & $\mathbf{1 0 0 , 0}$ \\
\hline Abrange outros países & $\mathbf{0}$ & $\mathbf{0 , 0}$ & $\mathbf{3}$ & $\mathbf{3 7 , 5}$ & $\mathbf{5}$ & $\mathbf{6 2 , 5}$ & $\mathbf{8}$ & $\mathbf{1 0 0 , 0}$ \\
\hline Outra abrangência & $\mathbf{0}$ & $\mathbf{0 , 0}$ & $\mathbf{7}$ & $\mathbf{4 3 , 8}$ & $\mathbf{9}$ & $\mathbf{5 6 , 3}$ & $\mathbf{1 6}$ & $\mathbf{1 0 0 , 0}$ \\
\hline Total & $\mathbf{1}$ & $\mathbf{0 , 7}$ & $\mathbf{4 8}$ & $\mathbf{3 4 , 0}$ & $\mathbf{9 2}$ & $\mathbf{6 5 , 2}$ & $\mathbf{1 4 1}$ & $\mathbf{1 0 0 , 0}$ \\
\hline
\end{tabular}

\subsection{Localização da instituição de tratamento quanto à natureza}

A Tabela 15 revela que, ao distribuir os dados de localização das instituições de acordo com a sua natureza, revela que a maioria das instituições de tratamento está localizada em área urbana. Das 107 instituições que realizam atividades de tratamento localizadas na área urbana, 42 (39,3\%) são governamentais e 65 (60,7\%) não-governamentais.

Existem apenas 20 instituições localizadas na área rural, todas (100\%) são nãogovernamentais. Esse dado expressa as limitações do suporte fornecido pelo Estado à população rural com problemas de álcool e/ou outras drogas.

Tabela 15: Localização da instituição de tratamento quanto à natureza

\begin{tabular}{l|c|c|c|c|c|c|c|c}
\hline \multicolumn{8}{c}{ Natureza da organização X Localização } \\
\hline & \multicolumn{2}{|c|}{ Não resposta } & \multicolumn{2}{c}{ Governamental } & \multicolumn{2}{c}{$\begin{array}{c}\text { Não } \\
\text { governamental }\end{array}$} & \multicolumn{2}{c}{ Total } \\
\hline & $\mathbf{N}$ & $\mathbf{\%}$ cit. & $\mathbf{N}$ & $\mathbf{\%}$ cit. & $\mathbf{N}$ & $\mathbf{\%}$ cit. & N & $\%$ cit. \\
\hline Não resposta & $\mathbf{1}$ & $\mathbf{1 0 0 , 0}$ & $\mathbf{0}$ & $\mathbf{0 , 0}$ & $\mathbf{0}$ & $\mathbf{0 , 0}$ & $\mathbf{1}$ & $\mathbf{1 0 0 , 0}$ \\
\hline Área urbana & $\mathbf{0}$ & $\mathbf{0 , 0}$ & $\mathbf{4 2}$ & $\mathbf{3 9 , 3}$ & $\mathbf{6 5}$ & $\mathbf{6 0 , 7}$ & $\mathbf{1 0 7}$ & $\mathbf{1 0 0 , 0}$ \\
\hline Área rural & $\mathbf{0}$ & $\mathbf{0 , 0}$ & $\mathbf{0}$ & $\mathbf{0 , 0}$ & $\mathbf{2 0}$ & $\mathbf{1 0 0 , 0}$ & $\mathbf{2 0}$ & $\mathbf{1 0 0 , 0}$ \\
\hline Area Urbana e rural & $\mathbf{0}$ & $\mathbf{0 , 0}$ & $\mathbf{1}$ & $\mathbf{1 0 0 , 0}$ & $\mathbf{0}$ & $\mathbf{0 , 0}$ & $\mathbf{1}$ & $\mathbf{1 0 0 , 0}$ \\
\hline Total & $\mathbf{1}$ & $\mathbf{0 , 8}$ & $\mathbf{4 3}$ & $\mathbf{3 3 , 3}$ & $\mathbf{8 5}$ & $\mathbf{6 5 , 9}$ & $\mathbf{1 2 9}$ & $\mathbf{1 0 0 , 0}$ \\
\hline
\end{tabular}

\subsection{Sexo da população atendida de acordo com a natureza}

A Tabela 16 mostra que das 35 instituições que afirmaram prestar atendimento somente ao sexo masculino, três $(8,6 \%)$ são governamentais e 32 (91,4\%) não- 
governamentais. Os dados confirmam a predominância do uso de drogas na população do sexo masculino.

As instituições que indicaram prestar atendimento específico ao sexo feminino somam apenas 3, sendo que todas são não-governamentais.

Em uma das entrevistas foi ressaltado que atendem somente pessoas do sexo masculino por falta de apoio dos órgãos e pela particularidade que as mulheres possuem.Como afirma um dirigente da instituição localizada em Brasília:

“(...) a mulher, ela tem uma característica diferente do homem. Ela vem grávida, já vem com criança no colo. Então, nos precisamos não só tratá-la como também da criança. E isso é caro" (entrevista nº 02 . Inst. Não-Governamental).

Tabela 16: Sexo do público-alvo atendido pela instituição de tratamento de acordo com a natureza

\begin{tabular}{|c|c|c|c|c|c|c|c|c|}
\hline \multicolumn{9}{|c|}{ Natureza da organização $X$ Gênero do público-alvo } \\
\hline & \multicolumn{2}{|c|}{ Não resposta } & \multicolumn{2}{|c|}{ Governamental } & \multicolumn{2}{|c|}{$\begin{array}{c}\text { Não } \\
\text { governamental } \\
\end{array}$} & \multicolumn{2}{|c|}{ Total } \\
\hline & $\mathbf{N}$ & $\%$ cit. & $\mathbf{N}$ & $\%$ cit. & $\mathbf{N}$ & $\%$ cit. & $\mathbf{N}$ & $\%$ cit. \\
\hline Não resposta & 1 & $100,0 \%$ & $\mathbf{0}$ & $\mathbf{0 , 0}$ & $\mathbf{0}$ & $\mathbf{0 , 0}$ & 1 & 100,0 \\
\hline Masculino & $\mathbf{0}$ & $\mathbf{0 , 0 \%}$ & 3 & 8,6 & 32 & 91,4 & 35 & 100,0 \\
\hline Feminino & $\mathbf{0}$ & $0,0 \%$ & $\mathbf{0}$ & 0,0 & 3 & 100,0 & 3 & 100,0 \\
\hline Ambos os sexos & $\mathbf{0}$ & $0,0 \%$ & 40 & 44,4 & 50 & 55,6 & 90 & 100,0 \\
\hline Total & 1 & $0,8 \%$ & 43 & 33,3 & 85 & 65,9 & 129 & 100,0 \\
\hline
\end{tabular}

\subsection{Faixa etária da população atendida de acordo com a natureza da instituição}

Na Tabela 17, observa-se que a maioria das instituições presta atendimento à população adulta, compreendida entre as idades de 18 e 59 anos. Das 31 instituições que prestam atendimento a crianças, $14(45,2 \%)$ são governamentais e $17(54,8 \%)$ nãogovernamentais; das 72 instituições que atendem adolescentes, 23 (31,9\%) são governamentais e $49(68,1 \%)$ são não-governamentais.

Tabela 17: Faixa etária da população atendida de acordo com a natureza da instituição

\begin{tabular}{|c|c|c|c|c|c|c|c|c|}
\hline & \multicolumn{2}{|c|}{ Não resposta } & \multicolumn{2}{|c|}{ Governamental } & \multicolumn{2}{|c|}{$\begin{array}{c}\text { Não } \\
\text { governamental }\end{array}$} & \multicolumn{2}{|c|}{ Total } \\
\hline & $\mathbf{N}$ & $\%$ cit. & $\mathbf{N}$ & $\%$ cit. & $\mathbf{N}$ & $\%$ cit. & $\mathbf{N}$ & $\%$ cit. \\
\hline Crianças: até 11 anos de idade & $\mathbf{0}$ & $\mathbf{0 , 0}$ & 14 & 45,2 & 17 & 54,8 & 31 & $\mathbf{1 0 0 , 0}$ \\
\hline Adolescentes: de 12 a 17 anos de idade & $\mathbf{0}$ & $\mathbf{0 , 0}$ & 23 & 31,9 & 49 & 68,1 & 72 & 100,0 \\
\hline Adultos jovens: 18 a 24 anos de idade & $\mathbf{0}$ & $\mathbf{0 , 0}$ & 37 & 33,0 & 75 & 67,0 & 112 & 100,0 \\
\hline Idosos: a partir de 60 anos de idade & $\mathbf{0}$ & $\mathbf{0 , 0}$ & 24 & $\mathbf{3 4 , 8}$ & 45 & 65,2 & 69 & 100,0 \\
\hline Total & 1 & 0,3 & 135 & 33,8 & 264 & 66,0 & 400 & $100,0 \%$ \\
\hline
\end{tabular}




\subsection{Média mensal de atendimentos de acordo com a natureza da instituição}

A Tabela 18 mostra que, 54 do total de instituições que realizam menos de 100 atendimentos por mês, 10 (18,5\%) são governamentais e 44 (81,5\%) não-governamentais. É interessante observar que, nas instituições não-governamentais, prevalece a capacidade de atendimento, pois de 100 a 499 atendimentos/mês, das 32 respostas obtidas, 12 (37,5\%) referem-se a instituições governamentais e $20(62,5)$ às não-governamentais; A instituição governamental só prevalece no atendimento de 500 a 999 atendimentos/mês, do total de 7 instituições, cinco $(71,4 \%)$ são governamentais e dois $(28,6 \%)$ não-governamentais.

Tabela 18: Média mensal de atendimentos de acordo com a natureza da instituição

\begin{tabular}{c|c|c|c|c|c|c|c|c}
\hline \multicolumn{7}{|c|}{ Natureza da organização X Média mensal de atendimentos } \\
\hline & \multicolumn{2}{|c|}{ Não resposta } & \multicolumn{2}{|c|}{ Governamenta } & \multicolumn{2}{c}{$\begin{array}{c}\text { Não- } \\
\text { governamental }\end{array}$} & \multicolumn{2}{c}{ Total } \\
\hline & $\mathbf{N}$ & $\mathbf{\%}$ cit. & $\mathbf{N}$ & $\mathbf{\%}$ cit. & $\mathbf{N}$ & $\mathbf{\%}$ cit. & $\mathbf{N}$ & $\mathbf{\%}$ cit. \\
\hline Não resposta & $\mathbf{1}$ & $\mathbf{3 , 3}$ & $\mathbf{1 3}$ & $\mathbf{4 3 , 3}$ & $\mathbf{1 6}$ & $\mathbf{5 3 , 3}$ & $\mathbf{3 0}$ & $\mathbf{1 0 0 , 0}$ \\
\hline Menos de 100 & $\mathbf{0}$ & $\mathbf{0 , 0}$ & $\mathbf{1 0}$ & $\mathbf{1 8 , 5}$ & $\mathbf{4 4}$ & $\mathbf{8 1 , 5}$ & $\mathbf{5 4}$ & $\mathbf{1 0 0 , 0}$ \\
\hline De 100 a 499 & $\mathbf{0}$ & $\mathbf{0 , 0}$ & $\mathbf{1 2}$ & $\mathbf{3 7 , 5}$ & $\mathbf{2 0}$ & $\mathbf{6 2 , 5}$ & $\mathbf{3 2}$ & $\mathbf{1 0 0 , 0}$ \\
\hline De 500 a 999 & $\mathbf{0}$ & $\mathbf{0 , 0}$ & $\mathbf{5}$ & $\mathbf{7 1 , 4}$ & $\mathbf{2}$ & $\mathbf{2 8 , 6}$ & $\mathbf{7}$ & $\mathbf{1 0 0 , 0}$ \\
\hline De 1 000 a 1 999 & $\mathbf{0}$ & $\mathbf{0 , 0}$ & $\mathbf{1}$ & $\mathbf{3 3 , 3}$ & $\mathbf{2}$ & $\mathbf{6 6 , 7}$ & $\mathbf{3}$ & $\mathbf{1 0 0 , 0}$ \\
\hline De 2 000 a 4 999 & $\mathbf{0}$ & $\mathbf{0 , 0}$ & $\mathbf{2}$ & $\mathbf{6 6 , 7}$ & $\mathbf{1}$ & $\mathbf{3 3 , 3}$ & $\mathbf{3}$ & $\mathbf{1 0 0 , 0}$ \\
\hline 5000 e mais & $\mathbf{0}$ & & $\mathbf{0}$ & & $\mathbf{0}$ & & $\mathbf{0}$ & $\mathbf{1 0 0 , 0}$ \\
\hline Total & $\mathbf{1}$ & $\mathbf{0 , 8}$ & $\mathbf{4 3}$ & $\mathbf{3 3 , 3}$ & $\mathbf{8 5}$ & $\mathbf{6 5 , 9}$ & $\mathbf{1 2 9}$ & $\mathbf{1 0 0 , 0}$ \\
\hline
\end{tabular}

\subsection{Acesso à população atendida de acordo com a natureza das instituições}

Na Tabela 19, observa-se que das 103 instituições cujo público-alvo é atingido por demanda do próprio usuário e/ou familiares diretamente à instituição, 30 (29,1\%) são governamentais e 73 (70,9\%) não-governamentais, e das 94 instituições cujo público-alvo é atingido por encaminhamentos de outras instituições, 30 (31,9\%) são governamentais e 64 $(68,1 \%)$ não-governamentais.

Nas entrevistas foi ressaltado que muitos dos pacientes procuram ajuda sozinhos, com as famílias, com os amigos, com as pessoas que já conhecem o tratamento, mas a maioria dos pacientes que chegam à instituição, vêm por meio de encaminhamentos pela justiça, no qual o paciente é obrigado a se submeter ao tratamento, inviabilizando o quesito concordância do paciente em fazer o tratamento. 
Tabela 19: Acesso à população atendida de acordo com a natureza das instituições

\begin{tabular}{|c|c|c|c|c|c|c|c|c|}
\hline \multicolumn{9}{|c|}{ Natureza da organização $X$ Meio de acesso do público-alvo } \\
\hline & \multicolumn{2}{|c|}{ Não resposta } & \multicolumn{2}{|c|}{ Governamental } & \multicolumn{2}{|c|}{$\begin{array}{c}\text { Não- } \\
\text { governamental }\end{array}$} & \multicolumn{2}{|c|}{ Total } \\
\hline & $\mathbf{N}$ & $\%$ cit. & $\mathbf{N}$ & $\%$ cit. & $\mathbf{N}$ & $\%$ cit. & $\mathbf{N}$ & $\%$ cit. \\
\hline Não resposta & 1 & 20,0 & 3 & $\mathbf{6 0 , 0}$ & 1 & 20,0 & 5 & 100,0 \\
\hline Encaminhamentos de outras instituições & $\mathbf{0}$ & $\mathbf{0 , 0}$ & 30 & 31,9 & 64 & 68,1 & 94 & 100,0 \\
\hline Demanda do próprio usuário e/ou familiares diretamente à instituição & $\mathbf{0}$ & $\mathbf{0 , 0}$ & 30 & 29,1 & 73 & $\mathbf{7 0 , 9}$ & 103 & 100,0 \\
\hline Atividades realizadas pela instituição junto à comunidade & 0 & 0,0 & 23 & 31,5 & 50 & 68,5 & 73 & 100,0 \\
\hline Outro & 0 & 0,0 & 10 & 41,7 & 14 & 58,3 & 24 & 100,0 \\
\hline Total & 1 & 0,3 & 96 & 32,1 & 202 & 67,6 & 299 & 100,0 \\
\hline
\end{tabular}

\subsection{Procedência dos encaminhamentos de acordo com a natureza da instituição}

A Tabela 20 mostra que das 97 instituições que recebem encaminhamentos de Familiares e/ou amigos dos usuários de drogas, 27 (27,8\%) são Governamentais e 70 (72,2\%) são não-governamentais. 74 instituições recebem encaminhamentos da justiça. Desse total, 21 $(28,4 \%)$ são instituições governamentais e $53(71,6 \%)$ não-governamentais. Do total de 746 instituições que recebem encaminhamentos da rede hospitalar, $22(33,8 \%)$ são instituições governamentais e $43(66,2 \%)$ não-governamentais.

Tabela 20: Procedência dos encaminhamentos de acordo com a natureza da instituição

\begin{tabular}{|c|c|c|c|c|c|c|c|c|}
\hline \multicolumn{9}{|c|}{ Natureza da organização X Encaminhamento } \\
\hline & \multicolumn{2}{|c|}{ Não resposta } & \multicolumn{2}{|c|}{ Governamental } & \multicolumn{2}{|c|}{ Não governamental } & \multicolumn{2}{|c|}{ Total } \\
\hline & $\mathbf{N}$ & $\%$ cit. & $\mathbf{N}$ & $\%$ cit. & $\mathbf{N}$ & $\%$ cit. & $\mathbf{N}$ & \% cit. \\
\hline Não resposta & 1 & 10,0 & 5 & $\mathbf{5 0 , 0}$ & 4 & 40,0 & 10 & 100,0 \\
\hline Conselhos Antidrogas/Entorpecentes & $\mathbf{0}$ & $\mathbf{0 , 0}$ & 9 & 23,7 & 29 & 76,3 & 38 & 100,0 \\
\hline Conselho Tutelar & $\mathbf{0}$ & $\mathbf{0 , 0}$ & 22 & 32,4 & 46 & 67,6 & 68 & 100,0 \\
\hline Outros Conselhos & $\mathbf{0}$ & $\mathbf{0 , 0}$ & 8 & 27,6 & 21 & 72,4 & 29 & 100,0 \\
\hline Ministério Público & $\mathbf{0}$ & $\mathbf{0 , 0}$ & 23 & 33,3 & 46 & 66,7 & 69 & 100,0 \\
\hline Polícia & $\mathbf{0}$ & $\mathbf{0 , 0}$ & 14 & 31,1 & 31 & 68,9 & 45 & 100,0 \\
\hline Justiça & $\mathbf{0}$ & $\mathbf{0 , 0}$ & 21 & 28,4 & 53 & 71,6 & 74 & 100,0 \\
\hline Rede Hospitalar & $\mathbf{0}$ & $\mathbf{0 , 0}$ & 22 & 33,8 & 43 & 66,2 & 65 & 100,0 \\
\hline Entidades Religiosas & $\mathbf{0}$ & $\mathbf{0 , 0}$ & 15 & 20,8 & 57 & 79,2 & 72 & 100,0 \\
\hline Familiares e/ou amigos dos usuários de drogas & $\mathbf{0}$ & $\mathbf{0 , 0}$ & 27 & 27,8 & 70 & 72,2 & 97 & 100,0 \\
\hline Outras instituições & $\mathbf{0}$ & $\mathbf{0 , 0}$ & 13 & 40,6 & 19 & 59,4 & 32 & 100,0 \\
\hline Total & 1 & 0,2 & 179 & 29,9 & 419 & 69,9 & 599 & 100,0 \\
\hline
\end{tabular}




\subsection{Articulação das instituições de acordo com a natureza}

Observa-se na Tabela 21, que, pela distribuição das articulações realizadas pelas instituições de acordo com sua natureza, das 63 respostas referentes a articulações realizadas com a Secretaria Municipal de Assistência Social, 16 (25,4\%) são realizadas por instituições governamentais e $47(74,6 \%)$ por instituições não-governamentais. As articulações com os meios de comunicação (rádio, televisão, jornais, internet) são realizadas por 62 instituições, sendo $24(38,7 \%)$ governamentais e $38(61,3 \%)$ não-governamentais.

Percebe-se que, assim como ocorre com a Secretaria Municipal de Assistência Social e meios de comunicação, há maior prevalência das instituições não-governamentais na realização de articulações com os seguintes órgãos: Secretaria Municipal de Saúde, das 61 respostas obtidas, $26(42,6 \%)$ são realizadas por instituições governamentais e $35(57,4 \%)$ por instituições não-governamentais; Conselhos Antidrogas/Entorpecentes das 58 respostas, 21 (36,2\%) são de instituições governamentais e 37 (63,8 \%) de não-governamentais; Conselho Tutelar, das respostas obtidas, 24 ( 42,1\%) são de instituições governamentais e 33 (57,9 \%) de não-governamentais; Associações comunitárias, das 46 respostas obtidas, $11(23,9 \%)$ são de instituições governamentais e 35 ( 76,1\%) de não-governamentais ; Secretaria Nacional Antidrogas - Senad, das 53 respostas obtidas 20 (37,7\%) são de instituições governamentais e $33(62,3 \%)$ de não-governamentais. 
Tabela 21: Articulação das instituições de acordo com a natureza

\begin{tabular}{|c|c|c|c|c|c|c|c|c|}
\hline \multicolumn{9}{|c|}{ Natureza da organização X Articulações } \\
\hline & \multicolumn{2}{|c|}{ Não resposta } & \multicolumn{2}{|c|}{ Governamental } & \multicolumn{2}{|c|}{$\begin{array}{c}\text { Não } \\
\text { governamental } \\
\end{array}$} & \multicolumn{2}{|c|}{ Total } \\
\hline & $\mathbf{N}$ & $\%$ cit. & $\mathbf{N}$ & $\%$ cit. & $\mathbf{N}$ & $\%$ cit. & $\mathbf{N}$ & $\%$ cit. \\
\hline Não resposta & 1 & 33,3 & $\mathbf{0}$ & $\mathbf{0 , 0}$ & 2 & 66,7 & 3 & $\mathbf{1 0 0 , 0}$ \\
\hline Secretaria Nacional Antidrogas - SENAD & $\mathbf{0}$ & $\mathbf{0 , 0}$ & 20 & 37,7 & 33 & 62,3 & 53 & 100,0 \\
\hline Ministério da Educação & $\mathbf{0}$ & $\mathbf{0 , 0}$ & 4 & 33,3 & 8 & 66,7 & 12 & 100,0 \\
\hline Ministério da Saúde & $\mathbf{0}$ & $\mathbf{0 , 0}$ & 20 & 64,5 & 11 & 35,5 & 31 & 100,0 \\
\hline Ministério da Justiça & $\mathbf{0}$ & $\mathbf{0 , 0}$ & 10 & 35,7 & 18 & 64,3 & 28 & 100,0 \\
\hline $\begin{array}{l}\text { Ministério do Desenvolvimento Social e } \\
\text { Combate à Fome }\end{array}$ & $\mathbf{0}$ & $\mathbf{0 , 0}$ & 3 & 42,9 & 4 & $\mathbf{5 7 , 1}$ & 7 & 100,0 \\
\hline Secretaria Estadual de Educação & $\mathbf{0}$ & $\mathbf{0 , 0}$ & 11 & 39,3 & 17 & 60,7 & 28 & 100,0 \\
\hline Secretaria Estadual de Saúde & $\mathbf{0}$ & $\mathbf{0 , 0}$ & 29 & $\mathbf{5 5 , 8}$ & 23 & 44,2 & 52 & 100,0 \\
\hline Secretaria Estadual de Assistência Social & $\mathbf{0}$ & $\mathbf{0 , 0}$ & 11 & 29,7 & 26 & 70,3 & 37 & 100,0 \\
\hline Secretaria Estadual de Justiça & $\mathbf{0}$ & $\mathbf{0 , 0}$ & 11 & 44,0 & 14 & 56,0 & 25 & 100,0 \\
\hline Secretaria Estadual de Segurança Pública & $\mathbf{0}$ & $\mathbf{0 , 0}$ & 14 & 43,8 & 18 & 56,3 & 32 & 100,0 \\
\hline Secretaria Municipal de Educação & $\mathbf{0}$ & $\mathbf{0 , 0}$ & 16 & 48,5 & 17 & $\mathbf{5 1 , 5}$ & 33 & 100,0 \\
\hline Secretaria Municipal de Saúde & $\mathbf{0}$ & $\mathbf{0 , 0}$ & 26 & 42,6 & 35 & $\mathbf{5 7 , 4}$ & 61 & 100,0 \\
\hline Secretaria Municipal de Assistência Social & $\mathbf{0}$ & $\mathbf{0 , 0}$ & 16 & 25,4 & 47 & 74,6 & 63 & 100,0 \\
\hline $\begin{array}{l}\text { Universidades e/ou centros de ensino e } \\
\text { pesquisa }\end{array}$ & $\mathbf{0}$ & $\mathbf{0 , 0}$ & 18 & 40,0 & 27 & 60,0 & 45 & 100,0 \\
\hline Conselhos Antidrogas/Entorpecentes & $\mathbf{0}$ & $\mathbf{0 , 0}$ & 21 & 36,2 & 37 & 63,8 & 58 & 100,0 \\
\hline $\begin{array}{l}\text { Conselhos de Direitos da Criança e do } \\
\text { Adolescente }\end{array}$ & $\mathbf{0}$ & $\mathbf{0 , 0}$ & 14 & 32,6 & 29 & 67,4 & 43 & 100,0 \\
\hline Conselho Tutelar & $\mathbf{0}$ & $\mathbf{0 , 0}$ & 24 & 42,1 & 33 & $\mathbf{5 7 , 9}$ & 57 & 100,0 \\
\hline Conselho Comunitário de Segurança & $\mathbf{0}$ & $\mathbf{0 , 0}$ & 9 & 39,1 & 14 & 60,9 & 23 & 100,0 \\
\hline $\begin{array}{l}\text { Meios de comunicação (rádio, televisão, } \\
\text { jornais, internet) }\end{array}$ & $\mathbf{0}$ & $\mathbf{0 , 0}$ & 24 & 38,7 & 38 & 61,3 & 62 & 100,0 \\
\hline Associações comunitárias & $\mathbf{0}$ & $\mathbf{0 , 0}$ & 11 & 23,9 & 35 & 76,1 & 46 & 100,0 \\
\hline Outra(s) & $\mathbf{0}$ & $\mathbf{0 , 0}$ & 10 & 32,3 & 21 & 67,7 & 31 & 100,0 \\
\hline Não há articulação com outras instituições & $\mathbf{0}$ & $\mathbf{0 , 0}$ & $\mathbf{0}$ & $\mathbf{0 , 0}$ & 5 & 100,0 & 5 & 100,0 \\
\hline
\end{tabular}

\subsection{Existência do conselho antidrogas/entorpecentes no município na percepção do}

\section{dirigente de acordo com a natureza da instituição}

É importante observar, conforme Tabela 22 que 14 dirigentes afirmaram não saber se em seu município existe o conselho municipal antidrogas/entorpecentes, sendo que quatro $(28,6 \%)$ são de instituições governamentais e 10 (71,4 \%) são de instituições nãogovernamentais.

Tabela 22: Existência do conselho antidrogas/entorpecentes no município na percepção do dirigente de acordo com a natureza da instituição

Natureza da organização $X$ Existência do conselho anti-drogas

\begin{tabular}{|c|c|c|c|c|c|c|c|c|}
\hline & \multicolumn{2}{|c|}{ Não resposta } & \multicolumn{2}{|c|}{ Governamental } & \multicolumn{2}{|c|}{$\begin{array}{c}\text { Não- } \\
\text { governamental }\end{array}$} & \multicolumn{2}{|c|}{ Total } \\
\hline & $\mathbf{N}$ & $\%$ cit. & $\mathbf{N}$ & $\%$ cit. & $\mathbf{N}$ & $\%$ cit. & $\mathbf{N}$ & $\%$ cit. \\
\hline Não resposta & 1 & 8,3 & 4 & 33,3 & 7 & 58,3 & 12 & 100,0 \\
\hline Sim & $\mathbf{0}$ & $\mathbf{0 , 0}$ & 24 & 34,8 & 45 & 65,2 & 69 & 100,0 \\
\hline $\begin{array}{l}\text { Não } \\
\end{array}$ & $\mathbf{0}$ & 0,0 & 11 & 32,4 & 23 & 67,6 & 34 & 100,0 \\
\hline Não sei & $\mathbf{0}$ & $\mathbf{0 , 0}$ & 4 & 28,6 & 10 & 71,4 & 14 & 100,0 \\
\hline Total & 1 & 0,8 & 43 & 33,3 & 85 & 65,9 & 129 & 100,0 \\
\hline
\end{tabular}




\subsection{Registro das instituições junto ao Conselho Municipal Antidrogas/Entorpecentes de}

acordo com a natureza

A Tabela 23 mostra que o número de instituição que não possuem registro junto ao Conselho Municipal é maior que os que possuem. Das 129 instituições pesquisadas, 59 instituições não possuem registro junto ao conselho Municipal, enquanto que apenas 43 possuem o registro.

Observa-se que das 43 instituições que possuem registro no conselho municipal antidrogas/entorpecentes, 12 (27,9\%) são governamentais e 31 (72,1\%) não-governamentais.

Tabela 23: Registro das instituições junto ao Conselho Municipal Antidrogas/Entorpecentes de acordo com a natureza

\begin{tabular}{|c|c|c|c|c|c|c|c|c|}
\hline \multicolumn{9}{|c|}{ Natureza da organização $X$ Registro no conselho municipal } \\
\hline & \multicolumn{2}{|c|}{ Não resposta } & \multicolumn{2}{|c|}{ Governamenta } & \multicolumn{2}{|c|}{$\begin{array}{c}\text { Não } \\
\text { governamental }\end{array}$} & \multicolumn{2}{|c|}{ Total } \\
\hline & $\mathbf{N}$ & $\%$ cit. & $\mathbf{N}$ & $\%$ cit. & $\mathbf{N}$ & \% cit. & $\mathbf{N}$ & $\%$ cit. \\
\hline Não resposta & 1 & 3,7 & 13 & 48,1 & 13 & 48,1 & 27 & 100,0 \\
\hline Sim & $\mathbf{0}$ & $\mathbf{0 , 0}$ & 12 & 27,9 & 31 & 72,1 & 43 & 100,0 \\
\hline Não & $\mathbf{0}$ & $\mathbf{0 , 0}$ & 18 & $\mathbf{3 0 , 5}$ & 41 & 69,5 & 59 & 100,0 \\
\hline Não sei & $\mathbf{0}$ & & $\mathbf{0}$ & & 0 & & 0 & 100,0 \\
\hline Total & 1 & 0,8 & 43 & 33,3 & 85 & 65,9 & 129 & 100,0 \\
\hline
\end{tabular}

\subsection{Registro da instituição junto ao Conselho Estadual Antidrogas/Entorpecentes de acordo com a natureza}

$\mathrm{Na}$ Tabela 24, observa-se que das 51 instituições que afirmaram não possuir registro no Conselho Estadual Antidrogas/Entorpecentes, 17 (33,3\%) são governamentais e 34 $(66,7 \%)$ não-governamentais.

Tabela 24: Registro da instituição junto ao Conselho Estadual Antidrogas/Entorpecentes de acordo com a natureza

Natureza da organização X Registro no conselho estadual

\begin{tabular}{l|c|c|c|c|c|c|c|c}
\hline & \multicolumn{2}{|c|}{ Não resposta } & \multicolumn{2}{c|}{ Governamenta } & \multicolumn{2}{c|}{$\begin{array}{c}\text { Não- } \\
\text { governamental }\end{array}$} & \multicolumn{2}{c}{ Total } \\
\hline & $\mathbf{N}$ & $\mathbf{\%}$ cit. & $\mathbf{N}$ & $\mathbf{\%}$ cit. & $\mathbf{N}$ & $\mathbf{\%}$ cit. & N & \% cit. \\
\hline Não resposta & $\mathbf{1}$ & $\mathbf{4 , 8}$ & $\mathbf{1 1}$ & $\mathbf{5 2 , 4}$ & $\mathbf{9}$ & $\mathbf{4 2 , 9}$ & $\mathbf{2 1}$ & $\mathbf{1 0 0 , 0}$ \\
\hline Sim & $\mathbf{0}$ & $\mathbf{0 , 0}$ & $\mathbf{1 5}$ & $\mathbf{2 6 , 3}$ & $\mathbf{4 2}$ & $\mathbf{7 3 , 7}$ & $\mathbf{5 7}$ & $\mathbf{1 0 0 , 0}$ \\
\hline Não & $\mathbf{0}$ & $\mathbf{0 , 0}$ & $\mathbf{1 7}$ & $\mathbf{3 3 , 3}$ & $\mathbf{3 4}$ & $\mathbf{6 6 , 7}$ & $\mathbf{5 1}$ & $\mathbf{1 0 0 , 0}$ \\
\hline Não Sei & $\mathbf{0}$ & & $\mathbf{0}$ & & $\mathbf{0}$ & & $\mathbf{0}$ & $\mathbf{1 0 0 , 0}$ \\
\hline Total & $\mathbf{1}$ & $\mathbf{0 , 8}$ & $\mathbf{4 3}$ & $\mathbf{3 3 , 3}$ & $\mathbf{8 5}$ & $\mathbf{6 5 , 9}$ & $\mathbf{1 2 9}$ & $\mathbf{1 0 0 , 0}$ \\
\hline
\end{tabular}


Observa-se que 57 instituições possuem registro no Conselho Estadual Antidrogas/Entorpecentes e 43 instituições possuem registro no Conselho Municipal Antidrogas/Entorpecentes. Esse registro está aquém do desejado, havendo a necessidade de ações que visam sanar as limitações que permeiam as instituições de se registrar. Pois, o conselho é de fundamental importância no processo de desenvolvimento de ações de prevenção e de redução do uso de drogas, de tratamento e de reinserção social dos seus usuários/dependentes;

\title{
6 Recursos Físicos / Materiais das instituições de Tratamento de usuários/ Dependentes de Álcool e outras Drogas na Região Centro-Oeste do Brasil
}

\subsection{Recursos materiais de acordo com a natureza da instituição}

Segundo o Regulamento Técnico para o funcionamento das Comunidades Terapêuticas,

\begin{abstract}
Os Serviços de atenção a pessoas com transtornos decorrentes do uso ou abuso de substâncias psicoativas (SPA), são unidades que têm por função a oferta de um ambiente protegido, técnica e eticamente orientados, que forneça suporte e tratamento aos usuários abusivos e/ou dependentes de substâncias psicoativas, durante período estabelecido de acordo com programa terapêutico adaptado às necessidades de cada caso. É um lugar cujo principal instrumento terapêutico é a convivência entre os pares. Oferece uma rede de ajuda no processo de recuperação das pessoas, resgatando a cidadania, buscando encontrar novas possibilidades de reabilitação física e psicológica, e de reinserção social.( BRASIL 2001 a)
\end{abstract}

Todavia, os dados da Tabela 25, demonstram que os recursos físicos e materiais disponíveis nas instituições governamentais e não governamentais de tratamento não estão aquém de oferecer a qualidade dos serviços proposto pelo regulamento.

Como afirmam as entrevistas, os principais problemas enfrentados para o desenvolvimento do trabalho são de ordem financeira. Há uma carência de recursos, tanto físicos quanto materiais que dependem dos recursos financeiros, que de acordo com um entrevistado "esbarra sempre no financeiro" (entrevista $\mathrm{n}^{\circ}$ 3. Inst. Não-Governamental). As instituições tanto governamentais quanto não-governamentais possuem problemas com recursos.

Uma das entrevistadas conta que na transição do programa que trabalhava com a questão das drogas para a Secretaria da Saúde (criação do CAPSad), 
(...) ficamos sem apoio, porque a Secretaria não se preparou para nos receber e não nos aceita até hoje, tanto que nós não existimos ainda para a secretaria. É um serviço público, que está funcionando, que não deixou de funcionar... Quer dizer a gente existe para a Cosam, mas a Cosam não tem essa resolutividade que nos precisamos para funcionar. Eu falo isso em relação, mesmo, às coisas básicas em relação a materiais, equipamentos, computadores, impressoras, tinta, material para funcionar, material para oficinas, transporte de pacientes, todos os tipos de falta que você pode imaginar a gente teve aqui (entrevista 08. Inst. Governamental).

Como pode ser observado na fala de um dirigente de Brasília (entrevista 08. Inst. Governamental) que representa a opinião da maioria dos entrevistados "os recursos não são o suficientes, e os recursos físicos são precários”, ou seja, a problemática dos recursos físicos e financeiros está presente nas instituições e demonstra a desatenção para a questão do tratamento de álcool e outras drogas, por parte do governo.

É importante ressaltar que as instituições não governamentais, mesmo apresentando problemas, ainda possuem mais recursos que as instituições governamentais.

Tabela 25: Recursos materiais de acordo com a natureza da instituição

\begin{tabular}{|c|c|c|c|}
\hline \\
\hline \begin{tabular}{c|c}
\multicolumn{2}{c}{ Natureza da organização X Recursos materiais } \\
\end{tabular} & Governamental & $\begin{array}{c}\text { Não } \\
\text { governamental }\end{array}$ & Total \\
\hline Consultório ou sala para atendimento individual & 2,86 & 2,70 & 2,76 \\
\hline Consultório ou sala para atendimento em grupo & 1,96 & 2,05 & 2,02 \\
\hline Laboratório de análises clínicas & 1,00 & 2,33 & 1,80 \\
\hline Enfermaria ou dormitório coletivo & 3,30 & 6,36 & $\mathbf{5 , 7 0}$ \\
\hline Apartamento/suíte & $\mathbf{2 , 0 0}$ & 11,00 & 10,55 \\
\hline Leitos para permanência diurna & 16,43 & 60,45 & 49,04 \\
\hline Leitos para permanência noturna & 35,33 & 50,94 & 49,74 \\
\hline Banheiros & 5,44 & 9,18 & $\mathbf{8 , 0 2}$ \\
\hline Chuveiros & 6,42 & 9,31 & 8,68 \\
\hline Refeitório & 1,07 & 1,35 & 1,30 \\
\hline Cozinha & 1,04 & 1,19 & 1,15 \\
\hline Auditório & 1,20 & 1,26 & 1,26 \\
\hline Escritório & 1,77 & 1,73 & 1,74 \\
\hline Sala de convivência & 1,18 & 1,86 & 1,70 \\
\hline Sala de atendimento & 1,89 & 2,00 & 1,97 \\
\hline Sala de reuniões & 1,11 & 2,89 & 2,44 \\
\hline Salas de aula & 2,00 & 2,18 & 2,15 \\
\hline Sala de jogos & 1,00 & 1,33 & 1,27 \\
\hline Sala de TV & 1,11 & 1,48 & 1,38 \\
\hline Video cassete & 1,14 & 1,16 & 1,15 \\
\hline DVD & 1,06 & 1,30 & 1,22 \\
\hline Computador & 2,58 & 3,42 & 3,09 \\
\hline Impressora & 1,64 & 1,88 & 1,78 \\
\hline Copiadora & 1,00 & 1,27 & 1,14 \\
\hline Internet & 1,62 & 1,19 & 1,34 \\
\hline Data Show & 1,13 & 1,29 & 1,20 \\
\hline Retroprojetor & 1,00 & 1,17 & 1,10 \\
\hline Filmadora & 1,00 & 1,06 & $\mathbf{1 , 0 4}$ \\
\hline Máquina fotográfica & 1,05 & 1,13 & 1,10 \\
\hline Oficinas diversas (marcenaria, mecânica, entre out...). & 3,13 & 1,77 & 2,05 \\
\hline Horta/Jardim & 1,33 & 2,77 & 2,46 \\
\hline Capela & 1,50 & 1,30 & 1,31 \\
\hline Gráfica & - & 1,00 & 1,00 \\
\hline Sala de ginástica & 1,00 & 1,00 & 1,00 \\
\hline Quadra de esporte & 1,33 & 1,30 & 1,30 \\
\hline
\end{tabular}




\begin{tabular}{l|l|l|l|}
\hline Outros & $\mathbf{1 , 0 0}$ & $\mathbf{2 , 4 2}$ & $\mathbf{2 , 0 0}$ \\
\hline
\end{tabular}

\subsection{Recursos Humanos}

A Tabela 26 mostra o número de profissionais contratados, conveniados e voluntários por instituição na Região Centro-Oeste.

Nas entrevistas foram assinaladas que os trabalhos nas instituições funcionam com equipes com foco multidisciplinar, com uma equipe composta por profissionais de diversas áreas, ou seja, com formações acadêmicas diferentes e que trabalham em prol de um único objetivo: a reabilitação dos dependentes químicos. Fica evidente também que, apesar de possuir uma equipe multidisciplinar, o numero de profissionais de cada área é pequena, o que inviabiliza um bom atendimento por causa da grande demando pelos serviços, sobrecarregando os profissionais que trabalham na área (entrevista 03. Inst. NãoGovernamental).

Ressalta-se a importância do voluntário, mas que é preciso possuir um perfil para não comprometer o tratamento dos dependentes, conforme orientam alguns dirigentes.

Tabela 26: Número de profissionais

\begin{tabular}{|c|c|c|c|}
\hline & Contratado & Convenio & Voluntário \\
\hline Administrador & 1,24 & 1,71 & 2,21 \\
\hline Advogado & 0,75 & $\mathbf{1 , 0 0}$ & 1,24 \\
\hline Agente de saúde & 1,80 & 2,00 & 1,75 \\
\hline Assistente Social & 2,00 & $\mathbf{1 , 0 0}$ & 1,32 \\
\hline Auxiliar administrativo & 3,70 & 1,40 & 1,82 \\
\hline Auxiliar de serviços gerais & 8,66 & 3,25 & 3,12 \\
\hline Contador & 0,96 & $\mathbf{1 , 0 0}$ & $\mathbf{1 , 0 0}$ \\
\hline Dentista & $\mathbf{0 , 5 0}$ & 1,33 & 1,20 \\
\hline Educador social & 1,60 & 4,67 & 3,13 \\
\hline Enfermeiro & $\mathbf{1 , 5 7}$ & 1,33 & 1,42 \\
\hline Estagiários/Bolsistas & 3,40 & 10,89 & 2,44 \\
\hline Fisioterapeuta & $\mathbf{0 , 8 0}$ & 1,00 & 1,00 \\
\hline Médico & 2,74 & 1,40 & 1,48 \\
\hline Motorista & 1,30 & $\mathbf{1 , 0 0}$ & $\mathbf{1 , 5 0}$ \\
\hline Nutricionista & $\mathbf{0 , 8 6}$ & 1,00 & $\mathbf{1 , 0 0}$ \\
\hline Oficineiro & 2,00 & 4,00 & 3,15 \\
\hline Outros voluntários & $\mathbf{0 , 0 0}$ & $\mathbf{1 , 0 0}$ & 10,19 \\
\hline Pedagogo & 1,29 & 1,60 & 2,36 \\
\hline Professor & $\mathbf{1 , 8 0}$ & 1,75 & 2,63 \\
\hline Psicólogo & 2,36 & 1,90 & 1,40 \\
\hline Redutor de danos & 3,50 & 10,00 & 3,57 \\
\hline Segurança/vigia & 2,69 & 1,75 & $\mathbf{1 , 0 0}$ \\
\hline Técnico/aux enfermagem & 10,69 & $\mathbf{1 , 5 0}$ & 1,73 \\
\hline Terapeuta ocupacional & 1,46 & $\mathbf{1 , 8 0}$ & 1,21 \\
\hline
\end{tabular}

\subsection{Fontes de recursos financeiros das instituições de tratamento}

A tabela 27 mostra as fontes de recursos financeiros utilizados pelas instituições governamentais e não-governamentais para desenvolver suas atividades. Pode-se perceber que 
77 instituições pesquisadas têm seus recursos provenientes do governo brasileiro, dos quais 35 (45,5\%) são instituições governamentais e 42 (54,5\%) são não-governamentais. Observase que das 56 instituições que possuem receita própria, oito $(14,3 \%)$ são instituições governamentais e $48(85,7 \%)$ não-governamentais.

Tabela 27: Recursos financeiros de acordo com a natureza da instituição.

\begin{tabular}{|c|c|c|c|c|c|c|c|c|}
\hline \multicolumn{9}{|c|}{ Natureza da organização $X$ Fontes de recurso } \\
\hline & \multicolumn{2}{|c|}{ Não resposta } & \multicolumn{2}{|c|}{ Governamental } & \multicolumn{2}{|c|}{$\begin{array}{c}\text { Não- } \\
\text { governamental }\end{array}$} & \multicolumn{2}{|c|}{ Total } \\
\hline & $\mathbf{N}$ & $\%$ cit. & $\mathbf{N}$ & $\%$ cit. & $\mathbf{N}$ & $\%$ cit. & $\mathbf{N}$ & $\%$ cit. \\
\hline Não resposta & 1 & 6,3 & 6 & 37,5 & 9 & 56,3 & 16 & 100,0 \\
\hline Recursos públicos Governo Brasileiro & $\mathbf{0}$ & $\mathbf{0 , 0}$ & 35 & 45,5 & 42 & $\mathbf{5 4 , 5}$ & 77 & 100,0 \\
\hline Outras fontes de recursos & 0 & $\mathbf{0 , 0}$ & 3 & 5,2 & 55 & 94,8 & 58 & 100,0 \\
\hline Geração de receita própria & $\mathbf{0}$ & $\mathbf{0 , 0}$ & 8 & 14,3 & 48 & 85,7 & 56 & 100,0 \\
\hline Total & 1 & 0,5 & 52 & 25,1 & 154 & 74,4 & 207 & 100,0 \\
\hline
\end{tabular}

Recursos públicos (Governo Brasileiro): são aqueles provenientes de algum órgão governamental brasileiro, seja da esfera municipal (prefeituras, secretarias municipais, conselhos municipais, etc.), estadual (governo dos estados, secretarias estaduais, conselhos estaduais, etc.) ou federal (ministérios, conselhos federais, etc.);

Outras fontes de recursos: refere-se a recursos privados provenientes de entidades que não pertencem ao governo, podendo ser empresas, organizações não governamentais, igrejas e pessoas físicas. Estão incluídos neste item as doações, os recursos provenientes da mantenedora (se houver) e os recursos provenientes de entidades estrangeiras inclusive de governos estrangeiros.

Geração de receita própria: refere-se a recursos gerados pela própria instituição, seja pela contribuição de sócios ou usuários do serviço, pela prestação de serviços, como consultas, exames e internações, ou realização de eventos, como palestras e oficinas, além de produtos fabricados pela própria instituição (CARVALHO; DUARTE, 2007).

A tabela 28 mostra os tipos de recurso governamental de acordo com a natureza da instituição. Das 177 instituições pesquisadas, 51 instituições recebem recursos públicos Municipais, desse total, 20 (39,2\%) são instituições governamentais e 31 (60,8\%) nãogovernamentais; 43 instituições recebem recursos públicos Estaduais dos quais 24 (55,8\%) são instituições governamentais e 19 (44,2\%) não-governamentais; e 36 instituições recebem recursos públicos Federais, desse total 26 (72,2\%) são governamentais e 10 (27,8\%) nãogovernamentais. 
Tabela 28: Tipo de recurso governamental de acordo com a natureza da instituição

\begin{tabular}{l|c|c|c|c|c|c|c|c}
\hline \multicolumn{7}{c}{ Natureza da organização X Tipo de recurso governamental } \\
\hline & Não resposta & \multicolumn{2}{c|}{ Governament } & \multicolumn{2}{c}{$\begin{array}{c}\text { Não } \\
\text { governamental }\end{array}$} & \multicolumn{2}{c}{ Total } \\
\hline & N & \% cit. & N & \% cit. & N & $\%$ cit. & N & $\%$ cit. \\
\hline Não resposta & $\mathbf{1}$ & $\mathbf{2 , 1}$ & $\mathbf{5}$ & $\mathbf{1 0 , 6}$ & $\mathbf{4 1}$ & $\mathbf{8 7 , 2}$ & $\mathbf{4 7}$ & $\mathbf{1 0 0 , 0}$ \\
\hline Recursos públicos federais & $\mathbf{0}$ & $\mathbf{0 , 0}$ & $\mathbf{2 6}$ & $\mathbf{7 2 , 2}$ & $\mathbf{1 0}$ & $\mathbf{2 7 , 8}$ & $\mathbf{3 6}$ & $\mathbf{1 0 0 , 0}$ \\
\hline Recursos públicos estaduais & $\mathbf{0}$ & $\mathbf{0 , 0}$ & $\mathbf{2 4}$ & $\mathbf{5 5 , 8}$ & $\mathbf{1 9}$ & $\mathbf{4 4 , 2}$ & $\mathbf{4 3}$ & $\mathbf{1 0 0 , 0}$ \\
\hline Recursos públicos municipais & $\mathbf{0}$ & $\mathbf{0 , 0}$ & $\mathbf{2 0}$ & $\mathbf{3 9 , 2}$ & $\mathbf{3 1}$ & $\mathbf{6 0 , 8}$ & $\mathbf{5 1}$ & $\mathbf{1 0 0 , 0}$ \\
\hline Total & $\mathbf{1}$ & $\mathbf{0 , 6}$ & $\mathbf{7 5}$ & $\mathbf{4 2 , 4}$ & $\mathbf{1 0 1}$ & $\mathbf{5 7 , 1}$ & $\mathbf{1 7 7}$ & $\mathbf{1 0 0 , 0}$ \\
\hline
\end{tabular}

Após a exposição dos dados sobre as instituições, serão apresentados no próximo capítulo os dados referentes a características dos dirigentes das instituições de tratamento de usuários/dependentes de álcool e outras drogas na região centro-oeste no Brasil 


\section{CAPITULO IV}

\section{Características dos dirigentes das instituições de Tratamento de usuários/ Dependentes de Álcool e outras Drogas na Região Centro-Oeste no Brasil}

\subsection{Idade do dirigente de acordo com a natureza da instituição}

A Tabela 29 representa a distribuição da idade do dirigente de acordo com a natureza da instituição. Entre as 38 respostas do intervalo de idade de 40 a 59 anos, 14 $(36,8 \%)$ são de instituições governamentais e 24 (63,2\%) de não-governamentais. Em relação aos dirigentes com mais de 50 anos, a tabela mostra que das 47 respostas obtidas, cinco $(10,6 \%)$ são de instituições governamentais e 42 (89,4\%) são de instituições nãogovernamentais.

Uma das dirigentes das instituições ressaltou que houve a transição dos programas com a criação dos CAPSad, porém, não houve capacitação, e a equipe permaneceu a mesma, então a pratica e a visão do dependente permaneceu a mesma pelos profissionais. Mudou a estruturação dos serviços, mas as praticas continuaram (entrevista 08. Inst. Governamental).

Tabela 29: Idade do dirigente de acordo com a natureza da instituição

\begin{tabular}{l|c|c|c|c|c|c|c|c}
\hline \multicolumn{7}{|c|}{ Natureza da organização X Idade do dirigente } \\
& \multicolumn{2}{|c|}{ Não resposta } & \multicolumn{2}{c|}{ Governamental } & \multicolumn{2}{c}{$\begin{array}{c}\text { Não- } \\
\text { governamental }\end{array}$} & \multicolumn{2}{c}{ Total } \\
\hline & $\mathbf{N}$ & $\mathbf{\%}$ cit. & $\mathbf{N}$ & $\mathbf{\%}$ cit. & N & \% cit. & N & $\%$ cit. \\
\hline Não resposta & $\mathbf{1}$ & $\mathbf{6 , 7}$ & 7 & 46,7 & 7 & $\mathbf{4 6 , 7}$ & $\mathbf{1 5}$ & $\mathbf{1 0 0 , 0}$ \\
\hline Menos de 30 & $\mathbf{0}$ & $\mathbf{0 , 0}$ & $\mathbf{4}$ & $\mathbf{6 6 , 7}$ & $\mathbf{2}$ & $\mathbf{3 3 , 3}$ & $\mathbf{6}$ & $\mathbf{1 0 0 , 0}$ \\
\hline De 30 a 39 & $\mathbf{0}$ & $\mathbf{0 , 0}$ & $\mathbf{1 3}$ & $\mathbf{5 6 , 5}$ & $\mathbf{1 0}$ & $\mathbf{4 3 , 5}$ & $\mathbf{2 3}$ & $\mathbf{1 0 0 , 0}$ \\
\hline De 40 a 49 & $\mathbf{0}$ & $\mathbf{0 , 0}$ & $\mathbf{1 4}$ & $\mathbf{3 6 , 8}$ & $\mathbf{2 4}$ & $\mathbf{6 3 , 2}$ & $\mathbf{3 8}$ & $\mathbf{1 0 0 , 0}$ \\
\hline 50 e mais & $\mathbf{0}$ & $\mathbf{0 , 0}$ & $\mathbf{5}$ & $\mathbf{1 0 , 6}$ & $\mathbf{4 2}$ & $\mathbf{8 9 , 4}$ & $\mathbf{4 7}$ & $\mathbf{1 0 0 , 0}$ \\
\hline Total & $\mathbf{1}$ & $\mathbf{0 , 8}$ & $\mathbf{4 3}$ & $\mathbf{3 3 , 3}$ & $\mathbf{8 5}$ & $\mathbf{6 5 , 9}$ & $\mathbf{1 2 9}$ & $\mathbf{1 0 0 , 0}$ \\
\hline
\end{tabular}

7.2 Sexo do dirigente de acordo com a natureza da instituição

$\mathrm{Na}$ Tabela 30, observa-se que, na distribuição do gênero do dirigente de acordo com a natureza da instituição, 57 instituições marcaram o sexo masculino. Destas, oito (14\%) são instituições governamentais e 49 (86\%) são instituições não-governamentais. Das 67 instituições que possuem dirigentes do sexo feminino, 31 (46,3\%) são instituições governamentais e $36(53,7 \%)$ são não-governamentais. 
Tabela 30: Sexo do dirigente de acordo com a natureza da instituição

\begin{tabular}{|c|c|c|c|c|c|c|c|c|}
\hline \multicolumn{9}{|c|}{ Gênero do dirigente $X$ Natureza da organização } \\
\hline & \multicolumn{2}{|c|}{ Não resposta } & \multicolumn{2}{|c|}{ Governamental } & \multicolumn{2}{|c|}{$\begin{array}{c}\text { Não- } \\
\text { governamental }\end{array}$} & \multicolumn{2}{|c|}{ Total } \\
\hline & $\mathbf{N}$ & $\%$ cit. & $\mathbf{N}$ & $\%$ cit. & $\mathbf{N}$ & $\%$ cit. & $\mathbf{N}$ & $\%$ cit. \\
\hline Não resposta & 1 & $20,0 \%$ & 4 & $80,0 \%$ & 0 & $\mathbf{0 , 0 \%}$ & 5 & $100,0 \%$ \\
\hline Feminino & 0 & $\mathbf{0 , 0 \%}$ & 31 & $46,3 \%$ & 36 & $53,7 \%$ & 67 & $100,0 \%$ \\
\hline Masculino & $\mathbf{0}$ & $\mathbf{0 , 0 \%}$ & 8 & $14,0 \%$ & 49 & $86,0 \%$ & 57 & $100,0 \%$ \\
\hline Total & 1 & $0,8 \%$ & 43 & $33,3 \%$ & 85 & $65,9 \%$ & 129 & $100,0 \%$ \\
\hline
\end{tabular}

\subsection{Escolaridade do dirigente de acordo com a natureza das instituições de tratamento}

Ao se analisar a distribuição da escolaridade do dirigente de acordo com a natureza da instituição (Tabela 31), percebe-se que, do total de 54 dirigentes que possuem o ensino superior completo, 22 (40,7\%) são de instituições governamentais e 32 (59,3\%) são de instituições não-governamentais. Sobre os dirigentes que possuem pós-graduação das 45 respostas obtidas, $26(57,8 \%)$ são de instituições governamentais e 19 (42,2\%) são de instituições não-governamentais. É interessante observar que, dos 22 dirigentes que afirmaram possuir o ensino médio completo, dois $(9,1 \%)$ pertencem às instituições governamentais e $20(99,9 \%)$ pertencem às não-governamentais.

Tabela 31: Escolaridade do dirigente de acordo com a natureza das instituições de tratamento

\begin{tabular}{|c|c|c|c|c|c|c|c|c|}
\hline \multicolumn{9}{|c|}{ Natureza da organização X Escolaridade do dirigente } \\
\hline & \multicolumn{2}{|c|}{ Não resposta } & \multicolumn{2}{|c|}{ Governamental } & \multicolumn{2}{|c|}{$\begin{array}{c}\text { Não- } \\
\text { governamental }\end{array}$} & \multicolumn{2}{|c|}{ Total } \\
\hline & $\mathbf{N}$ & $\%$ cit. & $\mathbf{N}$ & $\%$ cit. & $\mathbf{N}$ & $\%$ cit. & $\mathbf{N}$ & $\%$ cit. \\
\hline Não resposta & 1 & 20,0 & 2 & $\mathbf{4 0 , 0}$ & 2 & 40,0 & 5 & 100,0 \\
\hline Ensino fundamental $\left(1^{\circ}\right.$ grau $)$ incompleto & $\mathbf{0}$ & $\mathbf{0 , 0}$ & $\mathbf{0}$ & $\mathbf{0 , 0}$ & 6 & $\mathbf{1 0 0 , 0}$ & 6 & 100,0 \\
\hline Ensino fundamental $\left(1^{\circ}\right.$ grau $)$ completo & $\mathbf{0}$ & $\mathbf{0 , 0}$ & $\mathbf{0}$ & $\mathbf{0 , 0}$ & 1 & 100,0 & 1 & 100,0 \\
\hline Ensino médio ( $\left.2^{\circ} \mathrm{grau}\right)$ incompleto & $\mathbf{0}$ & $\mathbf{0 , 0}$ & $\mathbf{0}$ & $\mathbf{0 , 0}$ & 2 & 100,0 & 2 & 100,0 \\
\hline Ensino médio ( $2^{\circ}$ grau $)$ completo & $\mathbf{0}$ & $\mathbf{0 , 0}$ & 2 & 9,1 & 20 & 90,9 & 22 & 100,0 \\
\hline Ensino superior incompleto & $\mathbf{0}$ & $\mathbf{0 , 0}$ & 3 & 27,3 & 8 & 72,7 & 11 & 100,0 \\
\hline Ensino superior completo & $\mathbf{0}$ & $\mathbf{0 , 0}$ & 22 & 40,7 & 32 & $\mathbf{5 9 , 3}$ & 54 & $\mathbf{1 0 0 , 0}$ \\
\hline Pós-graduação & $\mathbf{0}$ & $\mathbf{0 , 0}$ & 26 & 57,8 & 19 & 42,2 & 45 & 100,0 \\
\hline Não sabe ler & $\mathbf{0}$ & & $\mathbf{0}$ & & $\mathbf{0}$ & & $\mathbf{0}$ & 100,0 \\
\hline Não sabe escrever & $\mathbf{0}$ & & $\mathbf{0}$ & & $\mathbf{0}$ & & $\mathbf{0}$ & 100,0 \\
\hline Não sabe ler e escrever & $\mathbf{0}$ & & $\mathbf{0}$ & & $\mathbf{0}$ & & $\mathbf{0}$ & 100,0 \\
\hline Total & 1 & 0,7 & 55 & 37,7 & 90 & 61,6 & 146 & 100,0 \\
\hline
\end{tabular}

\subsection{Remuneração do dirigente de acordo com a natureza da instituição}

A Tabela 32 apresenta a distribuição da remuneração do dirigente de acordo com a natureza da instituição. Percebe-se que, dos 49 dirigentes que afirmaram receber alguma 
remuneração pelos serviços prestados na instituição, 34 (69,4\%) trabalham em instituições governamentais e $15(30,6 \%)$ trabalham em instituições não-governamentais. Já em relação àqueles que afirmaram não receber remuneração, do total de $77,69(89,6 \%)$ são dirigentes de instituições não-governamentais e apenas oito $(10,4 \%)$ são de instituições governamentais.

Tabela 32: Remuneração do dirigente de acordo com a natureza da instituição

\begin{tabular}{l|c|c|c|c|c|c|c|c}
\hline \multicolumn{6}{c}{ Dirigente recebe remuneração pelo serviço X Natureza da organização } \\
\hline & Não resposta & \multicolumn{2}{c}{ Governamental } & \multicolumn{2}{c}{$\begin{array}{c}\text { Não- } \\
\text { governamental }\end{array}$} & \multicolumn{2}{c}{ Total } \\
\hline & $\mathbf{N}$ & $\mathbf{\%}$ cit. & $\mathbf{N}$ & $\mathbf{\%}$ cit. & $\mathbf{N}$ & $\mathbf{\%}$ cit. & N & $\%$ cit. \\
\hline Não resposta & $\mathbf{1}$ & $\mathbf{3 3 , 3}$ & $\mathbf{1}$ & $\mathbf{3 3 , 3}$ & $\mathbf{1}$ & $\mathbf{3 3 , 3}$ & $\mathbf{3}$ & $\mathbf{1 0 0 , 0}$ \\
\hline Sim & $\mathbf{0}$ & $\mathbf{0 , 0}$ & $\mathbf{3 4}$ & $\mathbf{6 9 , 4}$ & $\mathbf{1 5}$ & $\mathbf{3 0 , 6}$ & $\mathbf{4 9}$ & $\mathbf{1 0 0 , 0}$ \\
\hline Não & $\mathbf{0}$ & $\mathbf{0 , 0}$ & $\mathbf{8}$ & $\mathbf{1 0 , 4}$ & $\mathbf{6 9}$ & $\mathbf{8 9 , 6}$ & $\mathbf{7 7}$ & $\mathbf{1 0 0 , 0}$ \\
\hline Total & $\mathbf{1}$ & $\mathbf{0 , 8}$ & $\mathbf{4 3}$ & $\mathbf{3 3 , 3}$ & $\mathbf{8 5}$ & $\mathbf{6 5 , 9}$ & $\mathbf{1 2 9}$ & $\mathbf{1 0 0 , 0}$ \\
\hline
\end{tabular}

\subsection{Exercício de atividade remunerada fora da instituição de acordo com a natureza}

$\mathrm{Na}$ análise da distribuição do exercício de atividade remunerada fora da instituição pelo dirigente de acordo com a natureza da instituição, conforme Tabela 33, percebe-se que, do total de 63 dirigentes que afirmaram possuir alguma atividade remunerada fora da instituição, $12(19,0 \%)$ pertencem às instituições governamentais e 51 (81,0\%) são de instituições não-governamentais.

Os dados da tabela revelam que a busca por atividade fora da instituição pode ter relação com o não recebimento pelos serviços prestados pelos dirigentes das instituições nãogovernamentais, revelada na tabela anterior, talvez, por isso precisam recorrer a outras fontes de provento.

Tabela 33:Exercício de atividade remunerada fora da instituição de acordo com a natureza

\begin{tabular}{c|c|c|c|c|c|c|c|c}
\hline \multicolumn{8}{c}{ Dirigente exerce atividade prof. fora da inst. X Natureza da organização } \\
\hline & Não resposta & Governamental & Não-governamental & \multicolumn{2}{c}{ Total } \\
\hline & $\mathbf{N}$ & $\mathbf{\%}$ cit. & $\mathbf{N}$ & $\mathbf{\%}$ cit. & $\mathbf{N}$ & $\mathbf{\%}$ cit. & N & $\%$ cit. \\
\hline Não resposta & $\mathbf{1}$ & $\mathbf{3 3 , 3}$ & $\mathbf{1}$ & $\mathbf{3 3 , 3}$ & $\mathbf{1}$ & $\mathbf{3 3 , 3}$ & $\mathbf{3}$ & $\mathbf{1 0 0 , 0}$ \\
\hline Sim & $\mathbf{0}$ & $\mathbf{0 , 0}$ & $\mathbf{1 2}$ & $\mathbf{1 9 , 0}$ & $\mathbf{5 1}$ & $\mathbf{8 1 , 0}$ & $\mathbf{6 3}$ & $\mathbf{1 0 0 , 0}$ \\
\hline Não & $\mathbf{0}$ & $\mathbf{0 , 0}$ & $\mathbf{3 0}$ & $\mathbf{4 7 , 6}$ & $\mathbf{3 3}$ & $\mathbf{5 2 , 4}$ & $\mathbf{6 3}$ & $\mathbf{1 0 0 , 0}$ \\
\hline Total & $\mathbf{1}$ & $\mathbf{0 , 8}$ & $\mathbf{4 3}$ & $\mathbf{3 3 , 3}$ & $\mathbf{8 5}$ & $\mathbf{6 5 , 9}$ & $\mathbf{1 2 9}$ & $\mathbf{1 0 0 , 0}$ \\
\hline
\end{tabular}

\subsection{Horas semanais dedicadas pelo dirigente de acordo com a natureza da instituição}

Observa-se na Tabela 34, que das 63 marcações referentes à dedicação de 40 horas ou mais por semana, $32(50,8 \%)$ referem-se a dirigentes pertencentes às instituições governamentais e $31(49,2 \%)$ a instituições não-governamentais. 
Tabela 34: Horas semanais dedicadas pelo dirigente de acordo com a natureza da instituição

\begin{tabular}{l|c|c|c|c|c|c|c|c}
\hline \multicolumn{7}{c}{ Natureza da organização X Horas semanais dedicados à instituição } \\
\hline & Não resposta & \multicolumn{2}{|c|}{ Governamental } & \multicolumn{2}{c}{$\begin{array}{c}\text { Não- } \\
\text { governamental }\end{array}$} & \multicolumn{2}{c}{ Total } \\
\hline & $\mathbf{N}$ & $\mathbf{\%}$ cit. & $\mathbf{N}$ & $\mathbf{\%}$ cit. & $\mathbf{N}$ & $\mathbf{\%}$ cit. & N & $\mathbf{\%}$ cit. \\
\hline Não resposta & $\mathbf{1}$ & $\mathbf{1 2 , 5}$ & $\mathbf{3}$ & $\mathbf{3 7 , 5}$ & $\mathbf{4}$ & $\mathbf{5 0 , 0}$ & $\mathbf{8}$ & $\mathbf{1 0 0 , 0}$ \\
\hline Menos de 8 & $\mathbf{0}$ & $\mathbf{0 , 0}$ & $\mathbf{1}$ & $\mathbf{1 4 , 3}$ & $\mathbf{6}$ & $\mathbf{8 5 , 7}$ & $\mathbf{7}$ & $\mathbf{1 0 0 , 0}$ \\
\hline De 8 a 19 & $\mathbf{0}$ & $\mathbf{0 , 0}$ & $\mathbf{2}$ & $\mathbf{1 0 , 0}$ & $\mathbf{1 8}$ & $\mathbf{9 0 , 0}$ & $\mathbf{2 0}$ & $\mathbf{1 0 0 , 0}$ \\
\hline De 20 a 29 & $\mathbf{0}$ & $\mathbf{0 , 0}$ & $\mathbf{1}$ & $\mathbf{5 , 6}$ & $\mathbf{1 7}$ & $\mathbf{9 4 , 4}$ & $\mathbf{1 8}$ & $\mathbf{1 0 0 , 0}$ \\
\hline De 30 a 39 & $\mathbf{0}$ & $\mathbf{0 , 0}$ & $\mathbf{4}$ & $\mathbf{3 0 , 8}$ & $\mathbf{9}$ & $\mathbf{6 9 , 2}$ & $\mathbf{1 3}$ & $\mathbf{1 0 0 , 0}$ \\
\hline 40 e mais & $\mathbf{0}$ & $\mathbf{0 , 0}$ & $\mathbf{3 2}$ & $\mathbf{5 0 , 8}$ & $\mathbf{3 1}$ & $\mathbf{4 9 , 2}$ & $\mathbf{6 3}$ & $\mathbf{1 0 0 , 0}$ \\
\hline Total & $\mathbf{1}$ & $\mathbf{0 , 8}$ & $\mathbf{4 3}$ & $\mathbf{3 3 , 3}$ & $\mathbf{8 5}$ & $\mathbf{6 5 , 9}$ & $\mathbf{1 2 9}$ & $\mathbf{1 0 0 , 0}$ \\
\hline
\end{tabular}

\subsection{Motivação do dirigente de acordo com a natureza da instituição de tratamento}

As motivações são diversas vão dede a pessoal, religiosa até designação profissional alheia à sua escolha. Como pode ser observado na Tabela 35, a alternativa mais citada foi a motivação humanitária, com 49 respostas, sendo $12(24,5 \%)$ relativas às instituições governamentais e $37(75,5 \%)$ às não-governamentais. Em relação à motivação profissional, observa-se que das 29 respostas obtidas, 24 (82,8\%) se referem a instituições governamentais e apenas cinco $(17,2 \%)$ a instituições não-governamentais.

Tabela 35: Motivação do dirigente de acordo com a natureza da instituição de tratamento

\begin{tabular}{|c|c|c|c|c|c|c|c|c|}
\hline \multicolumn{9}{|c|}{ Natureza da organização X Motivação para trabalhar } \\
\hline & \multicolumn{2}{|c|}{ Não resposta } & \multicolumn{2}{|c|}{ Governamenta } & \multicolumn{2}{|c|}{$\begin{array}{c}\text { Não- } \\
\text { governamental }\end{array}$} & \multicolumn{2}{|c|}{ Total } \\
\hline & $\mathbf{N}$ & \% cit. & $\mathbf{N}$ & $\%$ cit. & $\mathbf{N}$ & \% cit. & $\mathbf{N}$ & $\%$ cit. \\
\hline Não resposta & 1 & $\mathbf{3 3 , 3}$ & 2 & 66,7 & $\mathbf{0}$ & $\mathbf{0 , 0}$ & 3 & 100,0 \\
\hline Motivação pessoal & $\mathbf{0}$ & $\mathbf{0 , 0}$ & 10 & 27,0 & 27 & 73,0 & 37 & $\mathbf{1 0 0 , 0}$ \\
\hline Motivação religiosa & $\mathbf{0}$ & $\mathbf{0 , 0}$ & $\mathbf{0}$ & $\mathbf{0 , 0}$ & 28 & $\mathbf{1 0 0 , 0}$ & 28 & 100,0 \\
\hline Motivação humanitária & $\mathbf{0}$ & $\mathbf{0 , 0}$ & 12 & 24,5 & 37 & $\mathbf{7 5 , 5}$ & 49 & 100,0 \\
\hline Motivação profissional & $\mathbf{0}$ & $\mathbf{0 , 0}$ & 24 & 82,8 & 5 & 17,2 & 29 & 100,0 \\
\hline Designação profissional alheia à sua escolha & $\mathbf{0}$ & $\mathbf{0 , 0}$ & 3 & 100,0 & $\mathbf{0}$ & $\mathbf{0 , 0}$ & 3 & 100,0 \\
\hline Solicitação/convite de amigos/conhecidos & $\mathbf{0}$ & $\mathbf{0 , 0}$ & 6 & 46,2 & 7 & 53,8 & 13 & 100,0 \\
\hline Outra motivação & $\mathbf{0}$ & & 5 & 29,4 & 12 & 70,6 & 17 & 100,0 \\
\hline Total & 1 & & 62 & 34,6 & 116 & 64,8 & 179 & 100,0 \\
\hline
\end{tabular}

Para compreender a o significado das motivações, foram colocadas no questionário as seguintes informações.

Motivação pessoal: vivência pessoal ou familiar em situações relacionadas ao consumo e a dependência de álcool e outras drogas.

Motivação religiosa: por crença ou determinação religiosa; porque a instituição está vinculada a uma entidade religiosa. 
Motivação humanitária: por solidariedade aos seus semelhantes; por estar sensibilizado com os problemas relacionados ao uso indevido de álcool e outras drogas; por acreditar que todos são responsáveis pela resolução dos problemas sociais; por vontade de ajudar os que precisam.

Motivação profissional: profissional de nível superior em busca de aprofundamento e experiência na sua área de atuação.

Designação profissional alheia à sua vontade: por cumprimento de suas obrigações como funcionário público, empregado de empresa ou de outra organização designado para a função por determinação superior.

Solicitação/convite de amigos/conhecidos que ofereceram ou pediram sua participação no trabalho da instituição (CARVALHO; DUARTE, 2007).

\subsection{Participação dos dirigentes em conselhos de acordo com a natureza da instituição}

A Tabela 36 apresenta a distribuição dos dirigentes em conselhos de acordo com a natureza da instituição. Observa-se que a participação Conselho Municipal de Saúde foi a alternativa com maior índice de marcação, obtendo 24 respostas, sendo que 10 (41,7\%) correspondem a instituições governamentais e 14 (58,3\%) a não-governamentais. Em relação à participação no Conselho Municipal Antidrogas/Entorpecentes, 20 dirigentes marcaram essa opção, sendo que cinco $(25,0 \%)$ se referem a instituições governamentais e 15 (75,0\%) a nãogovernamentais. Deve-se observar que a opção nunca participou de conselhos obteve 52 respostas, $15(28,8 \%)$ referentes às instituições governamentais e $37(71,2 \%)$ às nãogovernamentais.

Das entrevistas analisadas, somente uma instituição é filiada ao conselho Estadual, mas o dirigente afirma nunca ter recebido os benefícios reivindicados e que em 30 anos de trabalho da instituição, somente um presidente do conselho foi visitar e conhecer a instituição.

Uma das entrevistadas quando questionada sobre a participação em conselhos, expõe que não participa dos conselhos porque "há pouca informação e estimulação na questão do conselho" (entrevista 04. Inst. Governamental). Isso demonstra que muitos dirigentes desconhecem as atribuições dos conselhos e evidenciam desarticulação em sua gestão na instituição. Como afirma um dirigente entrevistado "os próprios conselhos são limitados, pois não tem verba; ajudam como podem" (entrevista 01 Inst. Não-Governamental). 
Tabela 36: Participação dos dirigentes em conselhos de acordo com a natureza da instituição Natureza da organização X Dirigente participa/participou de algum conselho

\begin{tabular}{|c|c|c|c|c|c|c|c|c|}
\hline & \multicolumn{2}{|c|}{ Não resposta } & \multicolumn{2}{|c|}{ Governamental } & \multicolumn{2}{|c|}{$\begin{array}{c}\text { Não- } \\
\text { governamental }\end{array}$} & \multicolumn{2}{|c|}{ Total } \\
\hline & $\mathbf{N}$ & $\%$ cit. & $\mathbf{N}$ & $\%$ cit. & $\mathbf{N}$ & $\%$ cit. & $\mathbf{N}$ & $\%$ cit. \\
\hline Não resposta & 1 & $14,3 \%$ & 3 & 42,9 & 3 & 42,9 & 7 & 100,0 \\
\hline Conselho Municipal Antidrogas/Entorpecentes & $\mathbf{0}$ & $\mathbf{0 , 0}$ & 5 & 25,0 & 15 & $\mathbf{7 5 , 0}$ & 20 & 100,0 \\
\hline ConselhoEstadual Antidrogas/Entorpecentes & $\mathbf{0}$ & $\mathbf{0 , 0}$ & 6 & $\mathbf{3 0 , 0}$ & 14 & $\mathbf{7 0 , 0}$ & 20 & $\mathbf{1 0 0 , 0}$ \\
\hline Conselho Nacional Antidrogas & $\mathbf{0}$ & $\mathbf{0 , 0}$ & 1 & 12,5 & 7 & 87,5 & 8 & 100,0 \\
\hline Conselho Municipal de Saúde & $\mathbf{0}$ & $\mathbf{0 , 0}$ & 10 & 41,7 & 14 & $\mathbf{5 8 , 3}$ & 24 & 100,0 \\
\hline Conselho Estadual de Saúde & $\mathbf{0}$ & $\mathbf{0 , 0}$ & 1 & $\mathbf{5 0 , 0}$ & 1 & $\mathbf{5 0 , 0}$ & 2 & $\mathbf{1 0 0 , 0}$ \\
\hline Conselho Tutelar & $\mathbf{0}$ & $\mathbf{0 , 0}$ & 3 & 25,0 & 9 & 75,0 & 12 & 100,0 \\
\hline Conselho dos Direitos da Criança e do Adolescente & $\mathbf{0}$ & $\mathbf{0 , 0}$ & 9 & 45,0 & 11 & $\mathbf{5 5 , 0}$ & 20 & $100,0 \%$ \\
\hline Conselho Estadual dos Direitos da Criança e do Adolescente & $\mathbf{0}$ & $\mathbf{0 , 0}$ & 3 & 100,0 & $\mathbf{0}$ & $\mathbf{0 , 0}$ & 3 & 100,0 \\
\hline Conselho Municipal de Assistência Social & $\mathbf{0}$ & $\mathbf{0 , 0}$ & 5 & 21,7 & 18 & 78,3 & 23 & 100,0 \\
\hline Conselho Estadual de Assistência Social & $\mathbf{0}$ & $\mathbf{0 , 0}$ & 2 & $\mathbf{5 0 , 0}$ & 2 & $\mathbf{5 0 , 0}$ & 4 & 100,0 \\
\hline Conselho Municipal de Educação & $\mathbf{0}$ & $\mathbf{0 , 0}$ & 2 & 50,0 & 2 & 50,0 & 4 & 100,0 \\
\hline Conselho Estadual de Educação & $\mathbf{0}$ & $\mathbf{0 , 0}$ & $\mathbf{0}$ & $\mathbf{0 , 0}$ & 1 & 100,0 & 1 & 100,0 \\
\hline Conselho Comunitário de Segurança & $\mathbf{0}$ & $\mathbf{0 , 0}$ & 2 & 22,2 & 7 & 77,8 & 9 & 100,0 \\
\hline Outro(s) Conselho(s) & $\mathbf{0}$ & $\mathbf{0 , 0}$ & 5 & 20,8 & 19 & 79,2 & 24 & 100,0 \\
\hline Nunca participou de conselhos & $\mathbf{0}$ & $\mathbf{0 , 0}$ & 15 & 28,8 & 37 & 71,2 & 52 & 100,0 \\
\hline Total & 1 & 0,4 & 72 & 30,9 & 160 & 68,7 & 233 & 100,0 \\
\hline
\end{tabular}

\section{Características da equipe profissional}

\subsection{Previsão de capacitação de acordo com a natureza das instituições}

Observa-se, na Tabela 37, que, das 98 instituições que indicaram prever a capacitação para os seus profissionais, 35 (35,7\%) são governamentais e 63 (64,3\%) nãogovernamentais.

Tabela 37: Previsão de capacitação de acordo com a natureza das instituições

\begin{tabular}{l|c|c|c|c|c|c|c|c}
\hline \multicolumn{7}{c}{ Previsão de capacitação X Natureza da organização } \\
\hline & Não resposta & \multicolumn{2}{c|}{$\begin{array}{c}\text { Não- } \\
\text { Governamental }\end{array}$} & \multicolumn{3}{c}{ Total } \\
\hline & $\mathbf{N}$ & $\%$ cit. & $\mathbf{N}$ & $\mathbf{\%}$ cit. & $\mathbf{N}$ & $\mathbf{\%}$ cit. & N & $\%$ cit. \\
\hline Não resposta & $\mathbf{1}$ & $\mathbf{1 1 , 1}$ & $\mathbf{3}$ & $\mathbf{3 3 , 3}$ & $\mathbf{5}$ & $\mathbf{5 5 , 6}$ & $\mathbf{9}$ & $\mathbf{1 0 0 , 0}$ \\
\hline Sim & $\mathbf{0}$ & $\mathbf{0 , 0}$ & $\mathbf{3 5}$ & $\mathbf{3 5 , 7}$ & $\mathbf{6 3}$ & $\mathbf{6 4 , 3}$ & $\mathbf{9 8}$ & $\mathbf{1 0 0 , 0}$ \\
\hline Não & $\mathbf{0}$ & $\mathbf{0 , 0}$ & $\mathbf{5}$ & $\mathbf{2 2 , 7}$ & $\mathbf{1 7}$ & $\mathbf{7 7 , 3}$ & $\mathbf{2 2}$ & $\mathbf{1 0 0 , 0}$ \\
\hline Total & $\mathbf{1}$ & $\mathbf{0 , 8}$ & $\mathbf{4 3}$ & $\mathbf{3 3 , 3}$ & $\mathbf{8 5}$ & $\mathbf{6 5 , 9}$ & $\mathbf{1 2 9}$ & $\mathbf{1 0 0 , 0}$ \\
\hline
\end{tabular}

\subsection{Atividades de capacitação desenvolvidas de acordo com a natureza da instituição}

$\mathrm{Na}$ Tabela 38, observa-se que, das 87 instituições que realizam palestras, conferências, seminários e/ou simpósios como atividades de capacitação, 32 (36,8\%) são governamentais e $55(63,2 \%)$ não-governamentais. Os Cursos de curta duração são realizados por 76 instituições, sendo 28 (36,8\%) governamentais e 48 (63,2\%) não-governamentais. A 
atividade de leitura e discussão de texto é realizada por 62 instituições, sendo $23(37,1 \%)$ governamentais e 39 (62,9\%) não-governamentais.

Tabela 38: Atividades de capacitação desenvolvidas de acordo com a natureza da instituição

\begin{tabular}{l|c|c|c|c|c|c|c|c}
\hline \multicolumn{7}{c}{ Natureza da organização X Atividades de capacitação } \\
\hline & Não resposta & \multicolumn{2}{|c|}{$\begin{array}{c}\text { Novername- } \\
\text { governamental }\end{array}$} & \multicolumn{2}{c}{ Total } \\
\hline & $\mathbf{N}$ & $\mathbf{\%}$ cit. & $\mathbf{N}$ & $\mathbf{\%}$ cit. & $\mathbf{N}$ & $\mathbf{\%}$ cit. & N & \% cit. \\
\hline Não resposta & $\mathbf{1}$ & $\mathbf{4 , 0}$ & $\mathbf{6}$ & $\mathbf{2 4 , 0}$ & $\mathbf{1 8}$ & $\mathbf{7 2 , 0}$ & $\mathbf{2 5}$ & $\mathbf{1 0 0 , 0}$ \\
\hline Cursos de curta duração & $\mathbf{0}$ & $\mathbf{0 , 0}$ & $\mathbf{2 8}$ & $\mathbf{3 6 , 8}$ & $\mathbf{4 8}$ & $\mathbf{6 3 , 2}$ & $\mathbf{7 6}$ & $\mathbf{1 0 0 , 0}$ \\
\hline Aulas & $\mathbf{0}$ & $\mathbf{0 , 0}$ & $\mathbf{8}$ & $\mathbf{2 0 , 5}$ & $\mathbf{3 1}$ & $\mathbf{7 9 , 5}$ & $\mathbf{3 9}$ & $\mathbf{1 0 0 , 0}$ \\
\hline Palestras, conferências, seminários, simpósios. & $\mathbf{0}$ & $\mathbf{0 , 0}$ & $\mathbf{3 2}$ & $\mathbf{3 6 , 8}$ & $\mathbf{5 5}$ & $\mathbf{6 3 , 2}$ & $\mathbf{8 7}$ & $\mathbf{1 0 0 , 0}$ \\
\hline Leitura e discussão de texto & $\mathbf{0}$ & $\mathbf{0 , 0}$ & $\mathbf{2 3}$ & $\mathbf{3 7 , 1}$ & $\mathbf{3 9}$ & $\mathbf{6 2 , 9}$ & $\mathbf{6 2}$ & $\mathbf{1 0 0 , 0}$ \\
\hline Exibição de materiais audiovisuais & $\mathbf{0}$ & $\mathbf{0 , 0}$ & $\mathbf{1 5}$ & $\mathbf{3 5 , 7}$ & $\mathbf{2 7}$ & $\mathbf{6 4 , 3}$ & $\mathbf{4 2}$ & $\mathbf{1 0 0 , 0}$ \\
\hline Oficinas de trabalho & $\mathbf{0}$ & $\mathbf{0 , 0}$ & $\mathbf{1 2}$ & $\mathbf{3 3 , 3}$ & $\mathbf{2 4}$ & $\mathbf{6 6 , 7}$ & $\mathbf{3 6}$ & $\mathbf{1 0 0 , 0}$ \\
\hline Dramatizações e psicodramas & $\mathbf{0}$ & $\mathbf{0 , 0}$ & $\mathbf{4}$ & $\mathbf{2 3 , 5}$ & $\mathbf{1 3}$ & $\mathbf{7 6 , 5}$ & $\mathbf{1 7}$ & $\mathbf{1 0 0 , 0}$ \\
\hline Outras & $\mathbf{0}$ & $\mathbf{0 , 0}$ & $\mathbf{3}$ & $\mathbf{3 0 , 0}$ & $\mathbf{7}$ & $\mathbf{7 0 , 0}$ & $\mathbf{1 0}$ & $\mathbf{1 0 0 , 0}$ \\
\hline Total & $\mathbf{1}$ & $\mathbf{0 , 3}$ & $\mathbf{1 3 1}$ & $\mathbf{3 3 , 2}$ & $\mathbf{2 6 2}$ & $\mathbf{6 6 , 5}$ & $\mathbf{3 9 4}$ & $\mathbf{1 0 0 , 0}$ \\
\hline
\end{tabular}

\subsection{Freqüência de capacitação de acordo com a natureza das instituições}

Na Tabela 39, observa-se que, das 33 instituições que prevêem capacitação eventualmente, 14 (42,4\%) são governamentais e 19 (57,6\%) não-governamentais. Das 20 instituições que realizam capacitação semanalmente, sete $(35,0$ \%) são governamentais e 13 $(65,0 \%)$ não-governamentais.

Tabela 39: Freqüência de capacitação de acordo com a natureza das instituições

\begin{tabular}{|c|c|c|c|c|c|c|c|c|}
\hline \multicolumn{9}{|c|}{ Natureza da organização $X$ Freqüência de capacitação } \\
\hline & \multicolumn{2}{|c|}{ Não resposta } & \multicolumn{2}{|c|}{ Governamental } & \multicolumn{2}{|c|}{$\begin{array}{c}\text { Não- } \\
\text { governamental }\end{array}$} & \multicolumn{2}{|c|}{ Total } \\
\hline & $\mathbf{N}$ & $\%$ cit. & $\mathbf{N}$ & $\%$ cit. & $\mathbf{N}$ & \% cit. & $\mathbf{N}$ & $\%$ cit. \\
\hline Não resposta & 1 & 4,0 & 5 & 20,0 & 19 & 76,0 & 25 & 100,0 \\
\hline Eventual & $\mathbf{0}$ & $\mathbf{0 , 0}$ & 14 & 42,4 & 19 & 57,6 & 33 & 100,0 \\
\hline Semanal & $\mathbf{0}$ & 0,0 & 7 & 35,0 & 13 & 65,0 & 20 & 100,0 \\
\hline Quinzenal & $\mathbf{0}$ & $\mathbf{0 , 0}$ & 2 & 40,0 & 3 & 60,0 & 5 & 100,0 \\
\hline Mensal & $\mathbf{0}$ & $\mathbf{0 , 0}$ & 3 & 33,3 & 6 & 66,7 & 9 & 100,0 \\
\hline Bimestral & $\mathbf{0}$ & $\mathbf{0 , 0}$ & $\mathbf{0}$ & $\mathbf{0 , 0}$ & 6 & 100,0 & 6 & 100,0 \\
\hline Trimestral & $\mathbf{0}$ & 0,0 & 2 & 28,6 & 5 & 71,4 & 7 & 100,0 \\
\hline Semestral & $\mathbf{0}$ & $\mathbf{0 , 0}$ & 4 & 66,7 & 2 & 33,3 & 6 & 100,0 \\
\hline Anual & $\mathbf{0}$ & 0,0 & 5 & 26,3 & 14 & 73,7 & 19 & 100,0 \\
\hline Outra & $\mathbf{0}$ & $\mathbf{0 , 0}$ & 3 & 42,9 & 4 & 57,1 & 7 & 100,0 \\
\hline Total & 1 & 0,7 & 45 & 32,8 & 91 & 66,4 & 137 & 100,0 \\
\hline
\end{tabular}

\subsection{Previsão de capacitação externa de acordo com a natureza da instituição}

Observa-se, na Tabela 40, entre as 129 instituições pesquisadas, 99 prevêem capacitação externa para os seus profissionais, sendo $36(36,4 \%)$ governamentais e 63 $(63,6 \%)$ não-governamentais. E nove instituições não prevêem capacitação externa para os 
seus profissionais, dos quais, um $(11,1 \%)$ são governamentais e oito $(88,9 \%)$ nãogovernamentais.

Tabela 40: Previsão de capacitação externa de acordo com a natureza da instituição

\begin{tabular}{|c|c|c|c|c|c|c|c|c|}
\hline \multicolumn{9}{|c|}{ Previsão de capacitação externa $X$ Natureza da organização } \\
\hline & \multicolumn{2}{|c|}{ Não resposta } & \multicolumn{2}{|c|}{ Governamental } & \multicolumn{2}{|c|}{$\begin{array}{c}\text { Não- } \\
\text { governamental }\end{array}$} & \multicolumn{2}{|c|}{ Total } \\
\hline & $\mathbf{N}$ & $\%$ cit. & $\mathbf{N}$ & $\%$ cit. & $\mathbf{N}$ & $\%$ cit. & $\mathbf{N}$ & $\%$ cit. \\
\hline Não resposta & 1 & 4,8 & 6 & 28,6 & 14 & 66,7 & 21 & 100,0 \\
\hline $\begin{array}{l}\text { Não, a instituição não prevê a capacitação } \\
\text { externa }\end{array}$ & $\mathbf{0}$ & 0,0 & 1 & 11,1 & 8 & 88,9 & 9 & 100,0 \\
\hline Sim & $\mathbf{0}$ & $\mathbf{0 , 0}$ & 36 & 36,4 & 63 & 63,6 & 99 & 100,0 \\
\hline Total & 1 & 0,8 & 43 & 33,3 & 85 & 65,9 & 129 & 100,0 \\
\hline
\end{tabular}

\subsection{Tipo de capacitação externa prevista de acordo com a natureza das instituições}

$\mathrm{Na}$ Tabela 41, observa-se que, em relação aos tipos de capacitação externa oferecida de acordo com a natureza das instituições, das 90 que indicam a participação em eventos externos (palestras, simpósios, congressos), 34 (37,8\%) são instituições de natureza governamental e $56(62,2 \%)$ de natureza não-governamental, ou seja, há certo equilíbrio em relação à oferta desse tipo de capacitação. Já em relação à participação em cursos de aperfeiçoamento, percebe-se que, das 66 instituições que prevêem esse tipo de capacitação, 23 $(34,8 \%)$ são governamentais e $43(65,2 \%)$ não-governamentais.

Tabela 41: Tipo de capacitação externa prevista de acordo com a natureza das instituições

\begin{tabular}{|c|c|c|c|c|c|c|c|c|}
\hline \multicolumn{9}{|c|}{ Natureza da organização $X$ Tipo de capacitação externa } \\
\hline & \multicolumn{2}{|c|}{ Não resposta } & \multicolumn{2}{|c|}{ Governamental } & \multicolumn{2}{|c|}{$\begin{array}{c}\text { Não- } \\
\text { governamental }\end{array}$} & \multicolumn{2}{|c|}{ Total } \\
\hline & $\mathbf{N}$ & \%cit. & $\mathbf{N}$ & $\%$ cit. & $\mathbf{N}$ & $\%$ cit. & $\mathbf{N}$ & $\%$ cit. \\
\hline Não resposta & 1 & 3,3 & 6 & 20,0 & 23 & 76,7 & 30 & 100,0 \\
\hline Participação em eventos externos (palestras, simpósios, congressos) & 0 & $\mathbf{0 , 0}$ & 34 & 37,8 & 56 & 62,2 & 90 & 100,0 \\
\hline Participação em cursos de extensão & 0 & $\mathbf{0 , 0}$ & 14 & 36,8 & 24 & 63,2 & 38 & 100,0 \\
\hline Participação em cursos de aperfeiçoamento & 0 & $\mathbf{0 , 0}$ & 23 & 34,8 & 43 & 65,2 & 66 & 100,0 \\
\hline $\begin{array}{l}\text { Participação em cursos para complementar a escolaridade (ensino } \\
\text { fundamental, médio e superior e educação de jovens e adultos) }\end{array}$ & o & $\mathbf{0 , 0}$ & 2 & 8,3 & 22 & 91,7 & 24 & 100,0 \\
\hline Participação em cursos de pós-graduação & 0 & $\mathbf{0 , 0}$ & 16 & 66,7 & 8 & 33,3 & 24 & 100,0 \\
\hline Outra & 0 & 0,0 & 5 & 50,0 & 5 & 50,0 & 10 & 100,0 \\
\hline Total & 1 & 0,4 & 100 & 35,5 & 181 & 64,2 & 282 & 100,0 \\
\hline
\end{tabular}


8.6 Participação em eventos científicos e de mobilização social de acordo com a natureza da instituição

Na Tabela 42, observa-se que 87 instituições participam de eventos científicos e de mobilização social, sendo que $37(42,5 \%)$ são governamentais e 50 (57,5\%) nãogovernamentais, enquanto 38 afirmaram não participar desses eventos, sendo cinco $(13,2 \%)$ de natureza governamental e $33(86,8 \%)$ não-governamentais.

Tabela 42: Participação em eventos científicos e de mobilização social de acordo com a natureza da instituição

\begin{tabular}{|c|c|c|c|c|c|c|c|c|}
\hline \multicolumn{9}{|c|}{ Participa de eventos de divulgação X Natureza da organização } \\
\hline & \multicolumn{2}{|c|}{ Não resposta } & \multicolumn{2}{|c|}{ Governamental } & \multicolumn{2}{|c|}{$\begin{array}{c}\text { Não- } \\
\text { governamental } \\
\end{array}$} & \multicolumn{2}{|c|}{ Total } \\
\hline & $\mathbf{N}$ & \% cit. & $\mathbf{N}$ & $\%$ cit. & $\mathbf{N}$ & \% cit. & $\mathbf{N}$ & $\%$ cit. \\
\hline Não resposta & 1 & 25,0 & 1 & 25,0 & 2 & 50,0 & 4 & 100,0 \\
\hline Não & $\mathbf{0}$ & $\mathbf{0 , 0}$ & 5 & 13,2 & 33 & 86,8 & 38 & 100,0 \\
\hline Sim & $\mathbf{0}$ & $\mathbf{0 , 0}$ & 37 & 42,5 & 50 & $\mathbf{5 7 , 5}$ & 87 & 100,0 \\
\hline Total & 1 & $\mathbf{0 , 8}$ & 43 & 33,3 & 85 & 65,9 & 129 & 100,0 \\
\hline
\end{tabular}




\section{Considerações Finais}

O trabalho buscou retratar a realidade das instituições existentes na Região Centro-Oeste, por meio de informações sobre os tratamentos oferecidos, recursos, características dos dirigentes e da equipe profissional. Revelando os avanços e as dificuldades que as instituições enfrentam para recuperar e reinserir os dependentes químicos na sociedade.

Percebe-se, com base nos dados quantitativos e qualitativos, que a construção das Políticas de atenção ao consumo de álcool e outras drogas é inovadora e também recente no contexto de políticas públicas para o tratamento aos usuários/dependentes de drogas. Contudo, revela a grande dificuldade que o Brasil encontra em adotar uma política publica menos conservadora e desvinculada dos interesses internacionais, principalmente dos nortes americanos.

Quanto a estruturação de instituições (mais não-governamentais que governamentais) pode estar relacionado com o contexto sócio histórico da política no país. A PAIUAD foi efetivada somente em 2003 com a incorporação das questões relacionadas ao álcool e outras drogas ao SUS, o que pode explicar o reduzido numero das instituições governamentais quando comparadas com as instituições não-governamentais. Outro fator explicativo pode ser a tendência do Estado brasileiro em transferir a realização de políticas a outros setores da sociedade. Trata-se da chamada desresponsabilização do Estado, no qual a sociedade civil através de entidades não-governamentais, de programas de voluntariado, toma para si a tarefa de prestar serviços que constitucionalmente é dever do Estado.

Ressaltando a conclusão do projeto Mapeamento, comparando a realidade do Centro-Oeste com a realidade Nacional pode se perceber que prevalece o maior número de instituições não governamentais que governamentais também em todo o território brasileiro. Pois das $1.256(100 \%)$ instituições que realizam atividades de tratamento no Brasil apenas 389 (31\%) são governamentais.

Com relação aos tipos de tratamento mais utilizados pelas instituições são a psicoterapia individual, familiar e grupal Onde os tipos de tratamento citados pelas instituições governamentais seguem a lógica do tratamento oferecido pelos CAPSad, que é oferecer atendimento diário à população que apresenta graves transtornos decorrentes do uso e dependência de substâncias psicoativas, evitando internações, como acontece nas instituições da região Centro-Oeste 
No Brasil a maioria das instituições de tratamento está localizada em área urbana (902). Foram mapeadas e pesquisadas 301 instituições localizadas na área rural, no qual apenas nove (3\%) são instituições governamentais e 289 (96\%) não-governamentais. Esses dados demonstram que as limitações do suporte fornecido pelo Estado à população rural com problemas de álcool e/ou outras drogas, também está presente em todo o território Nacional.

O público-alvo das instituições, tanto na região Centro-Oeste, quanto em todo o Brasil é do sexo masculino. Surge a indagação, o menor número de instituições que atendem o sexo feminino, é porque o número de usuárias e dependentes desse sexo é menor, ou porque o sistema não está preparado para atender essas mulheres dadas as características peculiares? Essa questão merece atenção. Fica como sugestão para novas pesquisas.

Outro dado em comum entre a região Centro-Oeste e o território brasileiro, analisadas pelo projeto Mapeamentos, é a importância dada pelas instituições à participação da família no tratamento do usuário/dependente de álcool e outras drogas. Haja vista que a atividade complementar para o usuário/dependente de álcool e/ou outras drogas mais oferecida pelas instituições que realizam atividades de tratamento é o acompanhamento familiar.

O requisito para admissão dos pacientes nas instituições que realizam atividades de tratamento, tanto na região Centro-Oeste, quanto no território nacional é a concordância do paciente, seguido do compromisso da família no acompanhamento do tratamento.

É importante ressaltar que apesar da Política Nacional de Drogas dos EUA ser mais definida, os programas americanos de prevenção e de combate às drogas não devem ser "importados", dadas as diferenças culturais, políticas e econômicas entre os países. Pode se observar que a grande maioria dos financiamentos oficiais e outros esforços realizados no âmbito da questão da droga no Brasil estão voltados para a repressão ao comércio e uso das substâncias ilícitas, enquanto pouco se faz no campo da prevenção, do tratamento e da pesquisa. Portanto, a formulação de política sob influência das políticas internacionais, sem levar em conta as diferenças da realidade existentes entre dois países, pode provocar, por exemplo, a falta de recursos financeiros, humanos, capacitação, entre outros problemas ressaltados pelos dirigentes. 


\section{Referências}

ANDRADE, Arthur Guerra de; DUARTE, Cláudio Elias; CUNHA, Paulo Jannuzzi. Princípios Gerais de Tratamento das Dependências Químicas. IN: BRASIL. Presidência da República. Secretaria Nacional Antidrogas. Tratamento das Dependências Químicas Aspectos Básicos. Brasília, DF, Senad, 2002.

BASÍLIO, Mirian Cátia Vieira. O Legislativo Municipal de Vitória e a Política de Enfrentamento às Drogas: atos, debates, formulações e não decisões. Vitória, 2008. Dissertação de Mestrado em Política Social da Universidade Federal do Espírito Santo.

BITTENCOURT, Ligia Maria. Do discurso jurídico à ordem médica: os descaminhos do uso de drogas no Brasil. Rio de Janeiro, 1986. Dissertação (Mestrado em Psicologia), Departamento de Psicologia, Pontifícia Universidade Católica do Rio de Janeiro.

BRASIL.Decreto no 3.696 de 21 de dezembro de 2000a. Diário Oficial [da] República Federativa do Brasil. Brasília. Disponível em:

$<\underline{\text { http://www.obid.senad.gov.br/portais/OBID/biblioteca/documentos/Legislacao/327025.pdf }>}$ Acessado em: 16 de outubro de 2008.

.Decreto no 3.845 de 11 de dezembro de 2001. Diário Oficial [da] República Federativa do Brasil, Brasília.

.Decreto no 54.216, de 27 de agosto de 1964. Disponível em: <http://www.unodc.org/ pdf/brazil/Convencao\%20Unica $\% 20$ de $\% 201961 \% 20$ portugues.pdf $>$ Acessado em: 8 de outubro de 2008.

.Decreto $\mathbf{N}^{0}$ 6.117, de 22 de Maio de 2007a. Disponível em:

$<$ http://www.normaslegais.com.br/legislacao/decreto6117 2007.htm $>$ Acessado em: 25 de outubro de 2008 .

Decreto $n^{0} 85.110$ de 2 de setembro de 1980. Disponível em:

$<$ http://www.abordabrasil.org/biblioteca/legislacao/lei85110.pdf $>$ Acessado em: 01 de outubro de 2008.

.Lei no 10.216, de 6 de abril de 2001. Disponível em:

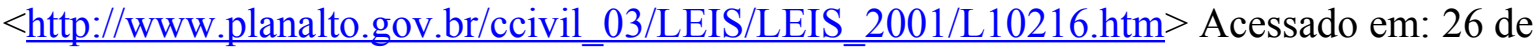
outubro de 2008.

.Lei $n^{0}$ 11.343, de 23 de Agosto de 2006. Disponível em:

$<$ https://www.planalto.gov.br/ccivil 03/ Ato20042006/2006/Lei/L11343.htm> Acessado em: 13 de outubro de 2008. 
.Lei no 11.705 de 19 de junho de 2008c. Disponível em:

$<$ http://www.planalto.gov.br/ccivil 03/ Ato2007-2010/2008/Lei/L11705.htm>Acessado em : 28 de outubro de 2008.

.Lei n $\mathbf{n}^{\mathbf{8}}$ 8.764, de 20 de dezembro de 1993. Disponível em:

$<$ http://www.planalto.gov.br/ccivil 03/leis/L8764.htm> Acessado em: 14 de novembro de 2008 .

.Medida Provisória $\mathrm{n}^{0}$ 415, de 21 de janeiro de 2008.Disponível em:

$<$ http://www.planalto.gov.br/Ccivil 03/ Ato2007-2010/2008/Mpv/415.htm acessado em :10> de outubro de 2008.

Ministério da Saúde, 2004. Saúde Mental no SUS: os centros de atenção psicossocial. Disponível em:

$<$ http://portal.saude.gov.br/portal/arquivos/pdf/ManualCapsFinal.pdfv $>$ Acessado em: 22 de outubro de 2008.

.Ministério da Saúde, 2007. Saúde Mental no SUS: acesso ao tratamento e mudança do modelo de atenção. Relatório de Gestão 2003-2006. Coordenação Geral de Saúde Mental. Disponível em:

$<$ http://portal.saude.gov.br/portal/arquivos/pdf/relatorio gestao saude mental 2006.pdf $>$ Ace ssado em: 23 de Setembro de 2008.

.Ministério da Saúde, 2007b. Mortes no trânsito: veja dados do Ministério da Saúde e da OMS. Disponível em: $<$ http://www.ensp.fiocruz.br/portal-ensp/index.php $>$ Acessado em: 24 de outubro de 2008.

.Ministério da Saúde. A Política do Ministério da Saúde para a Atenção Integral a Usuários de álcool e outras drogas, 2003. Disponível em:

$<$ http://bvsms.saude.gov.br/bvs/publicacoes/pns_alcool_drogas.pdf $>$ Acessado em: 26 de setembro de 2008 .

.Ministério da Saúde. Secretaria Nacional de Programas Especiais de Saúde, 1992. Divisão Nacional de DST/Aids. Boletim Epidemiológico da Aids, Brasília, ano 5, n.7.

.Nações Unidas: Escritório Sobre Drogas e Crimes 2008. Disponível em: $<$ http://www.unodc.org/brazil/pt/pressrelease 20080626.html $>$. Acessado em: 26 de Setembro de 2008.

Política Nacional Sobre Drogas, 2005. Disponível em:

$<\underline{\text { http://www.obid.senad.gov.br/portais/OBID/biblioteca/documentos/Legislacao/326979.pdf }>}$ Acessado em: 23 de setembro de 2008. 
.Portaria $\mathrm{N}^{\circ}$ 224/MS, de 29 de Janeiro de 1992a. Disponível em:

$<$ http://www.mp.sc.gov.br/portal/site/conteudo/cao/ccf/quadro $\% 20$ sinotico $\% 20$ sus/portaria $\% 20$ sas-ms $\% 20 \mathrm{n} \% \mathrm{C} 2 \% \mathrm{BA} \% 20224-92 \% 20-\% 20$ diretrizes $\% 20 \mathrm{e} \% 20$ normas $\% 20$ saude \%20mental.pdf $>$. Acessado em: 14 de outubro de 2008.

.Presidência da República. Secretaria Nacional de Políticas sobre Drogas (Senad) 2008a. Disponível em:

$<$ http://www.senad.gov.br/prevencao tratamento/tratamento.htm $>$ Acessado em: 28 de setembro de 2008

.Resolução - RDC n⿳ 101, de 30 de maio de 2001 a. Disponível em:

$\overline{<\mathrm{http}: / / w w w . a n v i s a . g o v . b r / l e g i s / r e s o l / 101 ~ 01 \mathrm{rdc} . \mathrm{htm}}>$ Acessado em: 28 de outubro de 2008 .

.senad. Aspectos Básicos do Tratamento da Síndrome de Dependência de Substâncias Psicoativas, 2000. Disponível em:

$<$ http://www.adolec.br/bvs/adolec/P/pdf/pdf_zip\%20drive/tratamento.pdf $>$ Acessado em: 20 de setembro de 2007.

.Senado Federal. Lei 8.080 de 19 de setembro de 1990. Brasil: Diário Oficial 1990.

.Senado Federal. Lei Ordinária no 7468 de 28 de abril de 1986. Brasil: Diário Oficial 1986

BUCHER, R; OLIVEIRA, S. R. M. O Discurso do Combate às Drogas e suas Ideologias. Revista Saúde Pública. São Paulo. V.28, n. 2, p.137-145, 1994.

CARNEIRO, H. Transformações do dignificado da palavra "droga": das especiarias coloniais ao proibicionismo contemporâneo. In: VENÂNCIO, R. P; CARNEIRO, H. (org.). Álcool e drogas na história do Brasil. São Paulo: alameda; Belo Horizonte, PUC , 2005.

CARVALHO, Denise Bomtempo. Birche. DUARTE. Paulina do Carmo Arruda Vieira. Mapeamento das instituições governamentais e não-governamentais de atenção às questões relacionadas ao consumo de álcool e outras drogas no Brasil, 2006/2007. Disponível em:

>http://www.obid.senad.gov.br/portais/OBID/biblioteca/documentos/Dados_Estatisticos/Instit uicoes/327691.pdf> acessado em: 10 de outubro de 2008 .

CIRINO, Oscar. Abuso de Drogas, Saúde Pública e Psicanálise. In: CIRINO, Oscar; MEDEIROS, Regina. (orgs.) Álcool e outras Drogas: escolhas, impasses e saídas possíveis. Belo Horizonte: Autêntica, 2006. 
CRUZ, Marcelo Santos. Considerações Sobre possíveis Razões para a Resistência às Estratégias de Redução de Danos. In: CIRINO, Oscar; MEDEIROS, Regina. (orgs.) Álcool e outras Drogas: escolhas, impasses e saídas possíveis. Belo Horizonte: Autêntica, 2006.

CRUZ, Marcelo Santos. Práticas Médicas, Toxicomanias e a Promoção do Exercício da Cidadania. In: ACSELRAD, G. (org.) Avessos do Prazer: drogas, AIDS e direitos humanos. Rio de Janeiro: FIOCRUZ, 2000.

CRUZ, Marcelo Santos; FERREIRA, Salette Maria Barros. Determinantes sócio-culturais do uso abusivo de álcool e outras drogas. In: CRUZ, Marcelo Santos; FERREIRA, Salette Maria Barros (Org.). Álcool e drogas: usos, dependências e tratamentos. Rio de Janeiro: Edições Ipub-Cuca, 2001, p.95-113.

DESLANDES, S. F. Introdução ao Método Científico - Disciplina: Saúde e Sociedade. 2002.

DUARTE, Paulina Vieira. Reinserção Social. In: BRASIL. Secretaria Nacional Antidrogas, 2002. Tratamento das Dependências Químicas- Aspectos Básicos. Brasília, DF, Senad.

FIORE, Mauricio. A medicalização da questão do uso de drogas no Brasil: reflexões acerca de debates institucionais e jurídicos. In: Venâncio, Renato P.; Carneiro, Henrique (Org.). Álcool e drogas na História do Brasil. São Paulo: Alameda. , 2005, p.257-290.

GARCIA, M. L. T; LEAL, F. X. Política antidrogas no Brasil. Relatório Final do Projeto de Pesquisa Política de Atenção à Dependência Química: Um estudo na ótica do controle social, 2006.

Gil, A. C. Como elaborar projetos de pesquisa. 1991. P. 45.

GREGO FILHO, V. Tóxicos: Prevenção-Repressão. São Paulo: Saraiva 2006.

GROISMAN, Moisés; LOBO, Mônica V; CAVOUR, Regina M. Histórias dramáticas: terapia breve para famílias e terapeutas. Rio de Janeiro: Rosa dos Tempos. 1996.

IPEA/MS e Cols. Impactos Sociais e Econômicos dos Acidentes de Trânsito nas Aglomerações Urbanas, em desenvolvimento 2004. Disponível em: $<$ http://www.ipea.gov.br/sites/000/2/estudospesq/acidentesdetransito/Renavam.pdf $>$. Acessado em 15 de outubro de 2008.

KARAM, M. L. Legislação brasileira sobre drogas: historia recente- a criminalização da diferença. In: ACSELRAD, G (org.) Avessos do prazer: drogas, AIDS e direitos humanos. Rio de Janeiro: FIOCRUZ, 2000. 
LANGE, Flávi. Dimensões Legais. In: BRASIL. Secretaria Nacional Antidrogas 2002.

Tratamento das Dependências Químicas- Aspectos Básicos. Brasília, DF, Senad.

LARANJEIRA, R; ROMANO, M. Políticas públicas para o álcool. São Paulo: Universidade Federal de São Paulo, 2003. Programa de pesquisa em políticas públicas.

LARANJEIRA, Ronaldo (org.). Boas Práticas no Tratamento do Uso e Dependência de Sustâncias. São Paulo: Roca, 2007.

LESSING, Benjamin. Drogas-Questões e perspectivas: Brasil e a Política Nacional sobre Drogas Disponível em: $<$ http://www.comunidadesegura.org/?q=pt/node/34809n $>$. Acessado em 16 de outubro de 2008.

MACHADO, Ana Regina. Uso Prejudicial e Dependência de Álcool e Outras Drogas na Agenda da Saúde Pública: Um Estudo Sobre o Processo de Constituição da Política Pública de Saúde do Brasil para Usuários de Álcool e Outras Drogas, 2006. $<$ http://www.medicina.ufmg.br/saudepublica/dissert/ana machado06.pdf $>$ Acessado em: 25 de setembro de 2008.

MACHADO, Ana Regina; MIRANDA, Paulo Sérgio CarneiroI. Fragmentos da história da atenção à saúde para usuários de álcool e outras drogas no Brasil: da Justiça à Saúde Pública 2007. Disponível em: $<$ http://www.scielo.br/pdf/hcsm/v14n3/06.pdf $>$ Acessado em: 25 de setembro de 2008.

MINAYO, Maria Cecília de Souza; DESLANDES, Suely Ferreira. A complexidade das relações entre drogas, álcool e violência. Cad. Saúde Pública, Jan./Mar. 1998, vol.14, no.1, p.35-42. ISSN 0102-311X. Disponível em: $<$ http://www.scielosp.org/pdf/csp/v14n1/0123.pdf $>$ Acessado em: 16 de outubro de 2008 .

MINAYO, Maria Cecília de Souza; SCHENKER, Miriam, 2004. A importância da família no tratamento do uso abusivo de drogas: uma revisão da literatura. Disponível em: $<$ http://www.scielo.br/pdf/csp/v20n3/02.pdf $>$ Acessado em: 18 de outubro de 2008.

MISSE, Michel. O movimento: a constituição e reprodução das redes do mercado informal ilegal de drogas a varejo no Rio de Janeiro e seus efeitos de violência. In: Baptista, Marcos; Cruz, Marcelo S.; Matias, Regina (Org.). Drogas e pós-modernidade: faces de um tema proscrito. Rio de Janeiro: Ed. UERJ. 2003, p.147-156.

MUSUMESCI, B. O consumo de álcool no país. In: ZALUAR, A (org). Drogas e Cidadania. São Paulo: Brasiliense, 1994. 
OLIVEIRA, C. J. O enfrentamento da questão do álcool e outras drogas pelo Estado Brasileiro. In: BRAVO, M. I. S. et al. (org.). Saúde e Serviço Social. São Paulo: Cortez; Rio de Janeiro: UERJ, 2004

OLMO, R. D. A face oculta da droga. Rio de Janeiro: REVAN, 1990.

PAYÁ, Roberta; FIGLIE, Neliana Buzi. Abordagem Familiar em Dependência Química. In: FIGLIE, Neliana Buzi; BORDIN, Selma; LARANJEIRA, Ronaldo (org.). Aconselhamento em Dependência química. São Paulo Roca, 2004.

PRATTA, Elisângela Maria Machado, SANTOS, Manoel Antônio dos. Levantamento dos motivos e dos responsáveis pelo primeiro contato de adolescentes do ensino médio com substâncias psicoativas, 2006. Disponível em: $<\underline{\text { http://pepsic.bvs-psi.org.br/scielo.php? }}$ script $=$ sci arttext\&pid=S1806-69762006000200005\&lng=pt\&nrm=is. $>$ Acessado em: 16 de outubro de 2008.

RIBEIRO, A. M. M.; IULIANELLI, J. A. S. (org.). Narcotráfico e violência no campo. Rio de Janeiro: DR\&A, 2000.

RIBEIRO, Marcelo. Organização de serviços para o tratamento da dependência do álcool, 2004. Disponível em: $<$ http://www.scielo.br/scielo.php? pid $=$ S151644462004000500015\&script=sci arttext $>$ Acessado em: 16 de outubro de 2008 .

RIBEIRO, Marcelo. Organização de Serviços para Tratamento do uso nocivo e Dependência do Álcool, 2007. In: CORDEIRO, Daniel Cruz; FIGLIE, Neliana Buzi;

ROCCO, R. Organização do crime, comércio as drogas: alternativas à conjuntura. In: RODRIGUES, T. política e droga nas Américas. São Paulo: EDUC: FAPESP, 2004.

SABINO, Nathalí Di Martino; CAZENAVE, Sílvia de Oliveira Santos. Comunidades Terapêuticas como Forma de Tratamento para a Dependência de Substâncias

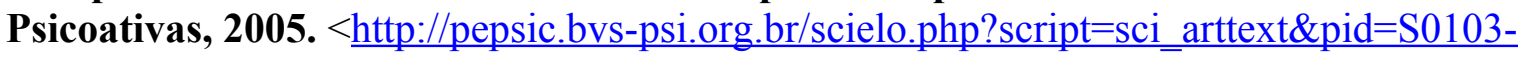
$\underline{166 \times 2005000200006>}$.

SEADI, Susana M. Sastre. A Terapia Multifamiliar e Dependência Química. Porto Alegre, 2007. Dissertação (Mestrado em Psicologia), Departamento de Psicologia, Pontifícia Universidade Católica do Rio Grande do Sul.

Senad. Coordenadoria ANTIDROGAS, 2008. Lei altera nome da Senad para Secretaria Nacional de Políticas sobre Drogas. Disponível em:

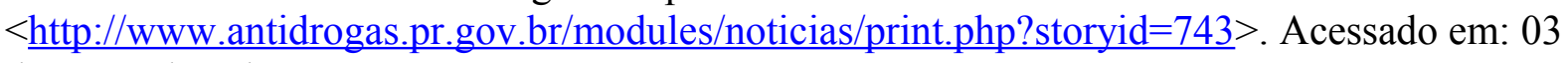
de novembro de 2008. 
SICA, L. Funções Manifestas e Latentes das Políticas de War on Drungs. In: Drogas: aspectos penais e criminológicos. Rio de Janeiro: Civilização Brasileira, 2003.

SUDBRACK, Maria de Fátima Olivier. Abordagem Interdisciplinar no Tratamento de Dependentes de Drogas. In: BRASIL. Secretaria Nacional Antidrogas. Tratamento das Dependências Químicas-Aspectos Básicos, 2002. Brasília, DF, Senad.

TAVARES, Aline Vieira; SBEGUE, Anita de Cássia; UEHARA, Carolina; OLIVEIRA; Fernanda; OLIVEIRA, Maria de Lourdes. A Dependência Química e o Papel da Família na Reabilitação e Ressocialização de Jovens Dependentes: um Estudo Sobre a Atuação do Grea. Disponível em: $<$ https://www.gpopai.usp.br/repositorio/document/? down $=416>$ Acessado em: 03 de outubro de 2008.

VELOSO, L.; CARVALHO, J; SANTIAGO, L. Redução dos danos decorrentes do uso de drogas: uma proposta educativa no âmbito das políticas públicas. In: In: BRAVO, M. I. S. et al. (org.). Saúde e Serviço Social. São Paulo: Cortez; Rio de Janeiro: UERJ, 2004.

World Health Organization. Department of Mental Health and Substance Abuse. Global status report on alcohol 2004. Geneva. Disponível em:

$<$ http://www.faslink.org/WHO global_alcohol_status_report_2004.pdf $>$ Acessado em15 de outubro de 2008.

II Levantamento domiciliar sobre o uso de drogas psicotrópicas no Brasil: estudo envolvendo as 108 maiores cidades do país, 2005. Disponível em:

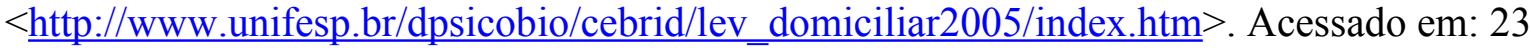
de setembro de 2008. 